University of Louisville

ThinkIR: The University of Louisville's Institutional Repository

Electronic Theses and Dissertations

$12-2017$

\title{
A University's student care team : 5 year case summary.
}

Laura Elizabeth Ulmer

University of Louisville

Follow this and additional works at: https://ir.library.louisville.edu/etd

Part of the Student Counseling and Personnel Services Commons

\section{Recommended Citation}

Ulmer, Laura Elizabeth, "A University's student care team : 5 year case summary." (2017). Electronic Theses and Dissertations. Paper 2829.

https://doi.org/10.18297/etd/2829

This Doctoral Dissertation is brought to you for free and open access by ThinkIR: The University of Louisville's Institutional Repository. It has been accepted for inclusion in Electronic Theses and Dissertations by an authorized administrator of ThinkIR: The University of Louisville's Institutional Repository. This title appears here courtesy of the author, who has retained all other copyrights. For more information, please contact thinkir@louisville.edu. 
A UNIVERSITY'S STUDENT CARE TEAM: 5 YEAR CASE SUMMARY

\author{
By: \\ Laura Elizabeth Ulmer \\ B.A., Mount Union College, 2005 \\ M.Ed., Ohio University, 2007 \\ A Dissertation \\ Submitted to the Faculty of the \\ College of Education and Human Development \\ In Partial Fulfillment of the Requirements \\ For the Degree of \\ Doctor of Philosophy \\ In Counseling DQGPersonnel Services
}

Department of Counseling and Human Development

University of Louisville

Louisville, Kentucky

December 2017 
Copyright 2017 by Laura E. Ulmer All Rights Reserved 

A UNIVERSITY'S STUDENT CARE TEAM: 5 YEAR CASE SUMMARY

\author{
By \\ Laura Elizabeth Ulmer \\ B.A., Mount Union College, 2005 \\ M.Ed., Ohio University, 2007 \\ A Dissertation Approved on
}

November 30, 2017

to the following Dissertation Committee

Dr. Amy Hirschy, Dissertation Chair

Dr. J. Michael Mardis

Dr. Jeff Valentine

Dr. Jake Gross 


\section{DEDICATION}

I dedicate this dissertation to my colleagues connected to the work of crisis management, student care, behavioral intervention, student conduct, and threat assessment as well as their colleagues, families, and friends who support them. Specifically, to those who assess risk for potential harm each day, are awoken in the middle of the night to respond to a student hospitalization and/or suicide attempt, and who are then responsible for providing appropriate resources and support to students in crisis. Additionally, to the loved ones of those team members who sacrifice time and rest in the support of the work that these team members perform. I truly believe that our work saves lives and we may never really know how deeply we impact our students.

This dissertation is also dedicated to my parents, Cathy \& Harley Brown, and husband, Blake Ulmer, for supporting me through 25 years of education and during the culminating process of the Ph.D. You have provided support of my education financially, academically, and socially - thank you.

Thank you, ma-ma, for introducing me to the environment of a college campus while working in higher education for decades. It was on your campus that I first used library books and the internet for resources needed in research projects. And, you served as my editor for this and many other documents during my education.

Thank you, daddy, for making sure I had the right tools for the job (tanks of gas, books, desktop and laptop computers, and commencement regalia). You have always been involved in 
and supportive of my classes, grades, and due homework/papers while challenging me not to "dig a hole academically" from the very beginning of college. I took your advice and it paid off.

Thank you Blake, for supporting me, celebrating steps along the way, and sharing our time with my bachelor's degree, my master's degree, and my Ph.D., GRE preparation, coursework, homework, compulsive grade checking, the comprehensive exam preparation and completion process, and this dissertation.

Thank you, to my colleagues at the University of Louisville, for this great work that we did together, for teaching me how to do it, and for showing me my passion for it. It is because of you that I wrote this dissertation - I simply wouldn't have thought to do so if we were not doing such great work. This dissertation is also dedicated to you and I am thrilled to share this summary of our work with you, as well as everyone else. 


\section{ACKNOWLEDGMENTS}

Thank you, Dr. Amy Hirschy for supporting me through the entire Ph.D. process and assisting me as we focused this research. I appreciate your willingness to think aloud with me, to answer my questions, and/or encourage me to think differently about my ideas. Thank you, Dr. Michael Mardis, for supporting me as a committee member but also for training me to perform this work. To the rest of my committee members, thank you for providing valuable recommendations to help me structure this research design in ways that helped me formulate my research questions, gather the information I wanted and needed to answer my questions, and the support I needed throughout the process.

Thank you, to the Dean of Students Office at the University of Louisville who not only are primarily responsible for the intake of referrals to the SCT and responding to issues in the middle of the night, but also supported me in the completion of this dissertation. I appreciate each of you who talked with me about the research, pulled information for me, and/or sat on the SCT with me.

To everyone who ever had a conversation with me about my research and/or the work of the SCT, thank you for providing me with new ideas for the presentation of information, recommendations for future research, and implications for practice. The dissertation can really be a lonely place, thank you to those who have engaged in dialogue with me about it as it was a tremendous help for me in the recognition of exactly what I wanted to study, what I did not want to study, and what I wanted to give back to the knowledge community. 


\begin{abstract}
A UNIVERSITY'S STUDENT CARE TEAM: 5 YEAR CASE SUMMARY

Laura E. Ulmer
\end{abstract}

October 30, 2017

At universities, the responsibility for safety falls on teams of professionals who collect information, assess risk, and provide appropriate resources for referrals of concerning behavior (Randazzo \& Plummer, 2009). This dissertation describes the demographic profile and nature of referrals to the Student Care Team (SCT) at the University of Louisville during 2010-2015. Using Astin's (1991) Input-Environment-Output model, this research analyzed the demographic profile of referred students (input) and the nature of incidents that comprise the student care caseload such as incidents of self-injurious behavior, medical hospital transportation and violence (environment). To measure the prediction of academic advancement (output), the dichotomous measure of earning of attempted credit hours for the semester which they were referred was used. Findings suggest the demographic profile was representative of the population at the University of Louisville. However, first-year students were referred more frequently than other classifications for every referral type (37\%). Referrals were most commonly for medical hospital transportation (24\%), general care (18\%), and self-injurious behavior (15\%) by the university police department. When considering the students who were referred to the SCT, logistic regression results revealed several negative predictors for academic 
advancement: first-year, graduate students, students discussed by the SCT three or more times, referrals during week, and referrals for self-injurious behavior. Recommendations for practice and research are offered. 


\section{TABLE OF CONTENTS}

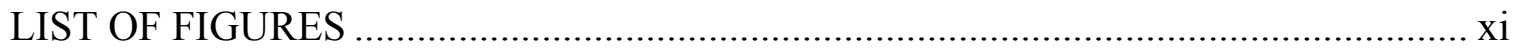

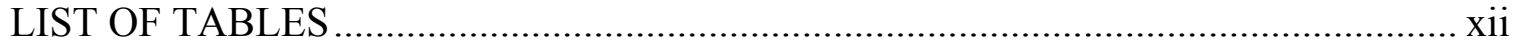

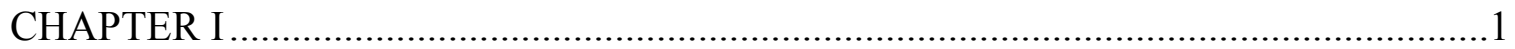

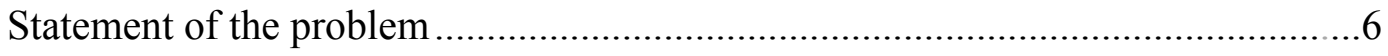

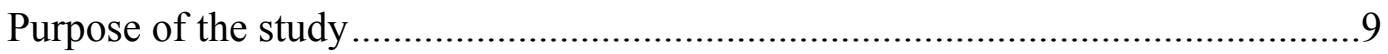

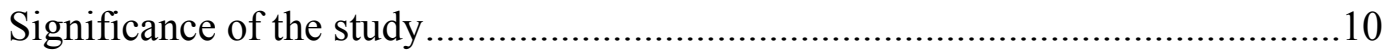

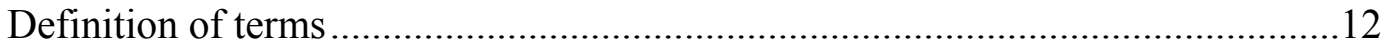

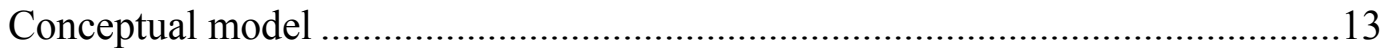

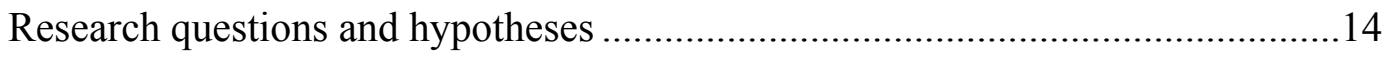

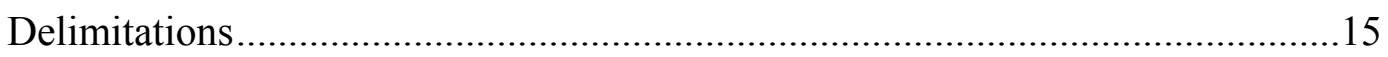

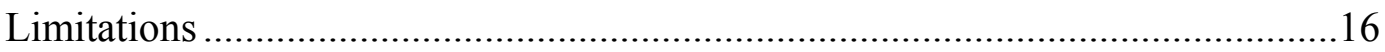

CHAPTER II: REVIEW OF LITERATURE …………….........................................

Conceptual and theoretical framework ……….................................................17

Input-environment-output model .........................................................18

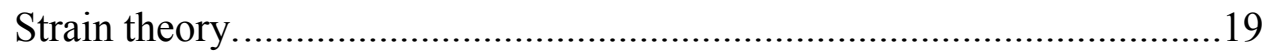

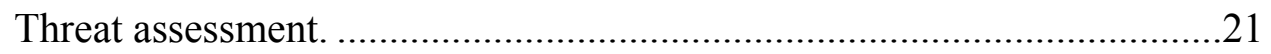

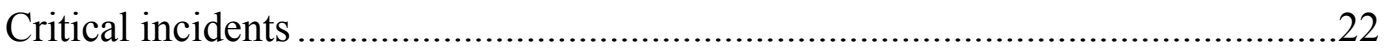

Threats of harm to others. ………….....................................................24

Impact of harm to others incidents on policies and practice.......................29

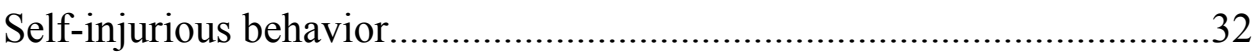

Impact of self-injurious behavior on practice ………………………..........

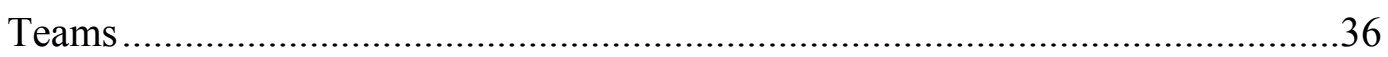

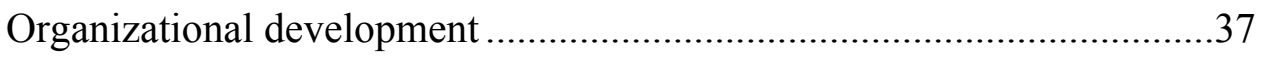

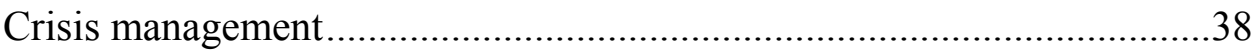

Team elements .......................................................................................

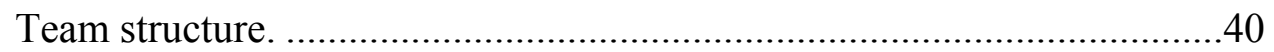

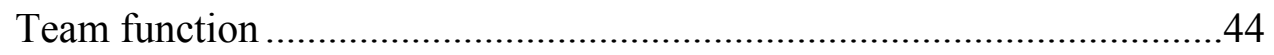

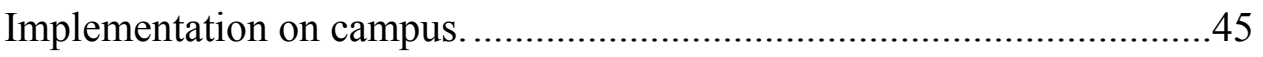

Communication during crisis ...................................................................46

University of Louisville Student Care Team ...............................................47

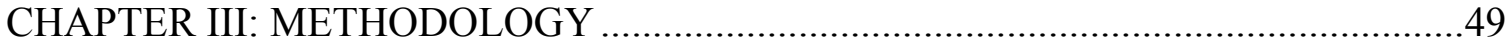




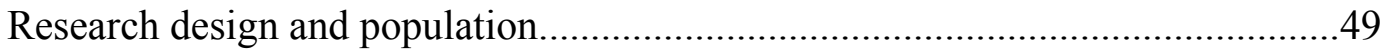

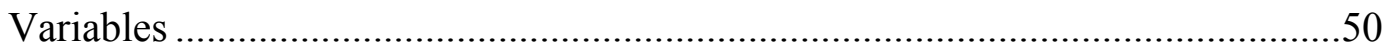

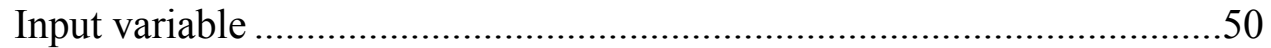

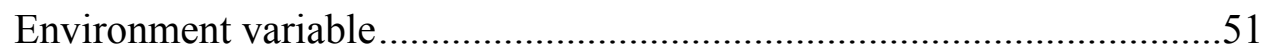

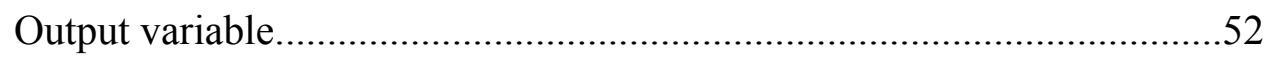

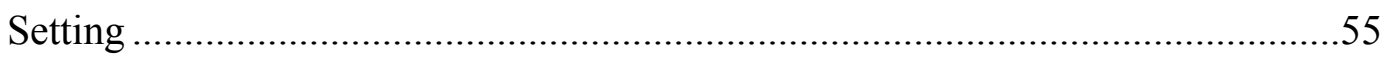

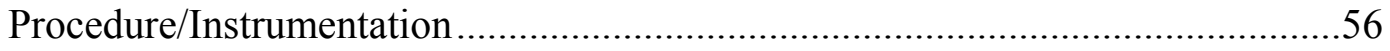

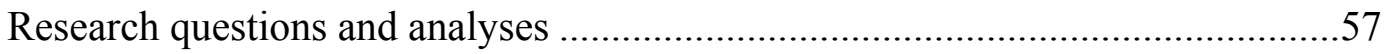

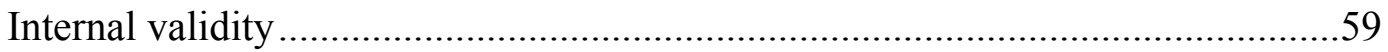

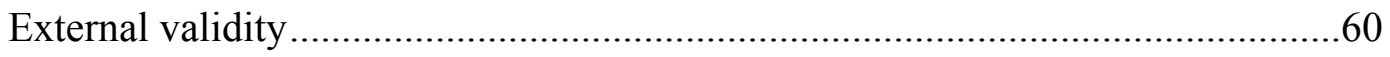

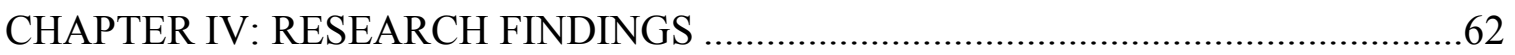

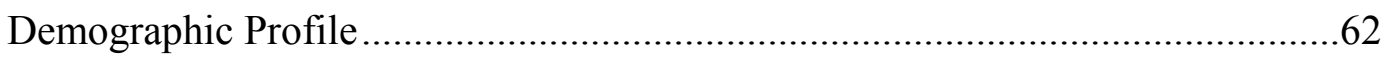

Research question 1. What is the demographic profile for students referred to SCT in comparison to the overall student population?...........................62

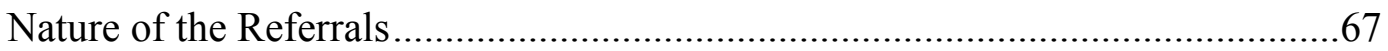

Research question 2. What is the nature of the referrals to SCT? .............67

Earning attempted credit hours .....................................................................

Research question 3. How do the demographic profile and nature of the referrals predict whether the student referred earns the credit hours for the semester they were referred to the SCT? .................................................... 71

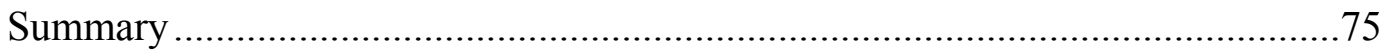

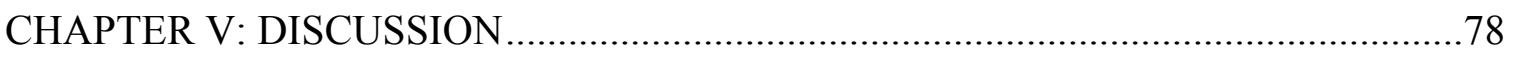

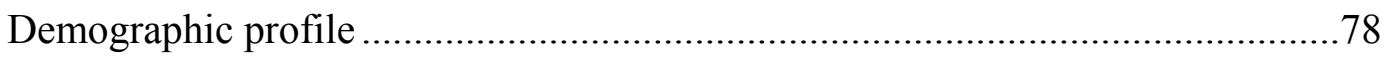

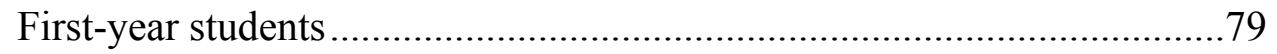

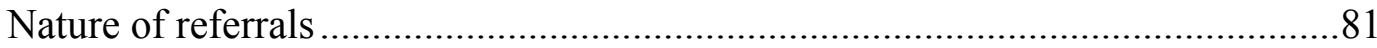

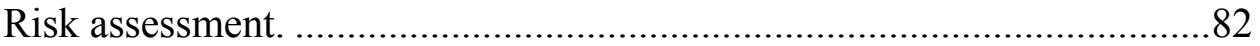

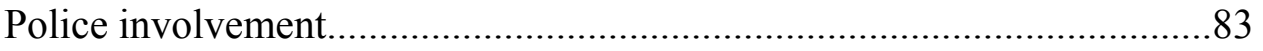

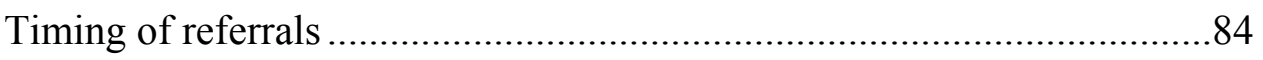

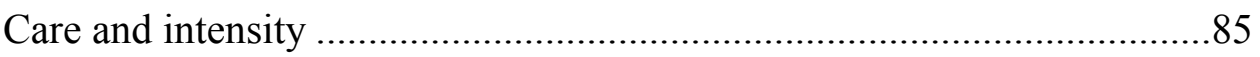

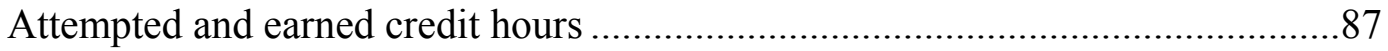

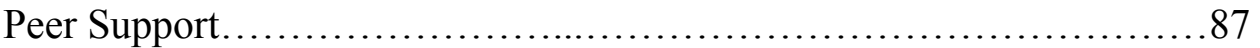

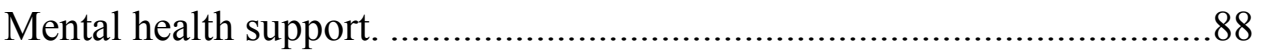

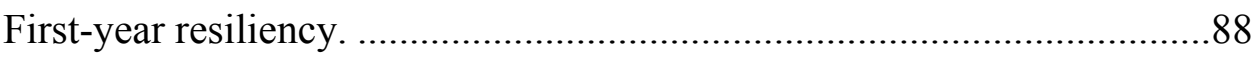




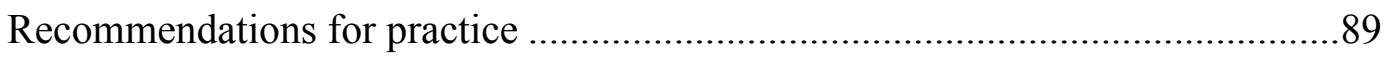

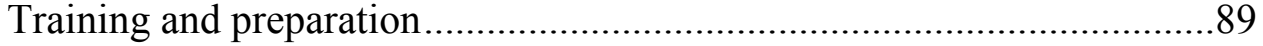

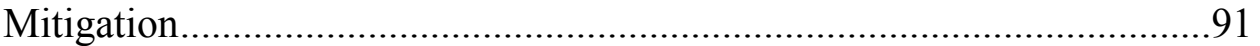

Recommendations for future research .........................................................92

Team structure and function ...........................................................99

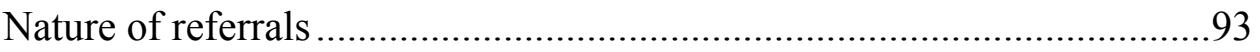

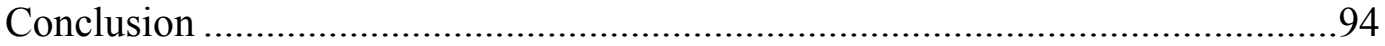

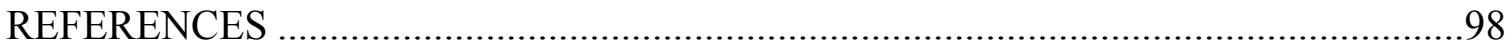

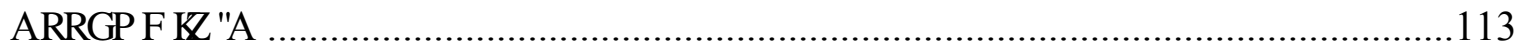

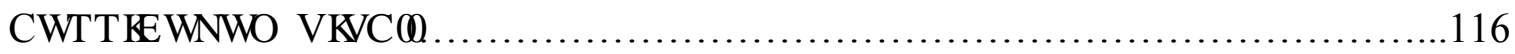




$$
\mathrm{L}, 672) \mathrm{F}, * 85 \text { ( } 6
$$

Figure 1. Conceptual Model ......................................................................................2

Figure 2. I-E-O Model of Assessment............................................................................

Figure 3. Strain Theory Deviance Typology ..................................................................2

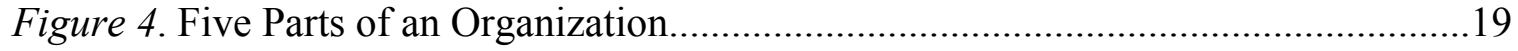

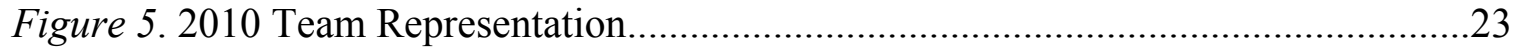

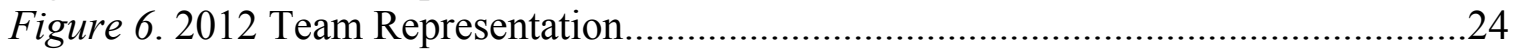

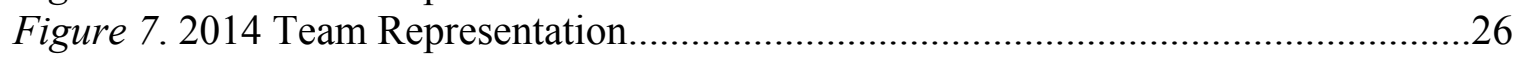

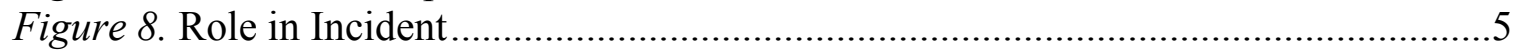

Figure 9. New Referrals \& Total Discussions by Week ..............................................

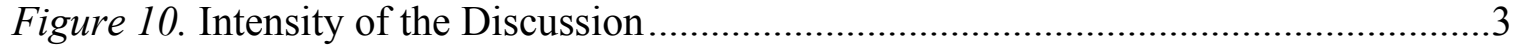

Figure 11. Classification....................................................................................... 


\section{LIST OF TABLES}

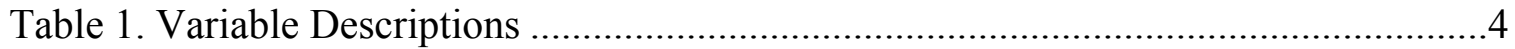

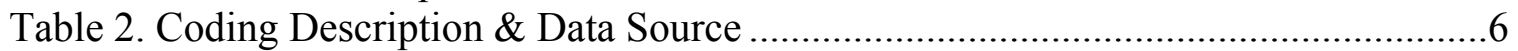

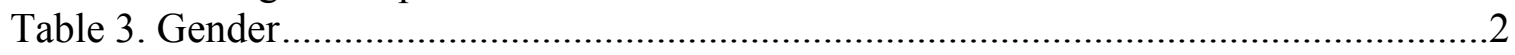

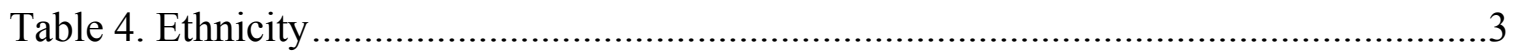

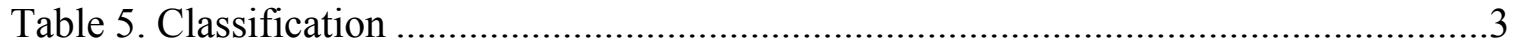

Table 6. Role in the Incident...............................................................................

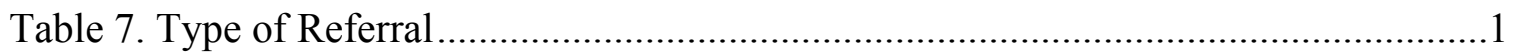

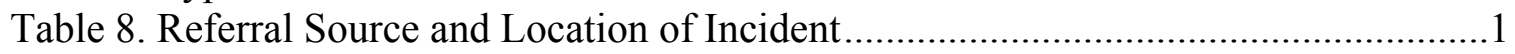

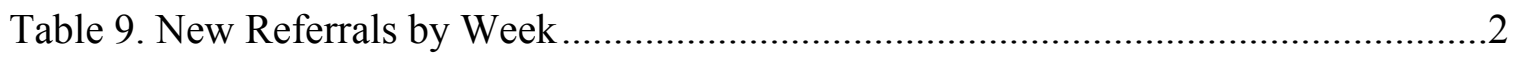

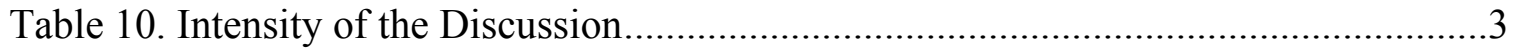

Table 11. Prediction by Location, Source, Week of Semester …………............................

Table 12. Major College \& Gender .............................................................................2

Table 13. Predictions by Classification, Ethnicity, Role \& Intensity .................................. 3

Table 14. Prediction by Referral Type....................................................................... 


\section{CHAPTER I}

When critical incidents occur on college campuses, a university's threat assessment or behavioral intervention team along with the police department may be asked to use a systematic process used to understand the risk (i.e., information gathering and initial threat analysis) (Randazzo \& Plummer, 2009) and respond appropriately. Threat assessment and behavioral intervention teams are designed to identify concerning behavior, "that threatens well-being of one or more individuals or the university community as a whole" (University of Louisville, 2008, p.2), and provide the appropriate resources to the student(s) involved in efforts to mitigate potential risk (Randazzo \& Plummer, 2009). For the purpose of this study, concerning behavior means threats of harm to others and/or self-injurious behavior. Because concerning behavior may be a result of underlying distress, and if behaviors are identified and resources are provided, chances increase that a student will learn to overcome the stressors (Whitman, Spendlove, \& Clark, 1986). Examples of concerning behavior for which teams are referred are psychological or mental health concerns $(45 \%)$, minor conduct infractions $(24 \%)$, alcohol and other drug-related incidents, $(15 \%)$, major conduct violations $(11 \%)$, and academic dishonesty (6\%) (Van Brunt, Sokolow, Lewis, \& Schuster, 2014).

Examples of these major conduct violations are threats of and/or harm to others such as physical misconduct (e.g., assault, fighting), or sexual misconduct (sexual harassment, dating violence, domestic violence, stalking and/or sexual assault). The collegestats.org's list of "Ten Most Violent Acts Committed on a College Campus," describes the 2007 and 2009 incidents at Virginia Tech, the University of Texas (1966), Cal State Fullerton (1976), Northern Illinois University (2008), and Oikos University 
(2012), which directly impacted multiple members of the campus community, including faculty, staff, and students; and indirectly impacted those who have a connection to these institutions; and since have shaped the field of threat assessment and behavioral intervention on college campuses. The Kent State University (1970) and South Carolina State University (1968) incidents involved the direct and indirect effects of police attempting to control protests by students that unfortunately turned deadly. The remaining three violent incidents on the list involved more isolated events that indirectly affected the campuses on which they occurred but directly affected single individuals.

In 2009, a Virginia Tech student, Xin Yang, befriended another student and, while having a seemingly calm conversation over coffee, stabbed the other student multiple times and decapitated her in the presence of other students. The 1986 Jeanne Clery murder at Lehigh University had a lasting impact on college campuses because she was raped multiple times in her on-campus residence hall prior to being murdered. In another example of violence on campus, the mother of a student, Stacy Pagli, strangled her daughter in her on-campus residence hall room at Manhattanville College in 2011.

Since 2002, four tragedies involving mass shootings have occurred at universities. The Appalachian State School of Law experienced a shooting by a former student leaving three wounded and three killed on January 16, 2002. The same year, at the University of Arizona, a failing nursing student shot and killed three professors prior to committing suicide on October 28, 2002. April 16, 2007, Seung-Hui Cho committed suicide after opening fire, killing thirty-two people, and wounding seventeen (The Virginia Tech Review Panel, 2007) at Virginia Tech. Within a year, Northern Illinois 
University experienced a similar incident on campus, on February 14, 2008 when a former student shot and killed five people prior to committing suicide.

In Tucson, Arizona on January 8, 2011, a recently academically withdrawn student from Pima Community College shot nineteen people, killing six at an open constituent meeting led by U.S. Representative Gabrielle Giffords. Jared Loughner displayed disturbing behaviors on campus months prior to the shooting and was recommended to receive a mental health evaluation. Loughner did not comply with the directive of the threat assessment team to receive mental health evaluation and, at that time, withdrew from the college. Because the institution's administrators knew of the concerning behaviors of Loughner, the college received criticism for failing to protect and maintain public safety (Berzon \& Eaton, 2011).

Threats of harm to others are not the only threats for which behavioral intervention teams are responsible to assess. Teams are also responsible for responding to self-injurious behavior. Whitlock, Eckenrode, and Silverman (2006) found $15.3 \%$ of an 11,529 student participant population has a history of self-injury, and $6.8 \%$ selfinjured in the past year. Furthermore, Whitlock et al. suggested respondents who identified as bisexual or questioning were more likely to have participated in selfinjurious behavior at least once or twice as compared with heterosexual participants. Similarly, Serras, Saules, Cranfield, and Eisenberg (2010) surveyed 13,000 college students (76.5\% undergraduate; $23.5 \%$ graduate) finding $13.1 \%$ heterosexual students, $34.8 \%$ bisexual students, $23.7 \%$ lesbian/gay/queer students, and $23 \%$ who identified as other participated in self-injurious behavior. 
Additional research suggests that self-injury among college students may be closer to $22 \%$ (Nock \& Kessler, 2006) and that the rates of self-injury are similar between college students who identify as male and those who identify as female (Briere \& Gil, 1998; Klonsky, Oltmanns, \& Turkheimer, 2003). Examples of self-injury are behaviors such as suicide ideation, gestures, threats, and attempts; as well as cutting, burning, and eating disorders (Sokolow, Lewis, Van Brunt, Schuster, \& Swinton, 2014). According to Spicer and Miller (2000), $68 \%$ to $86 \%$ self-injurious behaviors are drug overdoses and $9 \%$ to $23 \%$ are cutting behaviors. On the continuum of types of selfinjurious behavior, suicide completion is the most extreme form. The best ways to recognize in advance the difference between suicide and other forms of self-injury are intent, method, and psychological impact (Kerr, Muehlenkamp, \& Turner, 2010). Eightyseven to ninety-eight percent of successful suicidal methods are attributed to self-inflicted overdoses, gunshots, hanging, poisoning, and jumping from lethal heights. These data are presented as a range because more than one method may have been used (Spicer \& Miller, 2000; Kessler, Berglund, Borges, Nock, \& Wang, 2005).

From the early 1980s through the mid-1990s, suicide became the second leading cause of death among college students (National Center for Health Statistics, 1999). According to the Suicide Prevention Resource Center (2014), suicide is the leading cause of death among college students in the United States. Based on psychological autopsies, ninety percent of suicides were attributed to a psychiatric disorder, primarily mood disorders (Shaffer \& Craft, 1999). Because the Americans with Disabilities Act has increased accessibility to college, a growing number of college students enter college with pre-existing psychiatric treatment plans: colleges and universities are now 
responsible for providing services to a higher number of students with psychological problems.

Substance abuse may also be connected to self-injury and suicide according to case law (Lake \& Tribbensee, 2002). For example, in Wallace v. Broyles (1998) a University of Arkansas football player committed suicide via gunshot wound. A summary judgment ruling found there was sufficient evidence supporting that the defendant who provided the football player with Darvocet after a shoulder injury was responsible for the death of the football player because the Darvocet was not prescribed to the football player. The defendant provided the Darvocet unlawfully and did not explain the potential interactions of the drug with other substances such as alcohol.

At the University of Iowa in 2000, Sanjay Jain committed suicide by inhaling exhaust fumes from his moped two weeks after attempting suicide the same way in his residence hall. Jain's concerning behavior began with the use of alcohol and drug use resulting in a violation of the University's policies. Jain's ex-girlfriend notified resident assistants of his suicide attempt, an intervention was performed and the attempt was halted. However, after the completed suicide, Jain's father sued the university for wrongful death because the parents were not notified of the suicide attempt nor policy violation. The court ruled in favor of the university stating the university had no duty to prevent Jain's suicide even though the university had an unwritten policy that allowed for parental notification regarding suicide ideation.

In the case of White $v$ University of Wyoming, a first year student, Chauncey White, was transported to the hospital by police for severe alcohol intoxication and later discharged. After hospital discharge, White superficially slit his wrists with a razor blade 
or pocket knife; therefore, his residence hall director, police, and crisis intervention team assessed him for threat of suicide. After the hour-long assessment, White was determined to be "low risk" regarding threat of harm to self because he denied attempting suicide and seemed interested in receiving counseling. Two years later, White committed suicide. White's parents sued the University of Wyoming in which the court determined the university was not liable for the death of White because the employees were not operating as medical professionals and therefore had no duty to treat White's suicidal thoughts.

Additionally, teams are often referred cases involving substance abuse such as controlled substances and alcohol. According to Correia, Murphy, and Barnett (2012), national surveys indicate that $80 \%$ of college students drink alcohol each year and first year students are entering college with established drinking habits. Surveys from 19992007 by Substance Abuse and Mental Health Services Administration (2000, 2002, 2006, and 2008) showed that traditional college aged students (18-24 years old) who consumed five or more drinks during one occasion in the previous 30 days increased from $41.7 \%$ to $43.8 \%$.

\section{Statement of the problem}

According to the National Center for Addiction and Substance Abuse annual report (2007), a potential contributing factor for concerning behavior among college students is the use and abuse of substances such as alcohol and other drugs. In 2006$2007,83 \%$ of arrests on college campuses were associated with alcohol. Ninety-seven thousand students were victims of alcohol-related rape or other sexual assault, and 696,000 students were assaulted by another student who had been drinking heavily. 
Research also shows that alcohol is a contributing factor for suicide ideation and attempts. Specifically, suicide rates are six times higher for students who use alcohol than those who do not use alcohol (Harris \& Barraclough, 1997). A contributing factor of onethird of completed suicides occurring on college campuses was the use of alcohol (Harvard Public Health Review, 2006). By studying 15,000 college students, the Center for the Study of Collegiate Mental Health (2009) identified binge drinking as an indicator for thoughts of self-injurious behavior. Of participants who indicated using alcohol, 50\% who reported ten or more episodes of binge drinking two weeks prior to the study also reported seriously considering suicide.

According to Kessler, Berglund, Demler, Jin, Merikangas, and Walters (2005), another contributing factor for concerning behavior among college students is the emergence of serious mental health issues such as depression, anxiety, bipolar disorders, and schizophrenia. The median age for the onset of mood disorders is $25-35 y e a r s$ and substance abuse disorders is 19-23 years. Moreno, Laje, Blanco, Jiang, Schmidt, and Olfson (2007) indicated an increase of bipolar diagnoses during the past 10 years by 40 times in comparison to previous studies. Campus counseling center's staff also support the idea that mental health concerns are on the rise among college students over the past 20 years (Voelker, 2003; Gallagher, 2008). Benton, Robertson, Tseng, Newton, and Benton's (2003) research indicated an increase in complex issues among those seen at campus counseling centers noting a rise in relationship problems, anxiety, depression, suicide ideation, sexual assault, and personality disorders. Consistently, Arehart-Trichel (2002) and Kitzrow (2003) found an increase in college student hospitalizations. 
Because the college experience is designed to train the intellectual, moral, and character mind and those who join the community do so to make progress in intellectual life (Brubacher \& Rudy, 1968), it is the responsibility of the university to provide this ideal learning environment. Legal liability may be a possibility if a university does not adequately uphold the standards of the community or adequately respond when the learning environment is disrupted. Additionally, students possess a constitutional right of safety; therefore, universities have a legal obligation to protect the campus community and its members (Bowden, 2007).

In historical response, university personnel have been tasked with preserving the learning and living environment, the rights and safety of students, and the response to concerning behavior. The role of the university administration has transitioned through history from the period of in loco parentis wherein the personnel were expected to serve as student's guardians, through the bystander era wherein the university took little responsibility over the behavior of the students, to the current duty to care era (Bowden, 2007). The current duty to care era gives the university administration the responsibility to uphold safety and security for its members. At many colleges, behavioral intervention and/or threat assessment teams are responsible for performing in this way through referrals for concerning behavior. This dissertation aims to describe these referrals to the Student Care Team at the University of Louisville.

The growing but limited knowledge and publication base for threat assessment and behavior intervention teams on college campuses consists of suggestions for the creation and implementation of teams, team responsibilities, and university representation but lacks recommendations for practice of handling specific crises (Mardis, Gamm, \& 
Sullivan, 2013). Despite the optimistic trend of knowledge dissemination, work, and research are needed to identify these best practices for teams (Mardis et al., 2013). The current research has the potential to add to this new and growing field of threat assessment and behavioral intervention on college campuses. Identifying trends and patterns of concerning behavior may inform mitigation practices and better prepare teams for the proactive portion of the team's responsibilities.

\section{Purpose of the study}

The purpose of the current research is to describe the demographic profile and nature of the referrals to the SCT in order to understand what behaviors are associated with critical incidents on college campuses and whether students referred are likely to earn their attempted credit hours for the semester they were referred. The aims of the study are first to identify the demographic profile for students referred to the SCT, then the nature of referrals, and lastly, whether the referred students earn the credits they attempt for the referred semester. This study also aims to describe the work of the SCT team by identifying the types of behavior referred to/discussed by the SCT, the intensity of the SCT discussions (number of times discussed by the SCT), and when first incidents are most commonly discussed by the team. The demographic profile and nature of referrals are then used as predictors to identify whether there is an interaction among any of these categories and whether the student earned their attempted credit hours for the semester they were referred. 


\section{Significance of the study}

The demands for safety, security, and student well-being are very important for a university campus community (Mardis et al., 2013). Many universities have created teams to assess and respond to these safety and security expectations, specifically selfinjurious behavior and harm to others. The University of Louisville created a Student Care Team (SCT) in 2008 and discuss concerning behaviors during bi-weekly meetings each semester.

During SCT meetings, incidents involving self-injurious behavior and threats of harm to others are often a topic of discussion. The current research may inform teams by highlighting the types of cases most commonly referred. Team members will be able to assign additional on-call crisis responders or ensure a professional staff person is available to assist in necessary situations as well as developing programs and training for those who are already on the radar for concerning behavior in effort to mitigate the behavior.

Para-professionals and their trainers may also be interested in this research, as they are often responsible for responding to critical incidents. Housing and residence life para-professionals are often on the front lines in responding to concerning behavior of college students "because young students often feel more comfortable in talking to same age peers" (Shaikh \& Deschamps, 2006, p. 48). If these para-professionals are equipped with tools that mitigate the risk for concerning behavior, it is possible that there will be fewer incidents needing attention in a crisis.

Campus law enforcement officers may also be interested in the findings of the current research because they receive calls about and respond to critical incidents. Police officers determine levels of risk by assessing warning behaviors that may include acute, 
dynamic, and particularly toxic changes in patterns of behavior (Meloy, Hoffman, Guldimann, \& James, 2011). If campus police are trained on the nature of the incidents that have occurred, they are better able to respond to a similar incident in the future.

Faculty members may also be interested in the current research because they often witness and confront alarming behaviors in the classroom. If faculty members are informed of concerning behavior and know how to report, the behavior may be mitigated. Family members of college students who experience suicide ideation may be able to identify concerning behavior if informed about warning signs. If parents are aware of and able to identify concerning behaviors, they may be more inclined to report concerning behavior to a university official when their student needs assistance.

A well informed threat assessment and behavioral intervention team has the ability to identify concerning behaviors and provide assistance related to the needs of students in crisis (Meloy et al., 2011). The significance of the current research is that appropriate response to concerning behavior has the potential to mitigate risk and provide necessary resources that may prevent very preventable behavior such as self-injurious behavior and threats of harm to others. 


\section{Definition of terms}

The following definitions apply in the current research:

1. "Accused" is defined as any student who is charged with a violation of the Code of Student Conduct.

2. "Complainant" is defined as any student who has accused another student with a violation of the Code of Student Conduct.

3. "Concerning behavior" is defined by the Student Care Team (SCT) as any referrals of behavior that "threatens well-being of one or more individuals or the university community as a whole" (University of Louisville, 2008, p.2.).

4. "Critical incident" is defined as an incident of threat of harm to others and/or self-injurious behavior.

5. "First-year" is defined as a student with fewer than 30 earned credit hours.

6. "Harm to others," using Title II’s definition of direct threat ( $§ 35.139)$, is defined as a significant risk to the health or safety of others (42 U.S.C. $\S$ 12113(a)-(b) (2000).

7. "Intensity of student discussion" is defined by the number of meetings in which a student referral is reviewed $(1,2$, or 3 or more).

8. "Prevention, Education, Advocacy on the Campus and in the Community" (PEACC) is defined as the advocacy program at the University of Louisville for those affected by sexual misconduct and is responsible for reporting sexual misconduct complaints to the SCT (University of Louisville, 2017).

9. "Referral" is defined as any report made regarding concerning behavior to the SCT. 
10. "Referral source" is defined as the department from which a referral to the SCT is made.

11. "Referral type" is defined as the nature of the referral (sexual misconduct, harm to others, medical, self-injurious behavior, substance abuse, or multiple types).

12. "Sexual misconduct" is defined as any of the following behaviors: sexual harassment, sexual assault, stalking, voyeurism, dating violence, and/or domestic violence (University of Louisville, 2016).

13. "Student Care Team" (SCT) is defined as the University of Louisville's group designated to receive reports of and provide resources to students in crisis.

14. "Self-injurious behavior" is defined as any intentional or reckless behavior committed by the person impacted that requires medical or other attention (suicide ideation, gesture, and/or attempt).

15. "Student of concern" is defined as a student referred to the SCT that is not considered an accused nor complainant.

16. "Substance abuse" is defined as intoxication from an element such as alcohol, marijuana, cocaine, and heroin that requires medical or other attention.

17. "Team" is defined as an organized group on university campuses designed to receive reports of and assess concerning behavior and respond until the concern is no longer an issue (Fox \& Savage, 2009).

\section{Conceptual model}

Astin's (1991) Input-Environment-Output model of assessment was used as a foundational model for the current research because it conceptualizes the variables 
studied in the current research by outlining the consideration of the characteristics students bring with them into college, the college environment, and the impact the environment has on the student. Merton's (1938) Strain theory was used to understand that college students may behave inconsistently with expectations of a university community when experiencing stress levels related to those expectations. This study aimed to determine what input variables (demographic profile) were present in the university environment (nature of the referrals to the SCT) and if the university environment predicts whether a student completes the attempted number of credit hours for the referral semester. Figure 1 shows the conceptual model that guided this study.

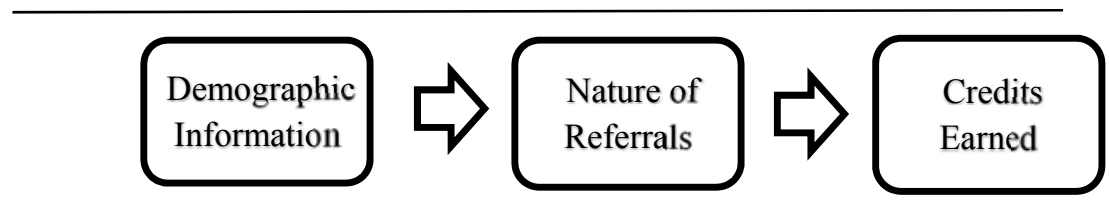

Figure 1. Conceptual Model

\section{Research questions and hypotheses}

The current research aims to answer the following research questions and test the following hypotheses to describe the students referred the SCT and the nature of the referrals made:

Q1: What is the demographic profile for students referred to SCT in comparison to the overall student population?

Q2: What is the nature of the referrals to SCT?

a. What types (threat of harm to others, self-injurious behavior, medical, substance abuse, sexual misconduct, other) of cases are referred?

b. What are the referral sources? 
c. Do the referred incidents occur on or off campus?

d. When is the first time the SCT discusses a referred student?

e. What is the intensity of the SCT discussions about each referral?

Q3: How does the demographic profile and nature of the referrals predict whether the student referred earns the credit hours for the semester they were referred to the SCT?

$\mathrm{H}_{3 \mathrm{a}}$ : Students referred for incidents involving threats of harm to others, substance abuse, or sexual misconduct are less likely to earn the attempted credits compared to those referred for incidents involving self-injurious behavior, medical, and other.

$\mathrm{H}_{3 \mathrm{~b}}$ : Students with higher intensity discussions (3 or more) are less likely to earn attempted credits than those with lower intensity discussions (1 or 2).

The remaining sections of this chapter describe the delimitations and limitations of the current research. The sample population is addressed in the delimitations section and the potential limitations include generalizability across teams as well as the chance that students do not earn attempted credits for reasons outside the University environment.

\section{Delimitations}

This dissertation research only encompasses the University of Louisville students. The population is also limited to the Student Care Team cases at the University of Louisville during 2010-2011, 2011-2012, 2013-2014 academic years and fall 2014 academic semester. 


\section{Limitations}

Using only the University of Louisville to collect data, generalizability of findings is of concern because teams at other universities may not maintain records of students discussed, the intensity of the SCT discussion, incidents referred to the team, or actions taken by the team members. Additionally, teams may not maintain records of demographic information that allow for the drawing of themes across teams. Also, there may be reasons outside their referral that impact why a student does not earn the attempted number of credit hours such as homelessness, financial concerns, health issues, and/or family health concerns. Lastly, multiple testing may be a limitation to the current research because it has the potential to lead to Type 1 errors. For example, because no control was performed to eliminate Type 1 error, there is a possibility that a null hypothesis is rejected when true. 


\section{CHAPTER II: REVIEW OF LITERATURE}

This chapter contains a review of pertinent theoretical and conceptual frameworks, previous literature, and response to critical incidents. In the first section: theoretical and conceptual frameworks, Astin's (1991) Input, Environment, Output (I-EO) is presented as the foundational model for the data assessment, the use of Strain theory describes behavior techniques by students whose goals and means do not align, and threat assessment explains functions of teams designed to assess potential for risk of harm. The second section, critical incidents, illustrates the variables of critical incidents and the connection to mental health concerns as well as substance abuse among college students, incidents involving threats of harm to others and their impacts on higher education policy and practice. Additionally, previous research about teams similar to the SCT are described to show the process for which these referrals are handled as well as illustrations for the makeup and design of such teams. The third section, teams, describes elements, structure, function of behavioral intervention and threat assessment teams as well as organizational development and crisis management concepts driving teams.

\section{Conceptual and theoretical framework}

Astin's (1991) Input-Environment-Output theory provides a framework for the research design of the current research, Merton's (1938) Strain theory explains how stress affects

behavior, and threat assessment is the recommended model for ways to respond to threats of harm to others and self-injurious behavior. 
Input-environment-output model. Astin's (1991) Input-Environment-Output (IE-O) model for assessment is the foundational concept used to organize the current research as it contextualizes the variables of demographic information as input, nature of referrals as environment, and the achievement of attempted credit hours as the output. For the purpose of the current research, Strain theory (1938) is examined to identify means (coping mechanisms) and goals for students. As Strain theory explains, when means and goals do not easily align, a person may perform coping mechanisms outside of the norm for the person. Similarly, if a student feels as though a goal may be in jeopardy, new means may be created in order to control this stressor. When students experience perceived stress, it is possible they will create new means (threatening harm of others or self-injurious behavior) in order to control the current stressor. The concept of threat assessment, used by teams on campuses is then used to examine the level of concern and appropriate response needed to mitigate potential risk.

Input-Environment-Output Model of Assessment. Astin’s (1991) “I-E-O model is very simple, yet it provides a powerful framework for the design of assessment activities and for dealing with even the most complex and sophisticated issues in assessment and evaluation" (Astin 1991, p. 16). The model analyzes unique student characteristics and the college environment on subsequent outcomes (Astin, 1991). Input variables include traits students bring with them to the college environment and the output assessed is academic advancement. For the purpose of this study, academic advancement is measured by the earning of attempted credit hours. 


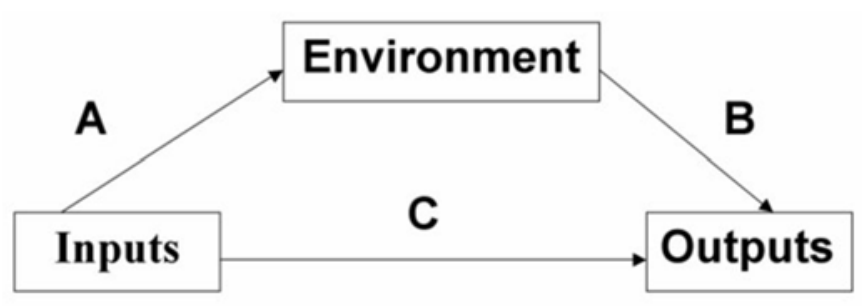

Figure 2. I-E-O Model of Assessment

The Environment portion of Astin's (1991) I-E-O theory considered in the current research involves the types of referrals made to the SCT. Additionally, Merton's (1938) Strain theory was used to explain ways the university's expectations may induce stress and why students may behave incongruent with the standards of the university community.

Strain theory. Merton's (1938) Strain Theory and Deviance Typology inform the current research by identifying responses to stressors once the stress is assessed by a student. The theory posited societal expectations and life goals may induce stress on a person to conform or deviate from the approved means for achieving the expectations. Merton explained strain occurs when there is incongruence in the availability of institutionalized means and cultural goals. When the institutionalized means and cultural goals are both accepted, the goal is met through approved means ("conformity"). If either or both of the means and goals are rejected, a person may adapt to reach the goal in unapproved means. For example, a person who attempts to attain a goal ("conformity") but perceives there is an uncontrollable circumstance jeopardizing attainment may be more likely to commit a crime ("innovation") in order to attain the goal than someone who has successfully conformed.

Acceptance of institutionalized means but rejection of cultural goals may cause the person to experience "ritualism", and for example, participate in college even though 
the person has no interest in a career in the studied field. "Retreatism" is the result of combining rejection of institutional means with rejection of cultural goals and can be described as someone who withdraws from cultural expectations and norms. The last mode for adaptation involves the creation of new goals and new means, "rebellion", and has the potential of being the most volatile.

This theory informs the current research by illustrating the stress created by the college environment. If students are unable to meet the perceived goals of the college environment, they may conform, innovate, ritualize, or retreat in order to adapt. In the cases of threats of harm to others or self-injurious behavior, concerning behavior could be the response to the college environment's institutional means. It is also possible that students are responding to stressors outside the university environment that impact them while in college. For the purpose of this study, some of these stressors are considered (homelessness, illness, or financial concerns) and encompassed in the environment variable if they led to the referral for SCT assistance.

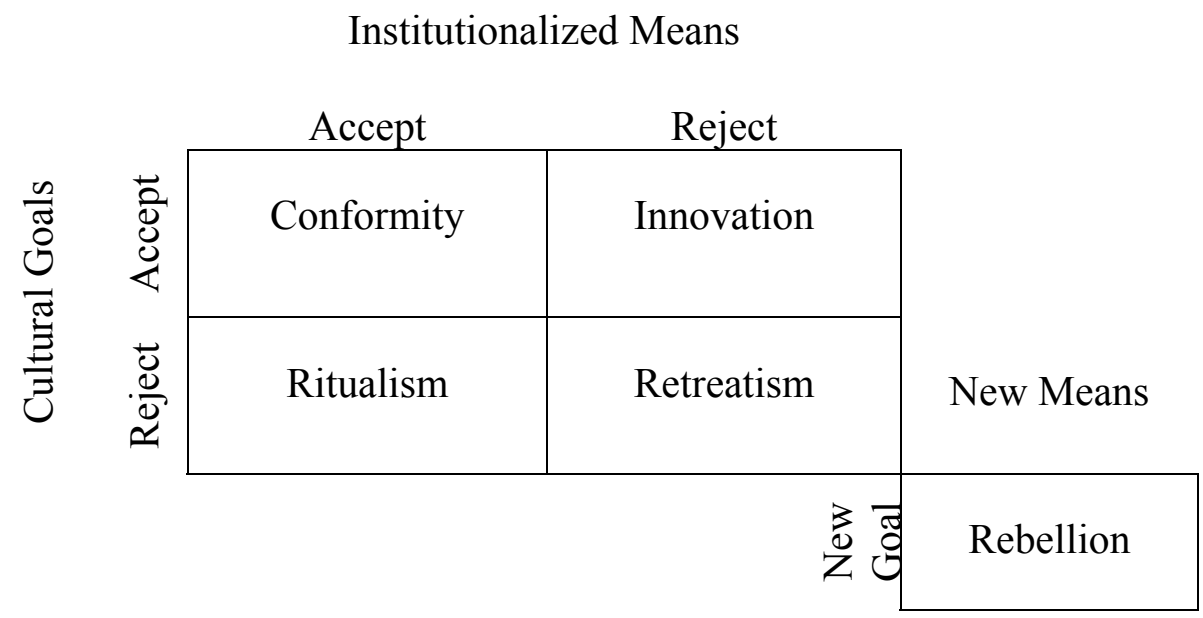

Figure 3. Strain Theory Deviance Typology

Because the university environment may cause stress that lead students to behave incongruently with the standards of the university, the threat assessment model is 
recommended for university administrators to respond in incidents related to threats of harm to others and self-injurious behavior. The following model explains the recommended methods for response.

Threat assessment. According to Borum, Fein, Vossekuil, and Berglund (1999), "threat assessment is a fact-based method of evaluation that has been developed, refined, and used by the U.S. Secret Service in its protective intelligence activities to protect the President of the United States and other U.S. and foreign leaders” (p. 327). Even though the model was first created to identify people who attacked or attempted to attack public figures, it may also be modified to evaluate risk for other forms of violence. The threat assessment concept "does not rely on descriptive, demographic, or psychological profiles" (p. 327) nor does it "rely on verbal or written threats as a threshold for risk" (p. 327). Principles of this approach include: 1) violence is an understandable process of thinking and behavior, it is not impulsive nor spontaneous. This principle suggests there is a series of critical factors planned such as targets, proper time and approach, and means for the violence. The second principle indicates that an interaction among the attacker, previous stressful events, the current situation, and the target stimulates violence suggesting a more situational understanding of risk. Furthermore, this principle considers that if typical coping skills are ineffective, people may become physically ill, psychotic, self-destructive, or violent. Similarity to previous situations and the current situation may also inform a threat assessment and the potential that self-destructive or violent behavior may recur. The third principle is the identification of a potential attacker's "attackrelated" behaviors, or the behaviors or thoughts related to the planning and preparations such as communication of these plans, and/or "inappropriate interest in others, following, 
approaching or visiting a potential target or scene of the attack, even with lethal means" (p. 330).

Threat assessment is used in a myriad of services in order to identify threatening behavior and the potential for threats to come into fruition. For the context of the current research, threat assessment is used by teams to assess the level of risk associated with the coping strategies of students experiencing stress. Even though SCT does not specifically identify itself as a threat assessment team as some other teams do, it is not uncommon for the team to use the previously described principles when investigating direct and indirect threats of harm to others.

The following section of this chapter describes critical incidents and their impact on policy and practice. This section is designed to illustrate the need to understand these concepts in order to provide context for the potential root of the concerning behavior.

\section{Critical incidents}

The following section discusses critical incidents such as threats of harm to others, self-injurious behavior, mental health concerns, and substance abuse incidents on college campuses and the way in which campuses have responded to these incidents. The analysis of cases referred to the University of Iowa's threat assessment illustrates the nature of the referral variable considered in this dissertation.

A review of the University of Iowa threat assessment team's caseload for 2008, 2009, and 2010, examined self-injurious behavior and external threats (Cao, 2011). External threats were defined as behavior aimed toward another person such as "expressed anger, assaultive behavior, expressed physical aggression, firearm concerns, threats, unwelcome electronic or written communication, unwelcome verbal 
communication, verbal aggression, or harassment or stalking" (Cao, 2011, p. 9). Selfinjurious behavior was defined as "behaviors that did not involve an expressed threat to another individual" such as "suicidal ideation or attempt, ongoing suicidal concerns, welfare checks; and mental health related behavior such as alcohol or drug issues, delusion, disturbing or disruptive behavior, mental health issues, sexual behavior, suspicious activity, termination, or work performance issues" (Cao, 2011, p. 9). Analyses involving the distribution of demographics, threat contributing factors, reported threats, referring person(s) and accused-victim relationships were compared with employees, students, and visitors via chi-square. Regression models and odds ratios were used to predict response type, situation type, and the need for follow up with the threat contributing factors identified in the case.

A total of 284 referrals to University of Iowa's threat assessment team were evaluated (13.03\% from 2008, 48.94\% from 2009, and 27.68\% from 2010). The most common contributing factor to the threat was a history of mental health problems (over one third), while $19.7 \%$ was alcohol, $14 \%$ was criminal history, and weapons was $5.3 \%$. More than half of cases (51.8\%) involved at least one contributing factor and 51 cases $(18 \%)$ involved more than two contributing factors. Incidents involving external threats and self-injurious behavior required the same frequency of response by the team. Most commonly reported incidents was suicidal behavior (35.1\%) for students and threatening behavior (47.3\%) for visitors. This review of the University of Iowa's threat assessment caseload informs the current research by highlighting the nature of the referrals to the SCT at the University of Louisville. 
Threats of harm to others. Flannery and Quinn-Leering (2000) explained a majority of college students are exposed to violence through victimization or witnessing a violent act. This exposure "can lead to emotions such as anger, anxiety, or depression that may, in turn, create a situation in which the students are not able to take full advantage of educational opportunities" (p. 840).

Drysdale et al. (2010) studied 272 acts of violence at universities from 1900-2008 as a collaborative effort between Secret Service's National Threat Assessment Center, the Department of Education's Office of Safe and Drug-Free Schools, and the Federal Bureau of Investigation's Behavior Analysis Unit. Information such as time and place, method of assault, relationship to victim as well as motivation for assault regarding direct assaults were the criterion for inclusion for the investigators to begin to understand the scope of the problem of targeted violence at universities (IHE). Researchers found that violent incidents occur throughout the calendar year and that 20 percent of the incidents affecting members of the institution occurred off campus. Additionally, researchers identified a three-step process to evaluate the level of potential threat of a person. The steps of the threat assessment are: 1) identify individuals whose behavior causes concern or disruption on or off campus, 2) assess whether the identified individual possesses the intent and ability to carry out an attack and if the individual has taken any steps to prepare for the attack, and 3) manage the threat posed by the individual.

Threats of harm to others are not restricted to incidents regarding the potential for homicide or death. Teams may also receive referrals for behavior involving harassment, stalking, bullying, or sexual harassment and may involve behavior that occurs in the online environment, through social media, phone (calls, voicemails, text messages), or in 
person. Additionally, teams may also receive concerns regarding students who carry weapons that violate a University's policy for fear that the possession of a weapon may relate to the potential that harm may occur.

The following research studies discuss dating and domestic violence and the correlation with substance abuse as a contributing factor. Additionally, these studies also include findings of previous exposure to violence in the home. The analysis of these studies informs the current research by highlighting college student victimization and perpetration of violence and the findings that substance abuse and use are often intertwined. To understand the potential of violence, the following researchers agree that substance abuse and exposure to violence are contributing factors.

Gover, Kaukinen, and Fox (2008) examined gender differences among victimization and perpetration in dating violence and psychological abuse. Using a survey developed for this study, "Family and Relationship Experiences and Attitudes Among College Students", a total of 2,541 students participated between August and December of 2005. One hundred and sixty seven questions regarding violence in participant's family of origin, attitudes toward women, dating relationship behaviors as well as protective and risk factors for perpetration and victimization were included in the survey. The analysis of survey responses explored the "association between exposure to violence in the family of origin and subsequent physical violence" (p. 1674) as well as psychological abuse. Chi-square analyses tested pairwise associations between exposure to violence as a child with physical violence and psychological abuse. To evaluate the relationship between exposure to childhood violence and subsequent violence and psychological abuse within the full sample as well as women and men. 
Overall results showed $29 \%$ of participants perpetrated physical dating violence while $22 \%$ were victims within the previous 12 months. Participants who indicated victimization of childhood abuse and participants who witnessed one parent hit the other parent "perpetrated and experienced significantly higher rates of physical violence in dating relationships" (p. 1675) in comparison with those who were not exposed to violence as a child. Of the participants who reported experiencing abuse, $38 \%$ perpetrated violence; however, $25 \%$ of those who did not experience violence perpetrated violence. Similarly, $32 \%$ of those who experienced violence during childhood reported being victims of violence in dating relationships while $18 \%$ of those who did not report childhood victimization reported victimization in dating relationships. Participants "who witnessed their father hitting their mother were almost twice as likely to perpetrate and experience violence compared to those who did not witness their father hitting their other ( $44 \%$ vs. $28 \%$ for perpetration and $39 \%$ vs. $21 \%$ for victimization)" (p. 1675). Significant gender differences among those who perpetrated violence in dating relationships ( $24 \%$ of males vs. $32 \%$ of females) were also found. No significant difference between gender and physical violence victimization was identified. In regards to psychological abuse, findings indicated $54 \%$ of college student participants reported perpetrating psychological abuse and 52\% reported victimization of psychological abuse within 12 months of participation. Participants who experienced childhood abuse and witnessed one parent hitting the other parent significantly reported higher rates of perpetration and victimization of psychological abuse compared with participants who did not experience childhood abuse or witness one parent hitting the other parent. Similar to those who witnessed fathers hitting mothers who were more likely to perpetrate and experience 
violence, participants who witnessed fathers hitting mothers were also more likely to perpetrate and experience psychological abuse. Females (57\%) were more likely to perpetrate and experience psychological abuse than males (50\%). Overall, findings suggested males are significantly less likely than females to perpetrate physical violence $(\beta=-0.706, p<.001)$ and specifically, being male decreases the odds of physical violence perpetration by $50 \%\left(e^{0.706}=0.494\right)$. Also, experiencing childhood abuse is significantly associated with perpetrating physical violence $(\beta=0.357, p<.01)$ and those who experience childhood abuse are $43 \%$ more likely to perpetrate violence in comparison with participants who did not experience childhood abuse. Research conducted by Gover et al. (2008) informs the current researcher's effort to identify the difference between male and female threats of harm to others.

Roudsari, Leahy, and Walters (2009) studied the correlation between dating violence and heavy drinking among college students. In order to do so, participants who were at least 18 years of age and reported at least one heavy drinking episode in the 2 weeks prior to the study were recruited in the fall of 2006 and spring of 2007 from a private university. In order to assess alcohol consumption, a modified version of the Daily Drinking Questionnaire (Collins, Parks, \& Marlatt, 1985) was used to calculate an estimated peak blood alcohol content in the past month. Participants' self-reported weight and gender in addition to number of drinks and hours spent drinking was used to calculate participant's heaviest drinking episode as well as the number of times the participants engaged in heavy drinking episodes during the 2 weeks and month prior to the study. The Conflict in Adolescent Dating Relationships (CADRI; Wolfe, Scott, Reitzel-Jaffe, 2001) questionnaire, a 36-item Likert scale, was used to identify abusive 
dating behaviors. Of Wolfe et al.'s (2001) five original subcategories: threatening abuse, relational abuse, physical abuse, sexual abuse, and verbal-emotional abuse, Roudsari et al. (2009) used 3: threatening, physical, and verbal-emotional. Chi-square analyses were conducted for comparisons of each subcategory with female and male responses. Linear regression analyses evaluated the association between scores on the CADRI with age, gender, race, fraternity or sorority affiliation, parental history of problem drinking, athletic team affiliation, and alcohol consumption.

Results of Roudsari et al.'s (2009) study found a higher proportion of male participants who were single and not dating while female students were involved in casual or exclusive dating. While statistics were not significant, male participants reported more heavy drinking episodes during the 2 weeks and month prior to the study. Of participants who reported being victims of verbal-emotional abuse, a higher proportion of females ( $75 \%$ ) reported their partners were under the influence of alcohol than male victims $(58 \% ; p=.016)$. Female perpetrators of verbal-emotional abuse reported they (75\%) and their partners (75\%) were under the influence of alcohol during the incident; however, $58 \%$ of males reported they and their partners $(55 \%)$ reported being under the influence when the incident occurred. In regards of physical abuse, male participants reported $100 \%$ of incidents occurred during times of which they and their partners were under the influence. On the other hand, $18 \%$ of females who perpetrated physical violence were under the influence at the time of the incident and $27 \%$ of their partners were not. Statistics involving the threat of violence, verbal-emotional abuse, and total abuse were positively correlated with both peak BAC and number of heavy drinking episodes. Male participants had significantly lower threatening abuse and physical abuse 
scores than females. This research informs the current research through the illustration of the difference in gender in physical abuse and threatening to abuse.

The previous literature included in this section shows that substance abuse is often involved in incidents involving threats of harm to others among college students. It also informs the current research about whether males or females are more likely to abuse substances and similarly, participate in harm to others as well as self-injurious behavior. However, while Drysdale et al.'s (2010) research findings about high referrals during April and October for violence, previous research does not specifically analyze the week of the semester in which the teams discuss these incidents; therefore, the current research will add depth to the literature. The following section discusses how previous incidents of harm to others have affected policies and practices for responding to threats of harm.

Impact of harm to others incidents on policies and practice. Violent incidents at universities have shaped legal requirements maintained by the U.S. Department of Education over the past few decades. For example, the Jeanne Clery Disclosure of Campus Security Policy and Campus Crime Statistics Act (Gross, 1990), originally known as the Campus Security Act, requires all institutions that participate in Title IV of the Higher Education Act federal student financial aid programs to:

1) annually publish statistics (Annual Security Report) regarding crimes on campus and in the adjacent areas of campus;

2) have a public crime log which includes nature, date, time, general location of each crime; and

3) publish crime statistics for incidents that occur on campus, in public areas adjacent to or part of campus, and any non-campus facilities controlled by the university 
(Department of Education, 2016) such as criminal homicide (murder and non-negligent manslaughter as well as negligent manslaughter), sex offenses (forcible and nonforcible), robbery, aggravated assault, burglary, motor vehicle theft, arson, liquor law violations, drug law violations, and illegal weapons possession.

4) devise an emergency response, notification, and testing policy,

5) compile and report fires and fire safety; and

6) enact policies and procedures for reporting missing students.

The Clery Act was originally created in response to a sexual assault and murder of a student, Jeanne Clery, which occurred in an on-campus resident hall at Lehigh University in 1986. When the family of Jeanne Clery learned of university security lapses, a \$25 million lawsuit was filed and was settled out of court. The Clery’s used the settlement to create Clery, Inc., a non-profit organization, and to lobby for statutes requiring institutions to report statistics about crime on and around campus. Since 1988, the U.S. Department of Education (DOE) has become responsible for the maintenance of the Clery Act on a national level. Annually, institutions are required to distribute statistics of crime on and surrounding campus on October $1^{\text {st }}$ to all current students and employees. The Clery Act requires crime and fire statistics to be submitted to the DOE through a Campus Safety and Security online survey. Requirements for compliance are published by the DOE in a comprehensive handbook, which outlines that failure to comply with the requirements may result in fines up to $\$ 35,000$ per violation and suspension from funding by federal financial aid programs (Gross, 1990).

An incident at Murray State University in 1998 involved an alleged prank that became deadly when a group of students lit a university resident's residence hall room 
door on fire and killed Michael Minger. The parents of the deceased and other students were unaware of a previous fire committed by students in the residence hall encouraging Gail Minger (mother of deceased) to champion a new law. The 2000 Minger Act requires private and public institutions in Kentucky to report all crimes including arson to the Kentucky Council on Postsecondary Education (CPE) (Kentucky Revised Statutes, Chapter 164, Sections 9485 to 9489; Section 993).

Incidents at Virginia Tech, Northern Illinois University, and Murray State University have shaped the work of student affairs administrators from the governmental level for some states such as Virginia, Illinois, and Kentucky (Mardis, 2013). These campus officials received notification of the gun holder, locked down the campus, and called for police responders to eliminate the threat. The hours during the events themselves were plenty to change lives, but changes did not end during that time or that day.

Virginia and Illinois have mandated state funded institutions to develop a campus wide committee charged with the education and prevention of violence on campus and the creation of a threat assessment team (Code of Virginia, § 23-9.2:10; Illinois Compiled Statutes, §110 ILCS 12-20). The Code of Virginia, § 23-9.2:10 required representation from residential life, human resources, counseling services and legal counsel and other constituencies as needed. To meet this requirement, Virginia Tech created a threat assessment team with the following representation: police, the associate vice president for student affairs, dean of students, registrar, vice provost, human resources, counseling center director, faculty, and advised by legal counsel. The purpose of this team at Virginia Tech is to identify and monitor threats on campus and respond appropriately. 
The field of research in threat assessment and behavior intervention is growing. Divisions of student affairs at universities implemented protocols for crisis preparedness and response. Virginia and Illinois received directive from state law requiring creation, implementation, and facilitation of behavior intervention, threat assessment, and/or crisis response teams. Many other institutions have also created teams to address crises and difficult student situations. Following the Virginia Tech massacre, the Governor of Virginia, Timothy M. Kaine commissioned a review panel to analyze the incident and make recommendations designed to prevent future mass shootings. In 2008, U.S. President George W. Bush commissioned a similar review panel identifying issues raised by the tragedy. The review panels recommended the creation of a reporting procedure for threats of violence as a priority.

Self-injurious behavior. Literature previously reviewed in this section discuss findings of suicide ideation, gestures, and attempts in addition to the increase of students entering college with mental health concerns. These studies support inclusion of selfinjurious behavior as part of the variable for the nature of referrals to SCT. The following studies describe incidents of suicide on campuses and mental health concerns that lead to these crises.

According to Hollingsworth, Dunkle, and Douce (2009) student affairs professionals have seen an increase in high-risk behavior such as alcohol use, the "hookup" culture, sleep deprivation, and competitive perfectionistic standards applied by students. The American College Health Association (2009) found among 80,121 surveyed college students, $38.8 \%$ reported feeling hopeless at least once, $27.3 \%$ reported feeling so depressed they found it difficult to function at least once, and $7.1 \%$ considered 
suicide one or more times. Suicide among college students (18-24 years) has increased over the past several decades (Haas, Hendin, \& Mann, 2003). Studies from Cambridge and Oxford (Carpenter, 1959; Parnell, 1951; Rook, 1959; Temby, 1961) and following studies (Atkinson, 1969; Braaten \& Darling, 1962; Bruyn \& Seiden, 1965) pointed at elevated suicide levels among college students.

An examination of all completed suicides among undergraduate and graduate students from September 1, 1980 to August 31, $1990(N=261)$ on campuses affiliated with the Big Ten University Athletic Association found the average rate for suicide was 7.5 per 100,000 students. These findings were compared with a national sample containing matched ages, genders, and races. Among students under the age of 25 years, the suicide rate was 5.8 , significantly lower than the national sample $(p \leq .001)$. Among students over the age of 25 years, the rate was 10.7 and while this rate is lower than the national population, it was not a statistically significant difference. Male students over the age of 25 years showed the highest rates of suicide and the rates of those who were between the age of 35 and 39 years was 24.1, the only group of matched which had higher numbers than the national population.

Ten percent of the students who participated in the 1995 National College Health Risk Behavior Survey (Youth Risk Behavior Surveillance, 1997) seriously considered attempting suicide during the previous 12 -month period, while $7 \%$ indicated they made a suicide plan, and $2 \%$ attempted suicide necessitating medical attention. In 2001, the National Survey of Counseling Center Directors (Gallagher, 2005) reported 30\% of 274 participating colleges and universities experienced at least one student suicide during the 1999-2000 academic year. A total of 80 suicides were reported across the nation. 
Suicide is only one form of self-injurious behavior among college students. In 2001, Gratz reviewed conceptual and operational definitions of deliberate self-injurious behavior used in literature and provided a conceptual definition to be used in future research. Additionally, Gratz (2001) also explored the Deliberate Self-injurious behavior Inventory (DSHI), a behavioral measure of self-injurious behavior. Participants included 159 students from undergraduate psychology courses at the University of Massachusetts Boston. After excluding 9 participants from the study for missing data, the final sample consisted of 150 students ( $18-64$ years of age) with a mean age of $23.19(S D=7.13)$. Sixty-eight percent of participants were female and $32 \%$ were male. "Sixty percent of the participants were Caucasian American, 18\% were Asian American, 13\% were African American or another ethnic group of African descent, 5\% were Hispanic American, and $4 \%$ were of another racial/ethnic background" (Gratz, 2001, p. 255). The Deliberate Selfinjurious behavior Inventory was created by the researcher and included 17-items that were behaviorally based on the self-report questionnaire. The inventory defined deliberate self-injurious behavior as the "deliberate, direct destruction or alteration of body tissue without conscious suicidal intent, but resulting in injury severe enough for tissue damage (e.g., scarring) to occur" (p. 255). It assessed frequency, severity, duration, and type of self-injurious behavior. Results of the research indicated that $35 \%$ of the participants $(N=53)$ reported a history of deliberate self-injurious behavior, $15 \%$ of whom reported over 10 incidents of self-injurious behavior in the past and $9 \%$ indicated over 100 incidents in the past. Eighty-three percent of self-injurious students reported using more than one type of self-injurious behavior. Nine percent of the sample and $26 \%$ of the self-injurious students reported in the use of four or more self-injurious behaviors. 
Skin cutting and needle-sticking were among the behaviors reported most (14\% of each), severe scratching (12\%), banging of the head (11\%), carving words into skin (9\%), punching self (9\%), interference with wound healing and other forms of self-injurious behavior (both 7\%). Five percent indicated behaviors such as burning with a cigarette and biting, $4 \%$ indicated carving pictures into skin, $3 \%$ indicated burning with a lighter or match and rubbing glass into skin while $1 \%$ indicated intentionally breaking bones. Gender was not significantly associated $\left(r_{\mathrm{b}}=-.09\right)$ with the rates for women as $34 \%$ and men $38 \%\left(x^{2}=.15, p>.10\right)$. Additionally, gender was also not associated with the types of self-injurious behavior except in the behavior of carving words into skin (W $=12 \%$; M $=2 \%)\left(x^{2}=3.87, p<.05\right)$.

Impact of self-injurious behavior on practice. Because suicide involving college students has increased, many mental health services departments experience a high number of clients (Whitlock, et al., 2006). Another way colleges approach suicide is through educational prevention programs such as stress management and the indicators of self-destructive behavior (Finding Hope and Help College Initiatives, 2002). Other initiatives focus efforts following a suicide or suicide attempt (Webb, 1986) specifically for students who have attempted suicide in the past.

The American Foundation for Suicide Prevention (AFSP) has developed the College Screening Project: A Program to Identify and Help Students With Significant Psychological Problems. In the Spring 2002 semester, the pilot test was administered at Emory University with first-year students $(N=$ approx. 1,000$)$ and involves a suicide risk model which focuses on the highest suicide risk as those who are diagnosed with psychiatric disorders. Specifically, psychiatric disorders that inhibit student's ability to 
adequately respond to college stress and in turn cause the student additional stress by not attending classes nor completing assignments. The most common psychiatric disorder and predictor among those who commit or attempt suicide is depression (Brent, 2002). Therefore, the screening incorporates a depression screening as well as questions regarding symptoms of anxiety, alcohol and drug abuse, and eating disorders. If a student's responses show significant signs of anxiety, alcohol or drug abuse, or eating disorders, a counselor invites the student for a personalized assessment. Other resources made available based on the responses are a feature allowing students to communicate directly with a counselor through the website and the offer for pharmacological and/or psychotherapeutic treatment.

The following section of this chapter describes concepts that comprise teams and the work performed by teams when responding to threats of harm to others and selfinjurious behavior. Mintzberg's parts of an organization (1979) as a broad basis for the foundation of a team, through Zdziarski, Dunkel, and Rollo's (2007) crisis response framework which describes the functions of a team, and ends most specifically with elements of a behavioral intervention team (Sokolow, 2014).

\section{Teams}

Because critical incidents are occurring on college campuses and universities are responsible for responding to these incidents, many institutions have created a team to respond. Team members meet regularly to discuss concerning behavior, share information from across campus departments, and take appropriate action by providing students referred with appropriate resources. Each of the following sections informs the current research by describing roles for members of the team, the team's function, and the 
best practices for performing the functions of the team. Mintzberg's (1979) parts of an organization describes the overall roles of team members and Zdziarski, et al.'s (2007) crisis response framework provides an overview for mitigation and response of crises.

Organizational development. Mintzberg (1979) identified five basic parts of an organization as the strategic apex or "superiors," middle line "managers," operating core or "subordinates," "support staff," and technostructure or "analysts." Superiors hold overall responsibility for the organization while middle line managers are responsible for communicating with the other components of the organization and often perform duties in the absence of superiors. Operating core or subordinates perform everyday duties to support the organization along with the support staff while the technostructure or analysts are often responsible for facility, financial, or data management.

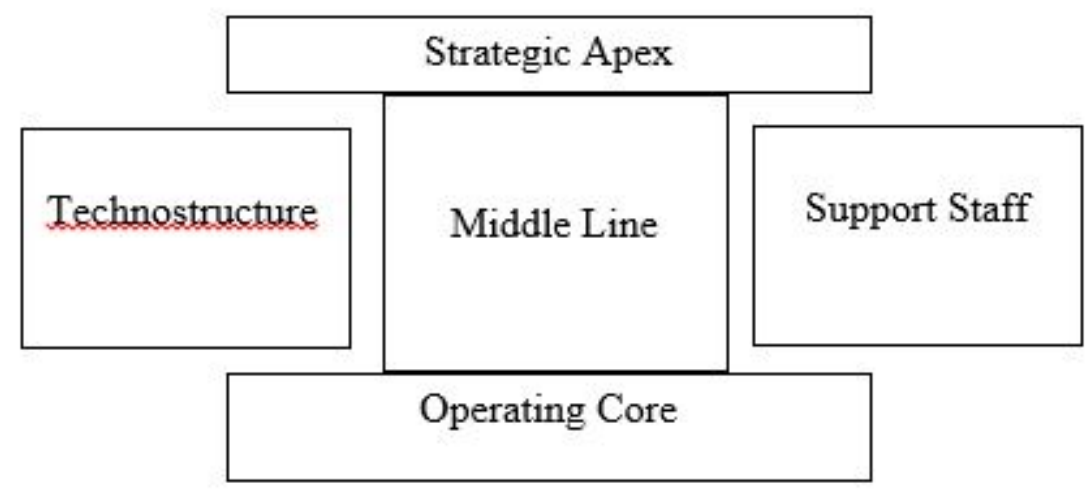

Figure 4. Five Parts of an Organization

Tierney (1988) states that “an organization's culture is reflected in what is done, how it is done, and who is involved in doing it. It concerns decisions, actions, and communication both on an instrumental and a symbolic level" (p. 3). Pfeffer (1981) defines power as the "capability of one social actor to overcome resistance in achieving a desired objective" (p. 2). Similarly, legitimacy is a series of accepted and expected 
activities and when paired with power, creates authority. In order for an organization to develop authority and legitimacy, each member of a team must perform appropriate tasks. Because teams are often performing tasks related to the assessment of threats of harm to others and self-injurious behavior, it is important that those serving in their particular roles are not only well informed on best practices for response but also are able to perform those important tasks in a swift manner in order to avoid potential crisis.

Crisis management. Zdziarski, et al. (2007, p. 5) define "a crisis is an event, which is often sudden or unexpected, that disrupts the normal operations of the institution or its educational mission and threatens the well- being of personnel, property, financial resources, and/or reputation." In order to establish consistent plans for dealing with crises, a matrix was created incorporating the following dimensions: critical, campus emergency and disaster levels; types (environment, facility and human); and intentionality. A cycle for managing such crises involves the planning, prevention, response, recovery, learning, and training.

Team elements. The National Center for Higher Education Risk Management (NCHERM) identified twelve key elements of modern behavior intervention teams (Sokolow, 2014, p. 4). These elements are considered best practices in designing and coordinating teams:

1. Use formalized protocols of explicit engagement techniques and strategies;

2. See their role as nominally to address threat, and primarily to support and provide resources to students;

3. Utilize mandated psychological assessment;

4. Have the authority to invoke involuntary medical/psychological withdrawal policies; 
5. Are undergirded by sophisticated threat assessment capacity, beyond law enforcement and psychological assessment tools;

6. Use risk rubrics to classify threats;

7. Foster a comprehensive reporting culture within the institution;

8. Train and educate the community on what to report and how;

9. Are technologically advanced and are supported by comprehensive databases that allow the team to have a longitudinal view of a student's behavior patterns and trends; 10. Focus not only on student-based risks, but on faculty and staff as well; 11. Intentionally integrate with campus risk management programs and risk mitigation strategies; and

12. Have a mechanism for "minding the gap".

Teams names are inconsistent across universities and colleges as some are called threat assessment, behavioral intervention, students of concern, student care, critical response, and many others (Dunkle, Silverstein, \& Warner, 2008; Pavela, 2008; Pavela \& Joffe, 2007; Randazzo \& Plummer, 2009; Sokolow \& Lewis, 2009). The president of Virginia Tech noted that the use of threat assessment in the naming of a team may incorrectly limit the function of the team's role (Randazzo \& Plummer, 2009). However, the theme remains that teams have emerged at universities since 2007's massacre at Virginia Tech. This section outlines team structure and function found in 2010, 2012, and 2014 surveys regarding threat assessment and behavioral intervention teams.

Mardis et al. (2013), explored team creation, content, and implementation practices by surveying a population of senior student affairs officers who belonged to the National Association for Student Personnel Administrators (NASPA). Through a combination of quantitative and qualitative questions, researchers captured general data about threat assessment and behavior intervention teams. Senior student affairs officers at 1,044 institutions across the United States were invited to participate in the pre- 
experimental survey and a total of 993 invitations were received after some invitations were not accepted due to poor email contact information. Of the total 993 invitations, 181 recipients responded (response rate of 18\%). One hundred seventy five respondents indicated that their institutions had a team designed to respond to students in distress. Eighty-eight percent of respondents with teams indicated that the institution for which they were describing were four- year institutions; and 12\% were 2-year institutions.

Team structure. Team structure is reference to team membership such as representation of a department or office or constituency. According to Randazzo and Plummer (2009), threat assessment teams should be managed by a multi-disciplinary team of administrators, representing the interests of faculty, students, and staff and chaired by the chief of police. Dunkle, et al. (2008) recommend that teams are chaired by a senior student affairs officer and consist of representation by a "mental health professional, disability specialist, law enforcement, and legal counsel, residence life staff, university chaplains and religious leaders, academic deans and faculty, international office representatives, campus health services" (p. 634).

Among 175 universities who responded to a 2010 survey by Mardis et al. (2013), the following positions were most frequently represented on teams: deans of students $(65 \%, n=114)$ or vice presidents $(34 \%, n=61)$, directors of counseling centers $(87 \%$, $n=153)$, public safety directors $(79 \%, n=139)$, housing directors $(71 \%, n=125)$, directors 
of health services $(46 \%, n=81)$ and faculty representatives $(41 \%, n=72)$.

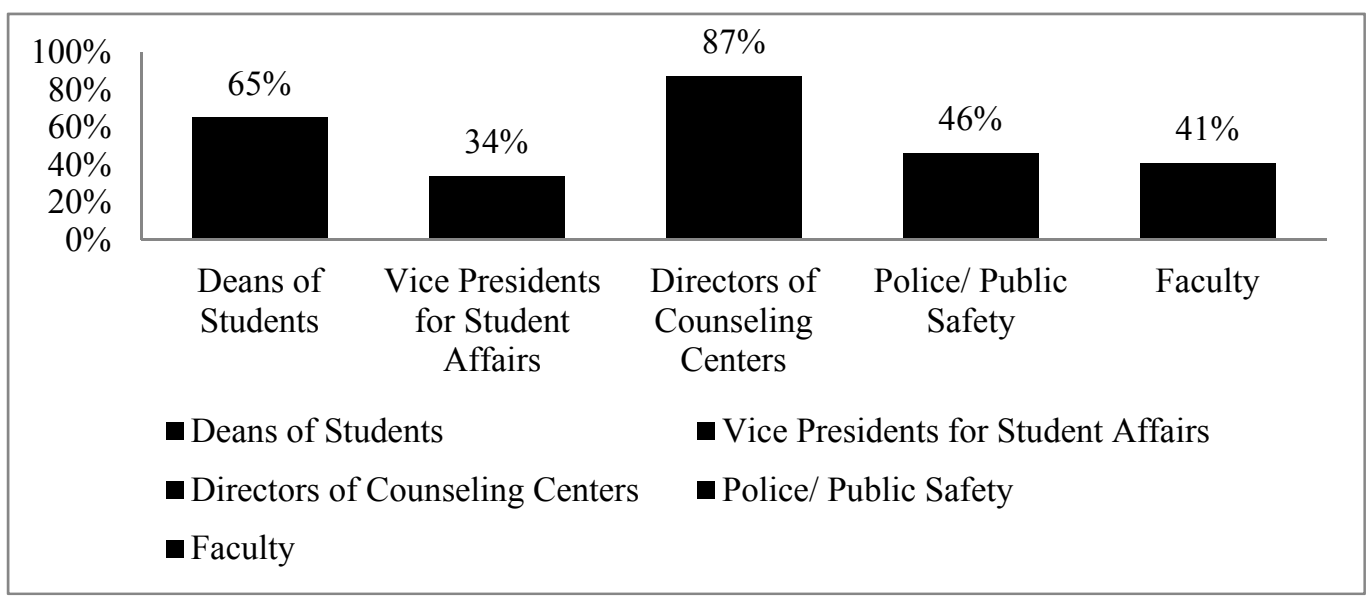

Figure 5. 2010 Team Representation

Additional representation on teams included: academic advising, financial aid, disabilities, legal counsel, campus ministry, athletics, international office, women's services, registrar, director of wellness services and career development services. In the case that teams also respond to faculty and staff referrals, human resources representation may also be included on the team. Ad hoc representation may be included depending on the case such as legal counsel or disability services for consultation purposes.

Additional consideration for team structure is the cultivation of relationships with constituents on campus for consultation such as Greek life, graduate or professional schools, minority affairs and international student services. Because international students may be vulnerable to many stressors, it may be important to consult with a representative from international student services (Fauman \& Hopkinson, 2010).

In 2012, the National Behavioral Intervention Team Association (NaBITA) conducted a survey of over 800 four-year (76\%) and community colleges $(24 \%)$ to identify trends among teams (Van Brunt, Sokolow, Lewis, \& Schuster, 2014). The institutions represented in the survey results included $75 \%$ residential and $25 \%$ non- 
residential, $65 \%$ public institutions and $35 \%$ private institutions. Of the institutions represented, 92\% reported having a team (threat assessment, behavioral intervention, and/or student of concern team). Deans of students (44\%), vice presidents for student affairs $(22 \%)$, student conduct (9\%), counseling (7\%), academic (4\%), and university police/public safety representation (3\%) led teams. Team membership consisted of representation from counseling $(87 \%)$, police/ campus safety $(82 \%)$, dean of students (72\%), housing and residential life (63\%), academic affairs (49\%), health services (42\%), vice president for student affairs (41\%), legal counsel (22\%), student activities (22\%), faculty $(27 \%)$, human resources $(19 \%)$, case manager (18\%), athletics $(13 \%)$, admissions (9\%), Greek life (5\%), and student $(2 \%)$.

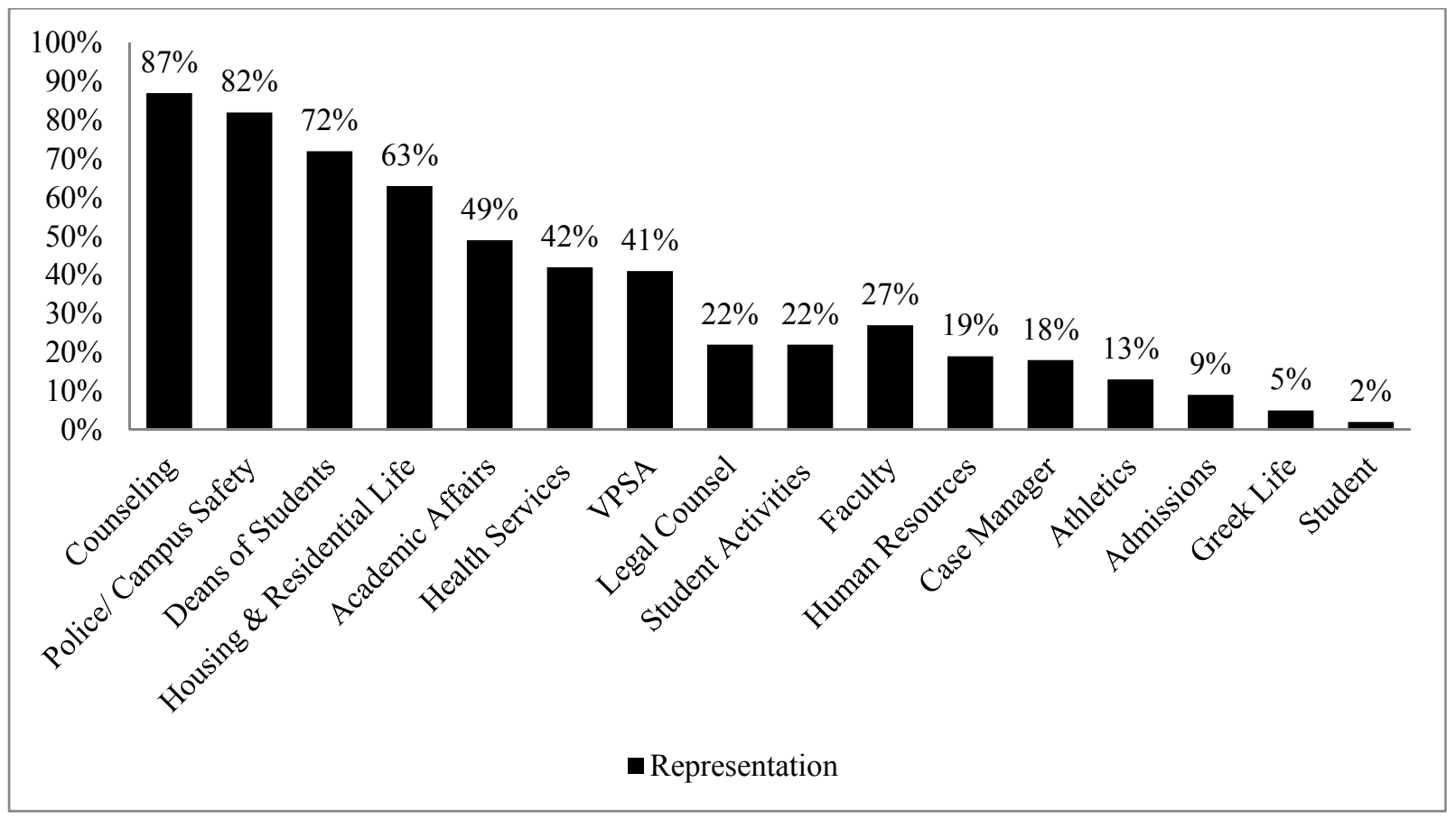

Figure 6. 2012 Team Representation

The National Behavioral Intervention Team Association (NaBITA) conducted a similar survey to the 2012 research in 2014 of over 500 four-year (67\%) and community 
colleges $(33 \%)$ to continue monitoring trends among teams (Van Brunt, Sokolow, Lewis, $\&$ Schuster, 2014). The institutions represented in the survey results included $64 \%$ residential and $36 \%$ non-residential, $70 \%$ public institutions and $28 \%$ private institutions. Of the institutions represented, 94\% reported having a team (threat assessment, behavioral intervention, and/or student of concern team). Reportedly, deans of students (44\%), vice presidents for student affairs (24\%), student conduct (9\%), counseling (6\%), university police/public safety (3\%) and other/miscellaneous representation (14\%), led teams. Average team size reported is 8.6 members; team membership consisted of representation from counseling (92\%), police/ campus safety $(88 \%)$, dean of students (75\%), housing and residential life (59\%), academic affairs (53\%), health services (40\%), vice president for student affairs (40\%), faculty (30\%), human resources (29\%), student activities (21\%), case manager (20\%), legal counsel (17\%), admissions (8\%), and Greek life $4 \%$ ).

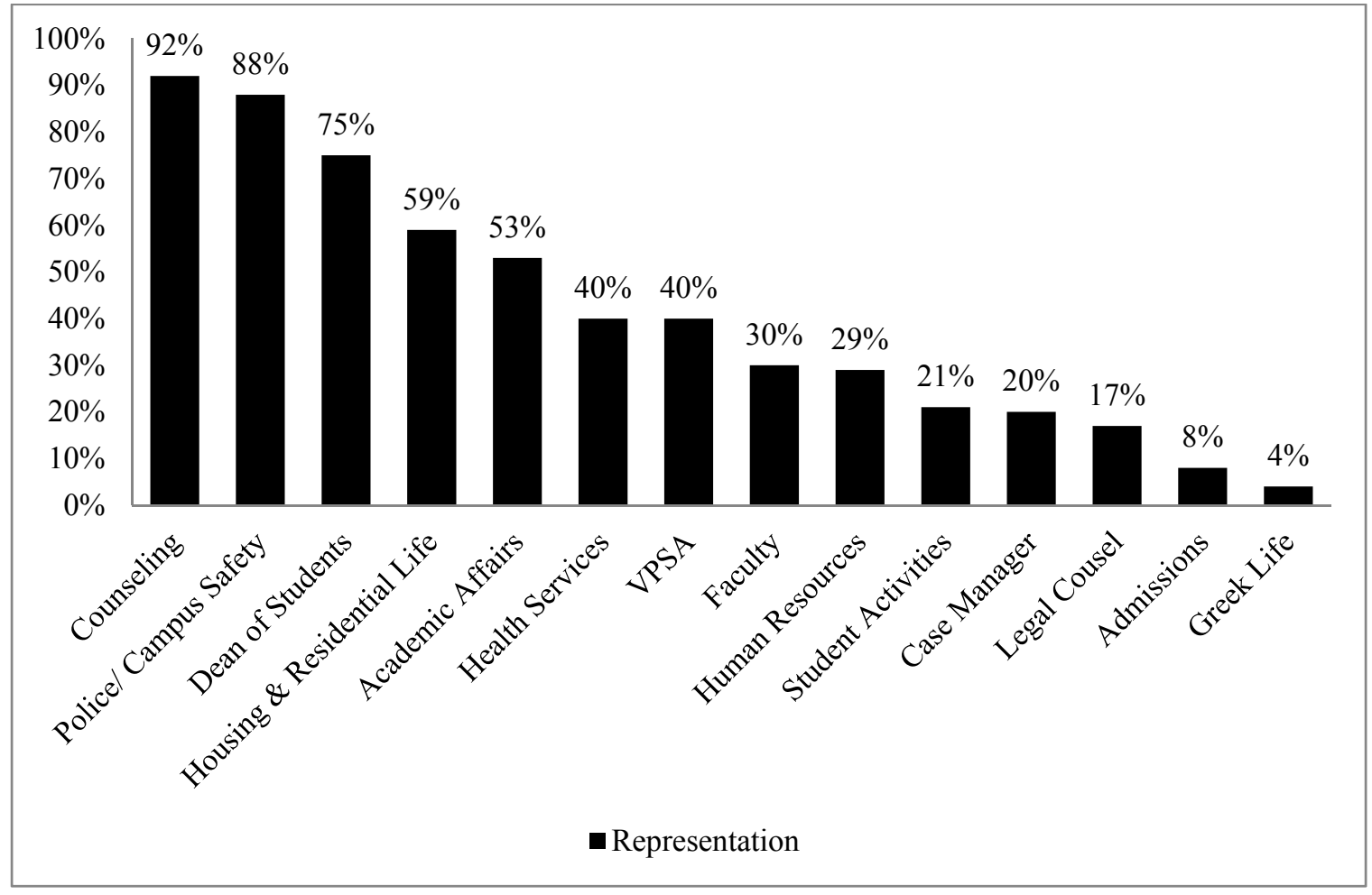




\section{Figure 7. 2014 Team Representation}

While team representation has evolved since 2010, the following representation on teams has remained across the years: deans of students, vice presidents for student affairs, counseling, public safety, housing and residence life, health services, and faculty representation. Roles represented on the team in the studies above are consistent with recommendations by Randazzo and Plummer (2009) and Dunkle, et al. (2008).

Team function. Team function is reference to responsibilities, resources, and activities that support team functioning while developing plans to deescalate and decrease vulnerability to risk as well as anticipate and mitigate effects potential (Pollard, Nolan, \& Deisinger 2010). Teams are faced with the importance of "active engagement with troubled students sooner, rather than later" (Pavela \& Joffe, 2007, slide 5). Additionally, Cornell (2010) stated, "the basic function of a college threat assessment team is to provide consultation and assistance to other units of the institution when dealing with a potentially dangerous situation" (p. 11).

According to the Higher Education Mental Health Alliance (2012), team responsibilities include gathering information, assessing information about the case, defining plan/response, implementing the response, monitoring the disposition of the case. A reason to include all of these functions under one team is "to prevent any particular instance of disturbed or disturbing behavior from falling through the organizational cracks" (p. 3). An additional reason is, "to connect disparate (and therefore seemingly innocuous or less troubling) pieces of information that may indicate a more serious or acute problem, in the hope of preventing a dangerous or critical outcome or event” (p. 3). After events of Virginia Tech and Northern Illinois University, teams were 
inclined to focus on threat assessment situations in order to avoid worse case scenarios. A disadvantage to the perspective of a threat assessment only framework is that teams may learn about a potentially concerning behavior once it becomes a serious or acute problem instead of prior to in order to address appropriately. An additional disadvantage is that if a team waits for a worst case situation to meet, it is possible the team will become stale and not know how to react in the most efficient and effective ways when a crisis occurs.

On the other hand, other institutions have chosen to focus on a broader approach, addressing a variety of student (and for some institutions faculty and staff) issues. These teams address psychological and behavioral problems that have or may negatively impact the student or community (Dunkle, et al., 2008). While challenges to this approach also exist, such as balancing intensity of intervention with respect of student autonomy and privacy, Pavela (2008) states that teams should provide students with professional help when necessary.

Implementation on campus. Randazzo and Plummer (2009) described a comprehensive threat assessment team as one that maintains and represents interests of faculty and staff and chaired by a chief of police. Similarly, Pollard, et al. (2010) discussed resources and activities that support team functioning: a systematic process used to understand concern (information gathering and initial threat analysis), efficient developmental support for adequate case management, and protocols for services. Team goals outlined by Randazzo and Plummer (2009) are to assess risk and decrease occurrence, supporting Pollard, et al.'s (2010) outlined team functions. Pollard et al. (2010) defined additional functions of teams as the developer of plans that deescalate and decrease vulnerability to risk as well as the mitigation and anticipation of effects. 
Higher Education Mental Health Alliance (2012), states that an important decision to be made by teams regarding scope and purpose is to "define the population on which the team will focus" (p.5). Proponents of the broad scope of team responsibilities include faculty and staff in the process for intervention because campuses are workplaces in addition to learning environments. Additionally, another population that may be addressed by a team is one that is not officially connected to the university but has been romantically involved with a faculty, staff, or student and may pose threat of stalking or violence.

Communication during crisis. According to Murphy (1996), assumptions and features of chaos theory may also be used for managing issues and crises. Specifically, the fact that chaos is characterized as nonlinear and may have the potential to take on a snowball effect; it is possible that small issues will turn into bigger ones as information detail increases. Therefore, transparency during a crisis is critical to encourage trust in the process from the community inside and outside of the situation. In order to protect a team's reputation during a crisis, Coombs (2007) suggests application of situational crisis communication theory. The following steps are to be considered in maintaining a credible reputation: 1) initial crisis responsibility, 2) crisis history (whether or not a similar crisis has occurred in the past) and 3) reputation because of previous crises.

According to Fischer and Wilson (2007), communication during a crisis is very important. When information sharing occurs in silos, it prevents meaningful communication from occurring. The investigative reports conducted by Virginia Tech 
and the state of Virginia noted, "despite their different missions, both reports reached some similar conclusions, calling for better sharing of information about troubled students (Fischer \& Wilson, 2007).

University of Louisville Student Care Team. The Student Care Team at the University of Louisville was created in 2008 to "provide a regular opportunity for communication between University partners, identifying the resources and support for University of Louisville students who are in need of care, or who are experiencing distress" (University of Louisville, n.d., p.1). As middle line managers, members of the Student Care Team are responsible for providing ongoing care and support, communicating with colleagues as appropriate, monitoring the case, and reporting to the team at each meeting any updates to a referral. During the timespan of the current research (2010-2015), the team consisted of the Assistant Vice President and Dean of Students, Assistant Dean of Students, Coordinator of Student Rights \& Responsibilities, Student Care Manager, Director of Housing, Director of the Counseling Center, Chief of University Police, a Faculty representative, Medical Director, an Enrollment Management representative, an Academic Advising representative.

Team members perform consultations with university partners reporting concerning behavior; visit students in the hospital for car accidents, overdoses, illness, and injury; provide resources for students in crisis; and offer ongoing care after an incident. Team members are also responsible for the student conduct process; therefore, they assess the level of threat to the community when appropriate and issue sanctions (such as suspension, expulsion, psychological assessment). The team creates and approves protocols for responding to crises (e.g., suicide, hospital visit), provides training 
to university departments, faculty, staff, and students about reporting options, suicide prevention, and guides for responding to difficult student situations.

During each bi-weekly meeting, the SCT discussed students referred for concerning behavior by faculty, staff, students, and the non-university affiliated. As a part of the discussion, team members identified action items for members of the team to facilitate prior to the next meeting. Action items included but were not limited to police or housing staff wellness checks, homeless shelter resources, counseling services, and sexual misconduct resources. Members of the team tracked each student referred through the Maxient Conduct Manager database and took notes of each student discussed during every meeting. Some students of concern referred to the team were for mental health concerns, threats of harm, sexual misconduct, self-injurious behavior, and/or homelessness, among many others. 


\section{CHAPTER III: METHODOLOGY}

The following chapter outlines the methodological approach for this dissertation research study. The design is described and the research questions are reintroduced along with their corresponding methods of analyses. A brief overview of the setting and demographics of the sample follows. Additionally, the data sources, collection procedures, and instrumentation are discussed.

\section{Research design and population}

The current research is designed to describe referrals to the Student Care Team (SCT) at the University of Louisville from 2010-2015. The research design is foundationally based on Astin's (1991) Input-Environment-Output model for assessment. Consistent with Astin's variable definitions, this research uses demographic information to describe a profile of students in the college environment. The nature of the referrals variable in this research focuses Astin's definition of environment on the experience of those referred to the SCT. This environment consists of self-injurious behavior, medical hospital transportation, and violence and the surrounding details of these incidents (e.g., location, referral source, week of semester, and discussion intensity). These variable categories were selected to describe the link of Astin's model to Merton's (1938) Strain Theory in order to understand what factors place strain on a student. To measure this strain, the dichotomous variable of whether a student earned their attempted credit hours for the semester they were referred was used to predict academic advancement for that referral semester. The following equation represents the regression model used where $Y$ indicates the prediction of academic advancement for each variable in the demographic 
profile (i.e., classification, gender, ethnicity, major college, and role in incident).

Similarly, this equation also represents the prediction of academic advancement for variables among the nature of referrals (i.e., type of referral, location of incident, referral source, intensity of discussion, and week of semester discussed by the team): $\operatorname{logit}(Y)=$ $\ln \left(\frac{\pi}{1-\pi}\right)=a+\beta_{1} X_{1}+\beta_{2} X_{2}+\beta_{3} X_{3}+\beta_{4} X_{4}+\beta_{5} X_{5}$. The following section of this chapter describes each variable used to predict academic advancement.

\section{Variables}

Variables in the current research are drawn from relevant research cited in chapter two and data regularly collected by the SCT. The input variable is demographic information, the environment variable is the nature of the referral, and the output variable is attempted and earned credits for the semester of the referral. Demographics and referral case types are consistent with previous research by Roudsari et al. (2009) and Cao (2011). The nature of the referral data were drawn from existing data collected by the researcher. The attempted and earned credits were collected from the PeopleSoft database management system in order to measure academic advancement and achievement.

Input variable. Demographic data were collected from the PeopleSoft database management system, which consisted of academic classification, ethnicity, academic major college, and gender and for the purpose of the current research are considered input variables. Classification is considered the academic year for the student referred (firstyear, sophomore, junior, senior, graduate, or other). Classifications of master's, doctoral, and professional were combined into the classification of graduate. The classification of other is a combination of post baccalaureate and undergraduate non-degree seeking students. Ethnicity was collected from self-reported race and ethnicity data provided to 
the university. Major Colleges consist of Arts \& Sciences, Business, Dentistry, Education \& Human Development, School of Interdisciplinary \& Graduate Studies, Kent School of Social Work, Brandeis School of Law, Medicine, Music, Nursing, Public Health \& Information Sciences, and Speed School of Engineering). The additional input variable, Role in the Incident the student played (accused, complainant, witness, student of concern), was collected from SCT discussion notes. These data were used to answer the first research question: What is the demographic profile for students referred for SCT?

Environment variable. Nature of referrals were collected from SCT student discussion notes and were categorized as referral type, referral sources, location of incident, week of the semester incidents are discussed, and intensity of SCT discussions. Referral types described the behavior for which the student was referred (sexual misconduct, harm to others, medical, self-injurious behavior, substance abuse, or multiple types). Referral source categorized the area/department from which the student was referred for concerning behavior to the SCT (Academic Affairs, Care, Conduct, Housing \& Residence Life, PEACC, University of Louisville Police Department). Location of the incident describes the incident to have occurred on campus /or controlled by the university (University of Louisville Police Department, n.d.). Intensity of the SCT discussions referred to the number of meetings the student was discussed in SCT. Week of the semester describes the timing of the semester when each incident was discussed first by the SCT. These data were used to answer the second research question: What is the nature of the referrals to SCT? 
Output variable. Attempted and earned credits data were collected from the PeopleSoft database management system. This category is designed to measure academic achievement and advancement during the semester students were referred to the SCT. It considers earned credits may be because of action taken by the SCT such as a withdrawal from medical reasons and action taken by the student conduct process such as suspension or expulsion from the university. These data were used to answer the third research question: How does the input (gender and role in incident) and/or environment variable (nature of the referrals) predict the output variable (credits attempted vs. credits earned)?

Because the research is designed for categorical variables, dummy coding was performed to allow for regression analyses. To do so, each category was assigned values of 0 if the attribute was present or 1 to denote a lack of presence in the variable category (e.g., first-year $=0$, not first year $=1$ ). This created dichotomous variables for each category. The following table illustrates the dichotomous dummy coding for each variable category.

Table 1. Variable Descriptions

\begin{tabular}{|c|c|c|}
\hline $\begin{array}{l}\text { Type of } \\
\text { Variable }\end{array}$ & Variable & Coding \\
\hline $\begin{array}{l}\text { Input: } \\
\text { Demographic }\end{array}$ & $\begin{array}{l}\text { Classification } \\
\text { Ethnicity }\end{array}$ & $\begin{array}{l}\text { First-Year }(\text { Fewer than } 30 \text { credits })=0 ; \text { no }=1 \\
\text { Sophomore }(30-59 \text { credits })=0 ; \text { no }=1 \\
\text { Junior }(60-89 \text { credits })=0 ; \text { no }=1 \\
\text { Senior }(90+\text { credits })=0 ; \text { no }=1 \\
\text { Grad }=0 ; \text { no }=1 \\
\text { Other }=0 ; \text { no }=1 \\
\text { American Indian/Alaskan Native }=0 ; \text { no= }=1 \\
\text { Asian }=0 ; \text { no }=1 \\
\text { Black } / \text { African American }=0 ; \text { no }=1 \\
\text { Hispanic } / \text { Latino }=0 ; \text { no }=1 \\
\text { Multi-Race }=0 ; \text { no }=1 \\
\text { Native Hawaiian } / \text { Pacific Islander }=0 ; \text { no }=1 \\
\text { White }=0 ; \text { no }=1\end{array}$ \\
\hline
\end{tabular}




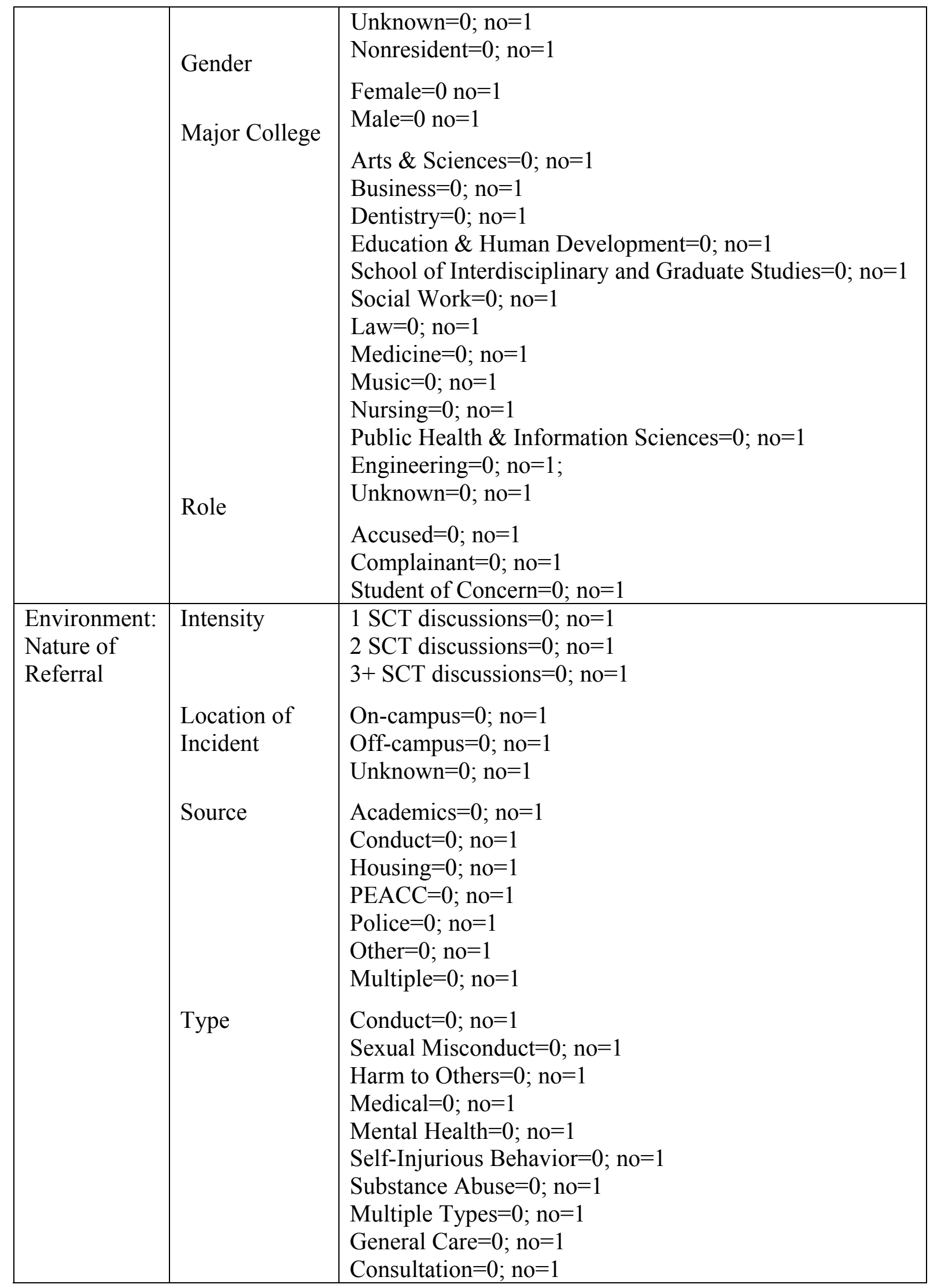




\begin{tabular}{|l|l|l|}
\hline & $\begin{array}{l}\text { Week of } \\
\text { Semester }\end{array}$ & $\begin{array}{l}\text { Week of Semester } 1-16=0 ; \text { no }=1 \\
\text { Other=0; no=1 }\end{array}$ \\
\hline $\begin{array}{l}\text { Output: } \\
\text { Academic } \\
\text { Advancement }\end{array}$ & Credits & $\begin{array}{l}\text { Earned Attempted Credits }=0 ; \\
\text { Did Not Earn Attempted Credits }=1\end{array}$ \\
\hline
\end{tabular}

The data were originally collected to maintain records of the discussions about

each referral to the SCT and not for the purpose of the current research; therefore, the following method explains the process for coding each entry. Table 2 describes the process for coding information included in the SCT student discussion notes.

Table 2. Coding Description \& Data Source

\begin{tabular}{|c|c|c|}
\hline Variable Type & Variable & Coding Description \& Data Source \\
\hline \multirow[t]{5}{*}{ Input } & Classification & $\begin{array}{l}\text { Academic rank determined by earned credit hours } \\
\text { Source: PeopleSoft }\end{array}$ \\
\hline & Ethnicity & $\begin{array}{l}\text { Self-reported cultural background } \\
\text { Source: PeopleSoft }\end{array}$ \\
\hline & Gender & $\begin{array}{l}\text { Self-reported gender identification } \\
\text { Source: PeopleSoft }\end{array}$ \\
\hline & Major & $\begin{array}{l}\text { Academic major college } \\
\text { Source: PeopleSoft }\end{array}$ \\
\hline & Role in Incident & $\begin{array}{l}\text { "Accused" of violating Code of Student Conduct, } \\
\text { "complainant" against another student for violating } \\
\text { Code of Student Conduct, or "student of concern" } \\
\text { Source: SCT discussion notes }\end{array}$ \\
\hline \multirow[t]{4}{*}{ Environment } & $\begin{array}{l}\text { Intensity of } \\
\text { Discussion }\end{array}$ & $\begin{array}{l}\text { Number of dates ("1", "2", or "3+") each student was } \\
\text { discussed by the SCT per incident } \\
\text { Source: SCT discussion notes }\end{array}$ \\
\hline & $\begin{array}{l}\text { Location of } \\
\text { Incident }\end{array}$ & $\begin{array}{l}\text { Whether the incident occurred "on campus" } \\
\text { (controlled by the university) or "off-campus" } \\
\text { (includes affiliated housing properties not controlled } \\
\text { by the university) } \\
\text { Source: SCT discussion notes }\end{array}$ \\
\hline & Source of Referral & $\begin{array}{l}\text { University department referring student to SCT; } \\
\text { sources from outside the university or from other } \\
\text { students are categorized as other; if more than one } \\
\text { source referred the student, it is categorized as } \\
\text { "multiple" } \\
\text { Source: SCT discussion notes }\end{array}$ \\
\hline & Type of Referral & $\begin{array}{l}\text { Concerning behavior referred to the SCT } \\
\text { (violations of the Code of Student Conduct; sexual }\end{array}$ \\
\hline
\end{tabular}




\begin{tabular}{|c|c|c|}
\hline & & $\begin{array}{l}\text { misconduct; harm to others; medical; mental } \\
\text { health; self-injurious behavior; substance abuse). } \\
\text { Referrals for "general care" include other referrals } \\
\text { not otherwise classified; "consultations" include } \\
\text { no other action taken by the SCT other than a } \\
\text { discussion by the SCT and with referral source. } \\
\text { For referrals of more than one concerning } \\
\text { behavior, "multiple types" are used. } \\
\text { Source: SCT discussion notes }\end{array}$ \\
\hline & Week of Semester & $\begin{array}{l}\text { For referrals during the academic year, the week of the } \\
\text { semester the first discussion occurred is recorded; for } \\
\text { referrals during the summer and winter breaks, the } \\
\text { week of the semester is classified as "other" } \\
\text { Source: SCT discussion notes }\end{array}$ \\
\hline Output & $\begin{array}{l}\text { Attempted/Earned } \\
\text { Credits }\end{array}$ & $\begin{array}{l}\text { Coded as yes or no for whether the student earned the } \\
\text { number of credits attempted during the semester for } \\
\text { which the student was referred } \\
\text { Source: PeopleSoft }\end{array}$ \\
\hline
\end{tabular}

\section{Setting}

The setting for the current research is the University of Louisville, categorized as a public, metropolitan, research university (2008-2010 Carnegie Foundation Data). According to UofL "Just the Facts" (2014), the university serves approximately 22,529 students $(17,198$ full-time; 5,331 part-time) in the commonwealth of Kentucky. The undergraduate student population is approximately 16,151 and the graduate population is approximately 5,620. Over 5,000 students live on campus (71\% or over 2000 first-time first-year students lived on campus with a 98\% housing occupancy). The university consists of approximately 11,540 females (51\%) and 10,989 (49\%) males, $74.3 \%$ White, 10.25\% African American, 4.89\% non-residential alien, 3.6\% Asian, 3.42\% Hispanic, $2.98 \%$ two or more races, .6\% Native Hawaiian/other Pacific Islander, .35\% unknown, and .16\% American Indian/Alaskan Native. The undergraduate student population's mean age is 23 (UofL, 2012, “Common Data Set 2011-2012”). 


\section{Procedure/Instrumentation}

Since fall of 2010, the SCT has collected statistics regarding the number of students who were referred and discussed during each meeting. Demographic information such as academic classification, ethnicity, and academic major college were gathered from the Oracle PeopleSoft data management system as well as attempted and earned credit hours. Role in the incident and nature of the referral were collected from SCT student discussion notes. Students referred to the SCT for more than one incident were counted as a separate student for the purpose of the study; therefore, the data may reflect a higher number of incidents than total number of students discussed.

Self-injurious behavior is identified by the researcher as suicide ideation (thought or consideration for self-injury with no plan or intent, desire to die/be dead), gestures (thought or consideration for self-injury with intent or plan, overt action such as gathering weapons, gathering medication, and/or a written statement) or suicide attempt (cutting, ingestion of pills, or other self-injury). The following charges of violating the Code of Student Conduct in the category of threat of harm to others: physical harm, weapons, false report, fire safety, theft, destruction of property, destructive devices, threatening, hazing, misuse of technology, false complaint, demonstration, failure to report, driving under the influence, and harassment. Sexually abusive contact, sexual harassment, voyeurism, deliberate incapacitation, stalking, dating violence, domestic violence, retaliation, and sexual exploitation Code of Student Conduct charges are included in the category of sexual misconduct. Medical referrals include cases involving hospitalization and emergency medical transportation. Substance abuse includes the possession and/or use of any controlled substance such as alcohol or other drugs. Multiple referral types include two or more of the above described referral types. 
These cross sectional data are collected for each of the following semesters: fall 2010, spring 2011, fall 2011, spring 2012, fall 2012, spring 2013, fall 2013, spring 2014 , fall 2014, and spring 2015. Because the data were not specifically gathered for the question(s) under consideration, two things must be considered. First, data categorization was created after the fact; therefore, the data coding and assignment were not originally designed as the information was collected. The collected data were interpreted and categorized into these variables by the researcher. Secondly, while attempts are made to control for other variables that may correlate with the measured variables (Vogt, 2005), it is possible that factors not considered in this research significantly impacted academic advancement.

\section{Research questions and analyses}

The current study addresses the three research questions and corresponding hypotheses. The data are analyzed using the Statistical Package for the Social Sciences (SPSS) (version 22) for Windows. The first part of this section of the chapter explains the methods and corresponding assumptions. The following section addresses the specific questions and corresponding analyses.

Nominal data were tested using chi-square tests. This test requires that the data are independent (i.e., scores are unrelated to scores of other participants). Logistic regression is used to predict associations of nominal and dichotomous categorical data. The significance for all statistical analyses is set at an alpha level of .05.

Q1. What is the demographic profile for students referred to SCT in comparison to the overall student population? 
Analyses: The demographic characteristics (classification, ethnicity, role in incident, academic major) were entered into SPSS and frequency analyses examined the demographic profile of students referred to the SCT from 20102015. To assess the overall student population, an average was calculated for same years the data were collected from the SCT. A chi-square test was performed to compare the gender of students referred to SCT with the genders of the overall student population. Another chi-square analysis was performed to compare the classification of the students (first-year, sophomore, junior, senior, graduate) referred to the SCT with the classifications of the overall student population. Lastly, a chi-square analysis was conducted to compare the ethnicities of those referred to the SCT with the overall student population. Q2: What is the nature of the referrals to SCT?

a. What types (threat of harm to others, self-injurious behavior, medical, substance abuse, sexual misconduct, other) of cases are referred?

b. What are the referral sources?

c. Do the referred incidents occur on or off campus?

d. When is the first time the SCT discusses a referred student?

e. What is the intensity of the SCT discussions about each referral? Analysis: Frequency analyses were performed on referral types, referral sources, incident location, week of the semester, and intensity of SCT discussions to describe the nature of the referrals. 
Q3: How do the demographic profile and nature of the referrals predict whether the student referred earns the credit hours for the semester they were referred to the SCT?

Analysis: Logistic regression was used to identify if any of the demographic profile variables and/or nature of the referrals variables were predictors for whether a student referred to the SCT earned the attempted credit hours for the semester they were referred.

\section{Internal validity}

The first potential threat to validity is the impact of missing data on the ability to determine associations. If the comparison between referrals and overall population were made using missing data, it could lead to bias results (McKnight, McKnight, Sidani, and Figueredo, 2008). Among the data collected for the current research, some referrals consisted of incomplete information. For example, in instances of anonymous reports, the identity of the referral may have been missing. To address referrals made that did not contain values for each variable measured, a list-wise deletion was performed on the missing not at random cases. This action deleted any referral with missing data and removed $16 \%$ of referrals from those analyzed.

Potential threats to internal validity are history, maturation, instrumentation, statistical regression, and selection. History could be a threat to internal validity because participant data is collected over a period of time. Therefore, it is possible outputs are a function of the time passing instead of based on action taken by the SCT. Similarly, maturation could also be a threat to internal validity. Specifically, all students in the category of "student death" were unable to earn their attempted credit hours because of 
the nature of their referral. These outputs however, were functions of the referral, or as a result of something outside the referral but not as an output from action taken by members of the team (e.g., suspension, or expulsion).

While instrumentation was not necessarily a threat to internal validity in the current research because there was only one observer in the coding of the variables and the creation of the database, additional steps were taken to address this validity concern for future research. To do so, the advisor to this dissertation research study used the same materials to code $5 \%+5(n=50)$ referrals and were then compared with the original coding to ensure they were all the same.

Regression may also be a threat to internal validity because the referrals studied contain extreme cases based on the nature of those cases being high level enough to necessitate referral to the SCT. Specifically, those who were referred to the SCT who were unable to earn their attempted credit hours may not have been able to do because of reasons external to action taken by the SCT or the original reason for which they were referred (e.g., financial reasons, academic difficulty in a specific course, etc.).

Lastly, selection may also be a threat to internal validity, because the demographic groups for comparison are different in size and may contain other differences that interacted with the variables. To address this concern, the population studied was compared with the overall university population.

\section{External validity}

A potential threat for external validity is situational specifics because of the setting in which the incidents occurred leading to referral to SCT. Because the participants are UofL students, there is a limit to generalizability to other universities. 
Additionally, institutions not on a semester academic year will not find the same generalizability in considering the week of semester for which incidents are most often discussed. 


\section{CHAPTER IV: RESEARCH FINDINGS}

The current research aimed to describe referrals to the SCT from 2010-2015. Specifically, what is the demographic profile of students referred to the SCT? What is the nature of the referrals? Are either predictions for earning attempted credit hours? To answer these questions, frequency analyses were performed along with chi-squares in the description of the demographics and referrals while logistic regression was used to determine prediction of earned credit hours. This chapter explains the analyses and results for each research question previously described.

\section{Demographic Profile}

Research question 1. What is the demographic profile for students referred to SCT in comparison to the overall student population?

Frequency analyses were performed to describe the demographic profile (gender, ethnicity, classification, academic major, role in the incident) of the students referred to the SCT from 2010-2015. Chi-square tests of independence were also conducted to compare the gender, ethnicity, and classifications of students referred to SCT with the overall student population. Averages of gender, ethnicity, and classifications of students enrolled 2010-2015 were used to compare with the averages of the same for those referred to the SCT.

The sample consisted of 984 referrals to the SCT from 2010-2015. Because not all of the referrals contained full information such as the identity of the referral (e.g., anonymous complaint/concern) or earned and/or attempted credit hours (i.e., never enrolled at the university), some data were missing from the original 984 referrals. Any 
referral information that did not contain demographic profile data or if the referral was not a student, it was removed from the final dataset.

Similar to the 2010-2015 average overall university student population $(51 \%$ females) (University of Louisville, 2012 - 2016), of the 824 in the final sample, 424 were females (52\%); in one case the gender was unknown. There was no significant difference between the genders of the sample and the overall university population, $X^{2}(1, \mathrm{~N}=824)$ $=0.89, \mathrm{p}>.05$. The following table illustrates the number and percentage of males and females referred to the SCT.

Table 3. Gender

\begin{tabular}{|l|c|c|c|}
\hline & $\mathrm{n}$ & Referrals & Population \\
\hline Female & 424 & $52 \%$ & $51 \%$ \\
\hline Male & 399 & $48 \%$ & $49 \%$ \\
\hline Unknown & 1 & $<1 \%$ & -- \\
\hline
\end{tabular}

The ethnicities represented in the sample consisted of $68 \%$ White students, $17 \%$ Black students, $5 \%$ Hispanic students, $5 \%$ students of multiple races, and $4 \%$ Asian students among the five most represented ethnicities. The University's student population (University of Louisville, 2014) consisted of the following 5 most highly represented ethnicities: 74\% White, 10\% Black, 5\% Nonresident Alien, 4\% Asian, and 3\% Hispanic. To compare the ethnicities of those referred to the SCT with the overall student population in a chi square test of independence, the five ethnicities with the highest percentage of representation (combining Nonresident Alien, Multi-races, Native Hawaiian/Other Pacific Islander, and American Indian/Alaska Native) over the five-year reporting period were used. There was no significant difference between the ethnicity of those referred to the SCT and the ethnicity representation of the overall student 
population, $\left.X^{2}(4, \mathrm{~N}=824)=2.94, p>.05\right)$. The following table shows a comparison of the 5 ethnicities with the most representation of those referred to the overall university population.

Table 4. Ethnicity

\begin{tabular}{|l|c|c|c|}
\hline & $\mathrm{n}$ & Referrals & Population \\
\hline White & 560 & $68 \%$ & $74 \%$ \\
\hline Black/African American & 139 & $17 \%$ & $10 \%$ \\
\hline Asian & 30 & $4 \%$ & $4 \%$ \\
\hline Hispanic/Latino & 39 & $5 \%$ & $3 \%$ \\
\hline Multi-Race & 37 & $5 \%$ & $3 \%$ \\
\hline
\end{tabular}

All classifications were represented in the findings; however, first-year students were the most referred to the SCT at $37 \%$. Additionally, $20 \%$ of the referrals were sophomores, $15 \%$ were juniors, $16 \%$ were seniors, $9 \%$ were graduate students, and $3 \%$ were classified as other. The following table compares the percentages of each classification referred with the population.

Table 5. Classification

\begin{tabular}{|l|c|c|c|}
\hline & $\mathrm{n}$ & Referral & Population \\
\hline First-Year: $<30$ earned credits & 301 & $37 \%^{*}$ & $17 \%$ \\
\hline Sophomore: 30-59 credits & 165 & $20 \%$ & $14 \%$ \\
\hline Junior: $60-89$ credits & 127 & $15 \%$ & $15 \%$ \\
\hline Senior: $90+$ credits & 134 & $16 \%$ & $19 \%$ \\
\hline Graduate Student Enrollment & 69 & $9 \%$ & $25 \%$ \\
\hline Enrollment in any other status & 27 & $3 \%$ & $10 \%$ \\
\hline
\end{tabular}

To compare the classifications of those referred to the SCT to the overall student population, a chi-square test of independence was used. A chi-square test was used to determine there was a significant difference between those referred to the SCT and the 2010-2015 averaged classifications for the overall student population. Specifically, when 
comparing the undergraduate referrals with the undergraduate population at the university, a significant association was found among the groups $(p=.047)$. Additionally, comparing the overall SCT referral classifications (undergraduate and graduate) to the overall university classifications, another significant association was found $(p=.0005)$. The following table compares the percentages of referrals by role for first-year students and the total referrals to the SCT.

Table 6. Role in the Incident

\begin{tabular}{|l|c|c|c|}
\hline & $\mathrm{n}$ & $\begin{array}{c}\text { First-Year } \\
\text { Referrals }\end{array}$ & Total Referrals \\
\hline Student of Concern & 675 & $83 \%$ & $82 \%$ \\
\hline Accused & 86 & $10 \%$ & $10 \%$ \\
\hline Complainant & 49 & $7 \%$ & $6 \%$ \\
\hline Student Death & 14 & -- & $2 \%$ \\
\hline
\end{tabular}

The majority of the students referred to the SCT were enrolled in a major within the College of Arts and Sciences (59\%), the College of Education \& Human Development (11\%), and the College of Engineering (10\%). Additionally, 7\% were enrolled in the College of Business, $5 \%$ in the College of Nursing, $3 \%$ in the College of Music, $2 \%$ in the Kent School of Social Work, $1 \%$ in the College of Medicine, $1 \%$ in the School of Dentistry. The remaining percent consisted of Law School students, unknown majors, and School of Public Health/ Information Sciences students. 
Table 7. Referrals by Major College

\begin{tabular}{|l|c|c|}
\hline & $\mathrm{n}$ & \% of referrals \\
\hline Arts \& Sciences & 486 & 59 \\
\hline $\begin{array}{l}\text { Education \& Human } \\
\text { Development }\end{array}$ & 94 & 11 \\
\hline Engineering & 80 & 10 \\
\hline Business & 58 & 7 \\
\hline Nursing & 40 & 5 \\
\hline Music & 21 & 3 \\
\hline Social Work & 13 & 2 \\
\hline Dentistry & 11 & 1 \\
\hline Medicine & 11 & 1 \\
\hline Law & 7 & $<1$ \\
\hline Unknown & 2 & $<1$ \\
\hline
\end{tabular}

Lastly, the majority of the referrals to the SCT were for students of concern $(82 \%)$, while $10 \%$ were accused of violating the Code of Student Conduct for a threat of harm, $6 \%$ were referred as complainants in an incident involving a threat of harm, and $2 \%$ were referred as student deaths. The following figure illustrates the percentage of each role discussed by the team:

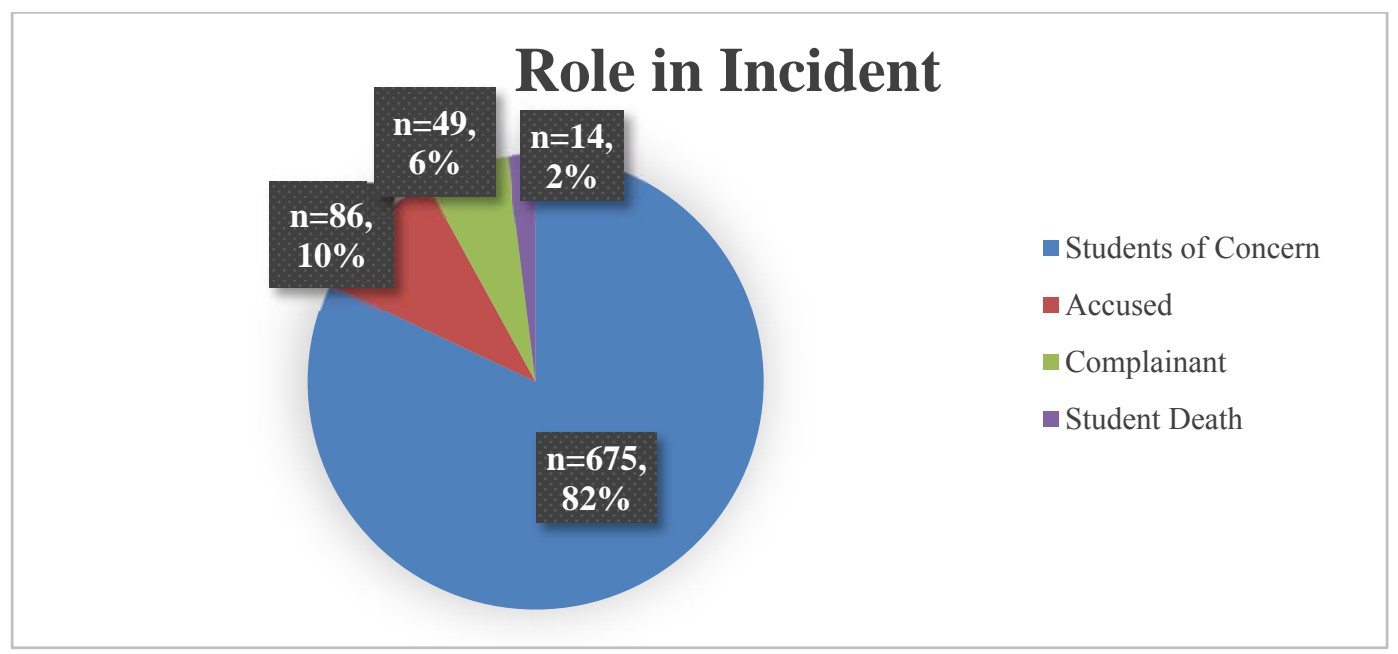

Figure 8. Role in Incident 


\section{Nature of the Referrals}

Research question 2. What is the nature of the referrals to SCT?

a. What types (threat of harm to others, self-injurious behavior, medical, substance abuse, sexual misconduct, other) of cases are referred?

b. What are the referral sources?

c. Do the referred incidents occur on or off campus?

d. When is the first time the SCT discusses a referred student?

e. What is the intensity of the SCT discussions about each referral?

Frequency analyses were performed to identify the types of cases referred, the referral sources, incident location, week of semester the SCT discusses the referral, and the intensity of the discussion. The types of referrals discussed by the SCT were medical concerns (24\%), general care (18\%), self-injurious behavior (15\%), multiple types (11\%), sexual misconduct ( $8 \%$ ), substance abuse (7\%), consultation (5\%), harm to others $(5 \%)$, mental health (4\%), and student conduct (4\%). The following table illustrates the types of referrals to the SCT.

Table 8. Type of Referral

\begin{tabular}{|l|c|c|}
\hline & $\mathrm{n}$ & \% of referral \\
\hline Conduct & 29 & $4 \%$ \\
\hline Sexual Misconduct & 67 & $8 \%$ \\
\hline Harm to Others & 37 & $5 \%$ \\
\hline Medical & 195 & $24 \%$ \\
\hline Mental Health & 34 & $4 \%$ \\
\hline Self-Injurious Behavior & 124 & $15 \%$ \\
\hline Substance Abuse & 59 & $7 \%$ \\
\hline Multiple Types & 91 & $11 \%$ \\
\hline General Care & 149 & $18 \%$ \\
\hline Consultation & 39 & $7 \%$ \\
\hline
\end{tabular}


The referral sources were University of Louisville Police Department (46\%), other (26\%), academic departments (16\%), Office of Housing \& Residence Life (8\%), multiple sources $(2 \%)$, the conduct process $(1 \%)$, and the PEACC program $(1 \%)$. The locations of the incidents referred to the SCT were on campus $(66 \%)$, off campus $(30 \%)$, and unknown (4\%). The following table illustrates the number and percentage of referral sources and incident locations.

Table 9. Referral Source and Location of Incident

\begin{tabular}{|l|c|c|}
\hline \multicolumn{1}{|c|}{ Referral Source } & $\mathrm{n}$ & $\%$ of referrals \\
\hline Academics & 130 & $16 \%$ \\
\hline Conduct & 11 & $1 \%$ \\
\hline Housing & 68 & $8 \%$ \\
\hline PEACC & 10 & $1 \%$ \\
\hline Police & 379 & $46 \%$ \\
\hline Other & 212 & $26 \%$ \\
\hline Multiple & 14 & $2 \%$ \\
\hline Location of Incident & & \\
\hline On-Campus & 547 & $66 \%$ \\
\hline Off-Campus & 243 & $30 \%$ \\
\hline Unknown & 34 & $4 \%$ \\
\hline
\end{tabular}

Weeks with the highest number of referrals were calculated by adding the number of referrals per week together and averaging by the number of meetings for that particular week number. The weeks began with the first day of class and were categorized as other if they fell outside the academic year. The following figure illustrates the average number of referrals in comparison to the total number of discussions per week of the semester. 


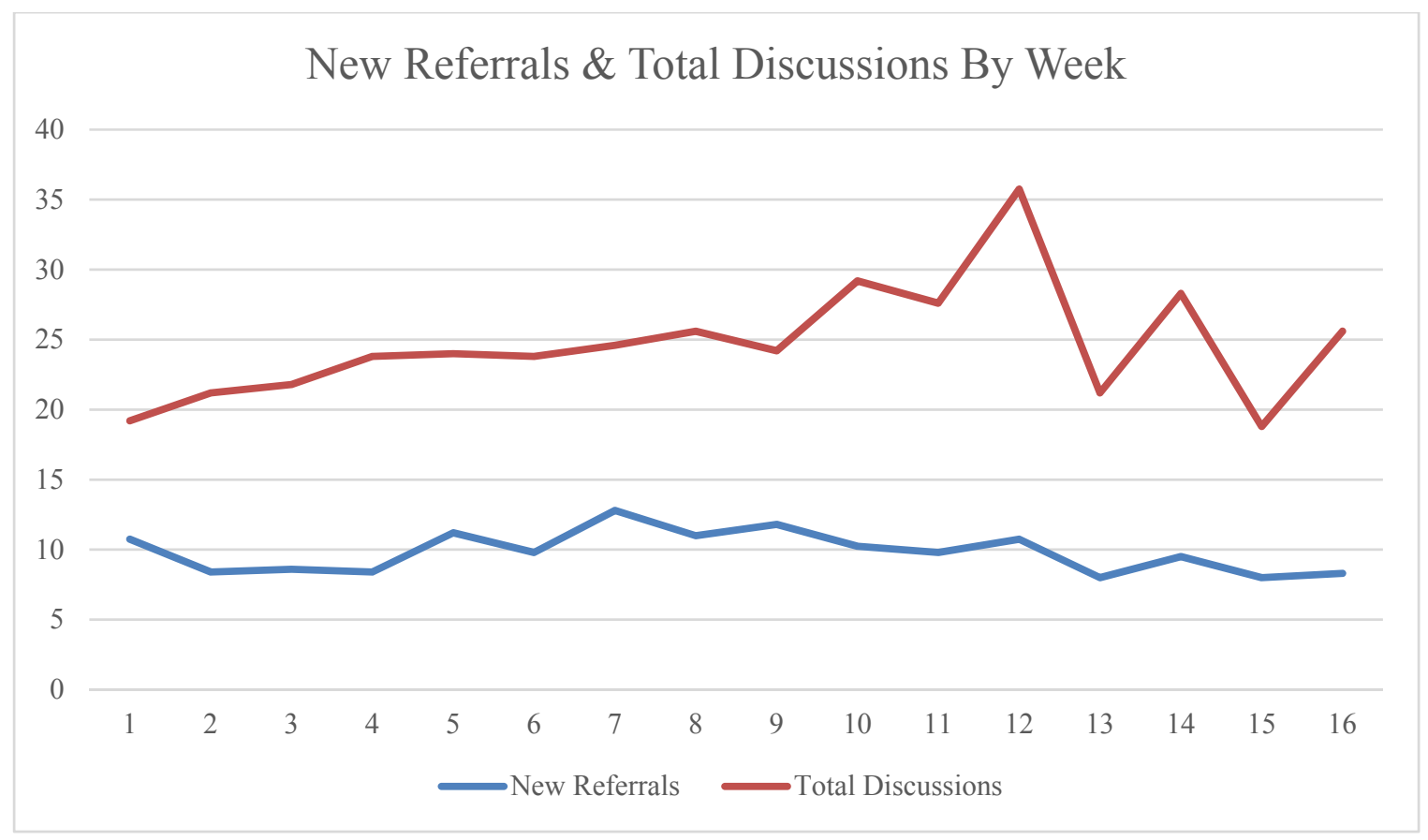

Figure 9. New Referrals \& Total Discussions by Week

The weeks with the highest number of referrals were: week 7 (13 referrals), week 9 (12 referrals), and weeks $1,5,8$, and 12 all averaged 11 referrals. The lowest average number of referrals were during weeks 13 and 15 at 8 referrals each. The following table shows the number of referrals and corresponding percentages of the overall referrals by week of the semester.

Table 10. New Referrals by Week

\begin{tabular}{|c|c|c|}
\hline $\begin{array}{c}\text { Week of } \\
\text { Semester }\end{array}$ & $\mathrm{n}$ & \% of referrals \\
\hline 1 & 42 & 10.75 \\
\hline 2 & 42 & 8.4 \\
\hline 3 & 52 & 8.6 \\
\hline 4 & 42 & 8.4 \\
\hline 5 & 56 & 11.2 \\
\hline 6 & 49 & 9.8 \\
\hline 7 & 64 & 12.8 \\
\hline 8 & 41 & 11 \\
\hline 9 & 59 & 11.8 \\
\hline 10 & 41 & 10.25 \\
\hline
\end{tabular}




\begin{tabular}{|c|c|c|}
\hline 11 & 59 & 9.8 \\
\hline 12 & 48 & 10.75 \\
\hline 13 & 32 & 8 \\
\hline 14 & 38 & 9.5 \\
\hline 15 & 40 & 8 \\
\hline 16 & 27 & 8.3 \\
\hline Other & 76 & 10 \\
\hline
\end{tabular}

Lastly, frequencies for the intensity of the discussion were calculated to identify the number of times students are most often discussed by the SCT. This was used to show increasing intensity as the number of discussions increased. Forty-two percent of students were discussed once by the team while $30 \%$ of students were discussed twice and $28 \%$ were discussed three or more times. The following table shows the number of students discussed once, twice, and three or more times by the SCT.

Table 11. Intensity of the Discussion

\begin{tabular}{|l|c|c|}
\hline & $\mathrm{n}$ & \% of Referrals \\
\hline 1 discussion & 347 & $42 \%$ \\
\hline 2 discussions & 247 & $30 \%$ \\
\hline $3+$ discussions & 230 & $28 \%$ \\
\hline
\end{tabular}

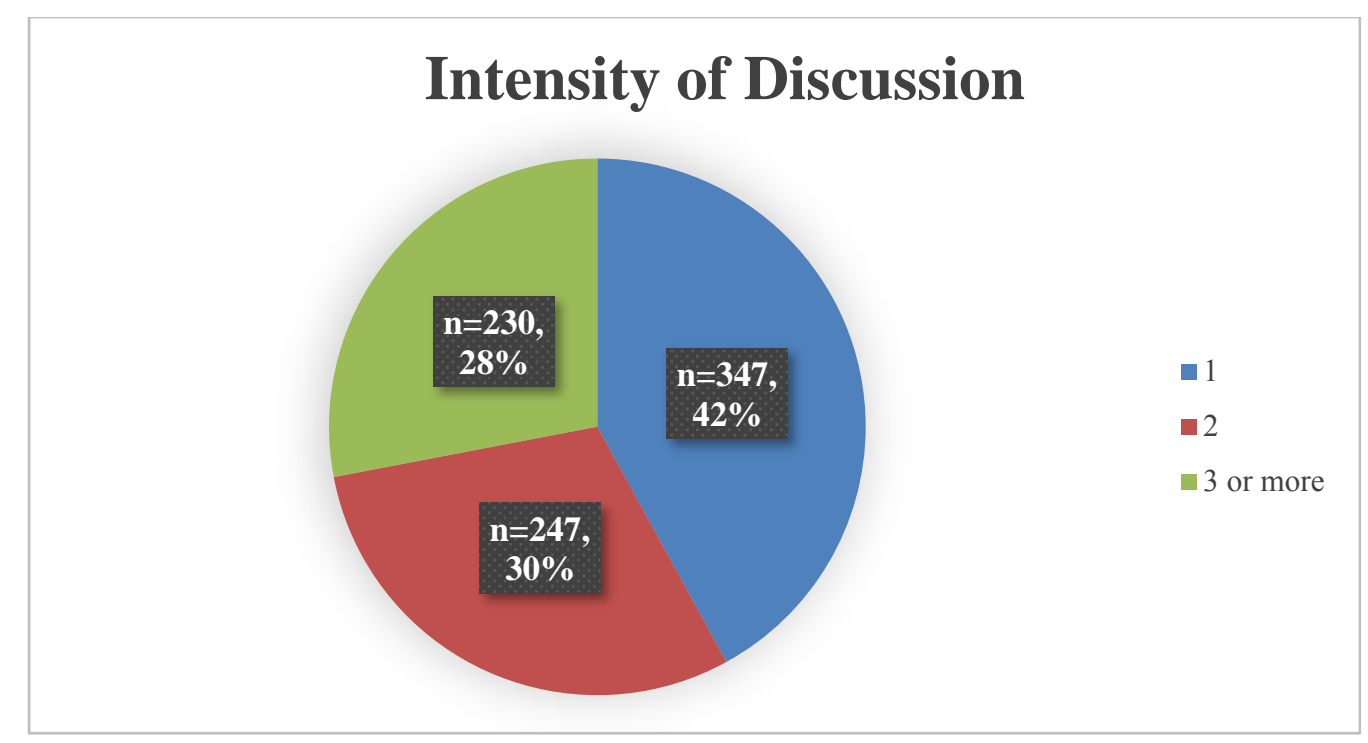

Figure 10. Intensity of the Discussion 


\section{Earning attempted credit hours}

Research question 3. How do the demographic profile and nature of the referrals predict whether the student referred earns the credit hours for the semester they were referred to the SCT?

Logistic regression was used to identify if any of the demographic profile variables and/or nature of the referrals variables were predictors for whether a student referred to the SCT earned the attempted credit hours for the semester they were referred. To determine this, the dichotomous dependent variable (academic advancement) was used to compare with each variable category of the demographic profile and nature of the referrals. Specifically, each category of variable (e.g., first-year) was compared with other categories (e.g., sophomore, junior, etc.) to predict academic advancement for the semester of which the student was referred to the SCT. Some of the regression models received an error message indicating they were unusable due to the maximum iterations being reached; therefore, no results from those variables are represented in the following tables. For example, some academic major colleges, ethnicities, classifications, and all genders are not represented in the regression analyses due to this error.

The unknown category of incident location $(F(1)=.779, p=.027)$ predicts academic advancement. The referral source also associated academic advancement is the police department $(F(1)=.409, p=.005)$; however, the referral source of academics does not predict academic advancement $(F(1)=-.437, p=.040)$. Referrals first discussed during the first week of the semester also predicted academic advancement $(F(1)=.865$, $p=.007)$. On the other hand, the $7^{\text {th }}$ week of the semester in which a referral is discussed was negatively associated with academic 
advancement $(F(1)=-6.94, p=.019)$. The following table illustrates regression analyses for the incident location, referral source, and week of semester the referral was first discussed by the SCT.

Table 12. Prediction by Location, Source, Week of Semester

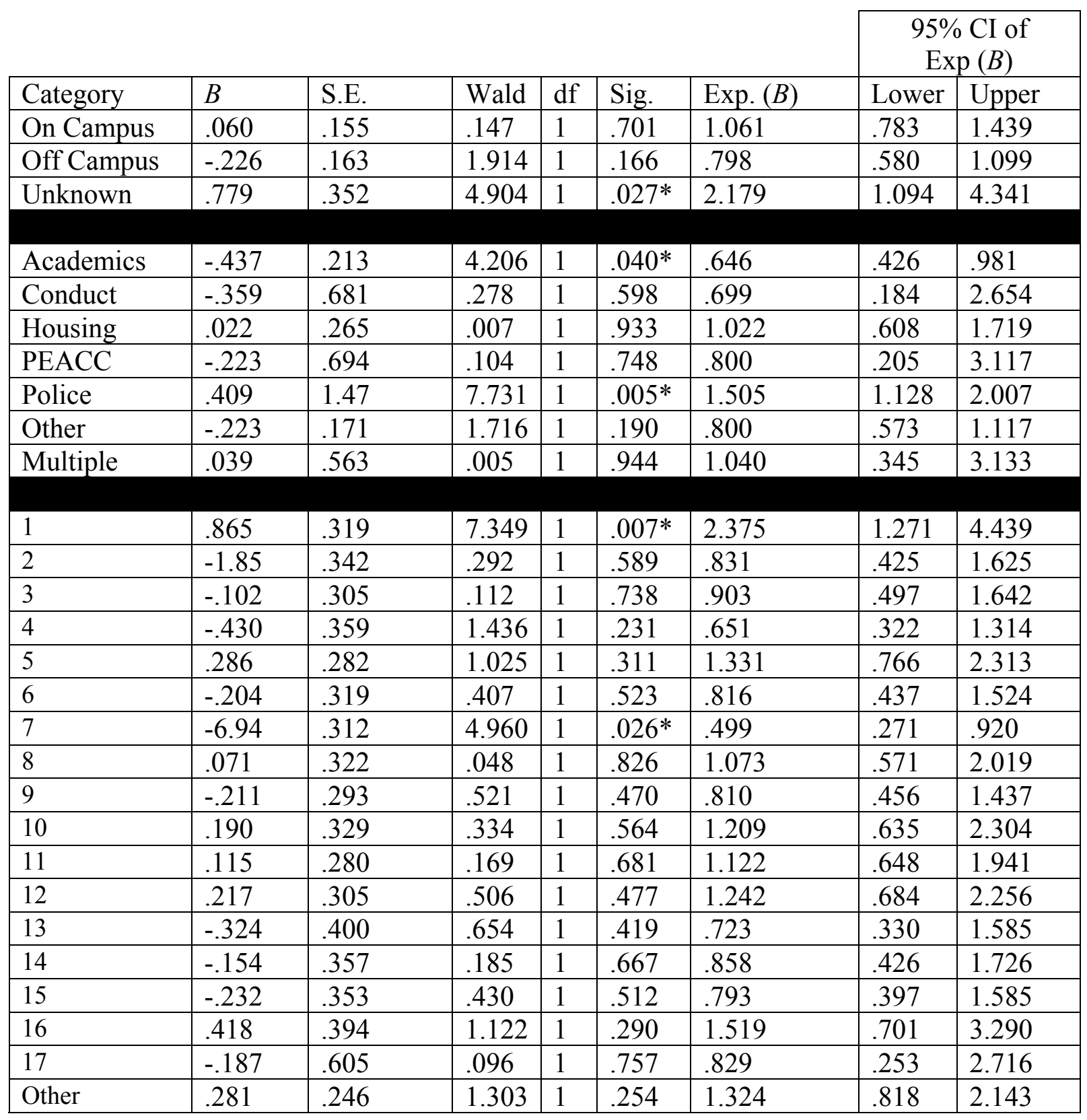


The intensity of discussion, week of the semester, type of referral, and referral source showed negative associations for academic advancement. These findings suggest these categories predict not earning the credit hours they attempted for the semester they were referred. Among the variables within the demographic profile, no statistically significant associations were found for ethnicity, major college, nor the role in the incident. The following table describes the regression results for remaining academic majors.

Table 13. Major College

\begin{tabular}{|l|l|l|l|l|l|l|l|l|}
\cline { 4 - 8 } \multicolumn{1}{l|}{} & \multicolumn{3}{c|}{$\begin{array}{c}95 \% \text { CI of } \\
\text { Exp }(B)\end{array}$} \\
\hline Category & \multicolumn{1}{|c|}{$B$} & \multicolumn{1}{|c|}{ S.E. } & Wald & df & Sig. & Exp. $(B)$ & Lower & Upper \\
\hline $\begin{array}{l}\text { Arts \& } \\
\text { Sciences }\end{array}$ & -.094 & .148 & .404 & 1 & .525 & .910 & .680 & 1.217 \\
\hline Engineering & -.361 & .239 & 2.278 & 1 & .131 & .697 & .436 & 1.114 \\
\hline Business & -.065 & .284 & .052 & 1 & .819 & .937 & .538 & 1.634 \\
\hline Nursing & .110 & .346 & .100 & 1 & .751 & 1.116 & .567 & 2.198 \\
\hline Music & -.348 & .447 & .606 & 1 & .436 & .706 & .294 & 1.696 \\
\hline Social Work & -1.878 & 1.043 & 3.238 & 1 & .072 & .153 & .020 & 1.182 \\
\hline Dentistry & 1.691 & 1.051 & 2.588 & 1 & .108 & 5.427 & .691 & 42.608 \\
\hline Medicine & -.821 & .610 & 1.810 & 1 & .179 & .440 & .133 & 1.455 \\
\hline
\end{tabular}

A statistically significant result was found for classification. To compare undergraduates with non-undergraduates (graduate, other), a univariate analyses of recoded variables for undergraduate and non-undergraduate was performed. In comparing non-undergraduates with undergraduates, a statistically significant result was found $(F(1)=4.435, p=.037)$ and another was found when comparing the categories among undergraduates for first-year $(F(1)=-.372, p=.016)$. Additional statistically significant results suggested being discussed once by the SCT is a negative predictor in academic advancement $(F(1)=-.630, p=.001)$. Three or more discussions was also identified as a 
negative predictor in academic advancement $(F(1)=-.502, p=.003)$. The following table illustrates the findings of regression analyses for classification, gender, ethnicity, role in the incident, and intensity of the discussion.

Table 14. Predictions by Classification, Ethnicity, Role \& Intensity

\begin{tabular}{|c|c|c|c|c|c|c|c|c|}
\hline & & & & & & & & $\begin{array}{l}\text { CI of } \\
p(B)\end{array}$ \\
\hline Category & $B$ & S.E. & Wald & $\mathrm{df}$ & Sig. & Exp. (B) & Lower & Upper \\
\hline First-Year & -.372 & .155 & 5.759 & 1 & $.016^{*}$ & .689 & .508 & .934 \\
\hline Sophomore & -.117 & .185 & .402 & 1 & .526 & .889 & .619 & 1.278 \\
\hline Junior & .072 & .201 & .128 & 1 & .721 & 1.075 & .725 & 1.594 \\
\hline Senior & -.318 & .193 & 2.709 & 1 & .100 & .728 & .498 & 1.063 \\
\hline Grad & -.528 & .253 & 4.345 & 1 & $.037 *$ & .590 & .359 & .969 \\
\hline Other & -.261 & .399 & .427 & 1 & .513 & .771 & .353 & 1.683 \\
\hline White & -.018 & .577 & .001 & 1 & .975 & .982 & .317 & 3.041 \\
\hline $\begin{array}{l}\text { Black/Africa } \\
\text { n American }\end{array}$ & -.436 & .600 & .528 & 1 & .467 & .646 & .199 & 2.096 \\
\hline Asian & -.916 & .730 & 1.574 & 1 & .210 & .400 & .096 & 1.674 \\
\hline $\begin{array}{l}\text { Hispanic/Lati } \\
\text { no }\end{array}$ & -.464 & .672 & .477 & 1 & .490 & .629 & .168 & 2.346 \\
\hline Multi-Race & -.390 & .674 & .335 & 1 & .563 & .677 & .181 & 2.537 \\
\hline Unknown & -.223 & 1.351 & .027 & 1 & .869 & .800 & .057 & 11.298 \\
\hline Accused & 1.168 & .797 & 2.149 & 1 & .143 & 3.214 & .675 & 15.315 \\
\hline Complainant & 1.248 & .819 & 2.321 & 1 & .128 & 3.484 & .699 & 17.354 \\
\hline $\begin{array}{l}\text { Student of } \\
\text { Concern }\end{array}$ & 1.178 & .768 & 2.351 & 1 & .125 & 3.247 & .721 & 14.627 \\
\hline $\begin{array}{l}\text { Student } \\
\text { Death }\end{array}$ & -1.181 & .767 & 2.368 & 1 & .124 & .307 & .068 & 1.381 \\
\hline 1 discussion & -.630 & .184 & $\begin{array}{l}11.66 \\
0\end{array}$ & 1 & $.001 *$ & .533 & .371 & .765 \\
\hline 2 discussions & -.316 & .201 & 2.479 & 1 & .115 & .729 & .492 & 1.080 \\
\hline $\begin{array}{l}3 \text { or more } \\
\text { discussions }\end{array}$ & -.502 & .171 & 8.624 & & $.003 *$ & 1.652 & 1.182 & 2.310 \\
\hline
\end{tabular}

Self-injurious behavior was the referral category of type of referral with

statistically significant results $(F(1)=-.648, p=.004)$. Which indicates that suicide 
ideation is not a predictor of academic advancement. The following table describes the prediction of academic advancement by referral type.

Table 15. Prediction by Referral Type

\begin{tabular}{|l|l|l|l|l|l|l|l|l|}
\multicolumn{3}{|c}{} & \multicolumn{3}{c|}{$\begin{array}{c}95 \% \text { CI of } \\
\text { Exp }(B)\end{array}$} \\
\hline Category & $B$ & S.E. & Wald & df & Sig. & Exp. $(B)$ & Lower & Upper \\
\hline Conduct & .178 & .408 & .190 & 1 & .663 & 1.195 & .537 & 2.660 \\
\hline $\begin{array}{l}\text { Sexual } \\
\text { Misconduct }\end{array}$ & -.322 & .259 & 1.546 & 1 & .214 & .724 & .436 & 1.204 \\
\hline $\begin{array}{l}\text { Harm to } \\
\text { Others }\end{array}$ & .244 & .367 & .442 & 1 & .506 & 1.277 & .621 & 2.623 \\
\hline Medical & -.292 & .169 & 2.998 & 1 & .083 & .746 & .536 & 1.039 \\
\hline Mental Health & .411 & .396 & 1.078 & 1 & .299 & 1.508 & .694 & 3.276 \\
\hline $\begin{array}{l}\text { Self-Injurious } \\
\text { Behavior }\end{array}$ & -.648 & .226 & 8.216 & 1 & $.004 *$ & 1.912 & 1.227 & 2.979 \\
\hline $\begin{array}{l}\text { Substance } \\
\text { Abuse }\end{array}$ & -4.20 & .273 & 2.361 & 1 & .124 & .657 & .385 & 1.123 \\
\hline $\begin{array}{l}\text { Multiple } \\
\text { Types }\end{array}$ & .384 & .247 & 2.417 & 1 & .120 & 1.469 & .905 & 2.384 \\
\hline General Care & -.075 & .189 & .160 & 1 & .690 & .927 & .641 & 1.342 \\
\hline Consultation & -4.97 & .330 & 2.272 & 1 & .132 & .608 & .319 & 1.161 \\
\hline
\end{tabular}

\section{Summary}

The demographic profile for students referred to the student care team was similar to the demographic profile of the overall student population. The total number of referrals considered consisted of 824 students for 2010-2015 (82\% students of concern; $10 \%$ accused; $6 \%$ complainants; $2 \%$ student deaths). Chi-square tests of independence determined there was no significant difference between the ethnicities nor genders of those referred to the SCT (52\% females; $48 \%$ males) and the averaged overall university population (51\% females; 49\% males), (University of Louisville, $2012-2016)$. The ethnicities represented in the referrals consisted primarily of White (68\%), Black/African American (17\%), Hispanic (5\%), multiple races (5\%), and Asian (4\%). First-year students (37\%) were most commonly referred, $20 \%$ were sophomores, $15 \%$ juniors, and 
$16 \%$ seniors while $10 \%$ consisted of graduate students, and $2 \%$ other classifications. There is a relationship between the undergraduate groups $(p=.047)$ and even stronger when comparing the overall classifications $(p=.0005)$. The major college of the majority of the students referred was the College of Arts \& Sciences (59\%), 11\% were enrolled in the College of Education \& Human Development, and 10\% from the College of Engineering. Other enrollments consisted of the College of Business (7\%), College of Nursing (3\%), Kent School of Social Work (2\%), College of Medicine (1\%) and School of Dentistry (1\%).

The nature of the referrals consisted of primarily medical concerns (24\%) and general care (18\%) while $11 \%$ were for multiple concerns, $8 \%$ for sexual misconduct, $7 \%$ substance abuse, $5 \%$ for harm to others, $4 \%$ for mental health, and $4 \%$ were referred for student conduct reasons. These referrals were discussed once $42 \%$ of the time, twice $30 \%$ of the time, and three or more times $28 \%$ of the time. Incidents discussed occurred on campus (66\%), off campus (30\%), and in unknown locations (4\%). The weeks with the highest number of referrals were: week 7 (13 referrals), week 9 (12 referrals), and weeks $1,5,8$, and 12 all averaged 11 referrals. The lowest average number of referrals were during weeks 13 and 15 at 8 referrals each. Sources of referrals consisted primarily of the University of Louisville Police Department (46\%) and other sources (26\%) while $8 \%$ of referrals came from the Office of Housing \& Residence Life, 2\% from multiple sources, $1 \%$ from conduct and $1 \%$ from the PEACC program.

Earning attempted credit hours for the semester in which the student was referred to the SCT was negatively associated with 3 or more discussions, during week 7 , regarding self-injurious behavior among first-year and non-undergraduate students 
enrolled in the School of Social Work referred by academics. Each of these findings results from univariate analyses between each independent variable category and the dichotomous dependent variable of earning attempted credit hours. The following chapter further discusses these findings as well as the conclusions made about the findings and recommendations for future research and practice. 


\section{CHAPTER V: DISCUSSION}

This dissertation was designed to describe the SCT referrals from 2010-2015. To do so, the demographic profile for those referred to the SCT and the nature of the referrals were examined. Additionally, this information was used to understand what behaviors are associated with critical incidents and how likely students who were referred to the SCT are to advance academically (earn attempted credit hours). This chapter provides conclusions and recommendations for practice and future research.

\section{Demographic profile}

All demographic profile variables were identified in the data suggesting that the SCT discussed students of all genders, ethnicities, academic majors, classifications, and roles in the incident. Those referred to the SCT were representative of the overall university population in the categories of gender and ethnicity. Not surprisingly, the academic major college with the highest overall enrollment (University of Louisville, n.d.) was also the highest academic major referred to the SCT. These findings suggest that all students, regardless of demographics, need support during crises and all departments at the university need resources for supporting students.

In comparison, another large public institution's (University of Iowa) team referrals consisted of a similar gender profile $(\mathrm{Cao}, 2011)$ but because Iowa's referrals consisted of missing gender and ethnicity data, these data could not be appropriately compared to the overall university population. To adequately compare demographic profile of referrals for 
future research, a standard for measured demographic information is needed. A recommendation for future research is to use the demographic coding structure presented in the current research to replicate this analysis for comparison across universities.

First-year students. Regarding classification, the referrals to the SCT for first-year students $(37 \%)$ exceeded the proportion of first-year students in the university population $(17 \%)$. The demographic profile of the SCT referrals suggests that students referred to the SCT is very similar to the overall population of the university community with the exception of the amount of students referred by classification. This exception is explained by previous literature indicating that stress causes students to behave in potentially dangerous ways (Merton, 1938; Mason \& Smithey, 2012). These findings along with historical incidents involving first-year students and alcohol, substance abuse, and selfinjurious behavior (White v University of Wyoming, 1998), show that considerable attention is given and needed to assist first-year students in crisis.

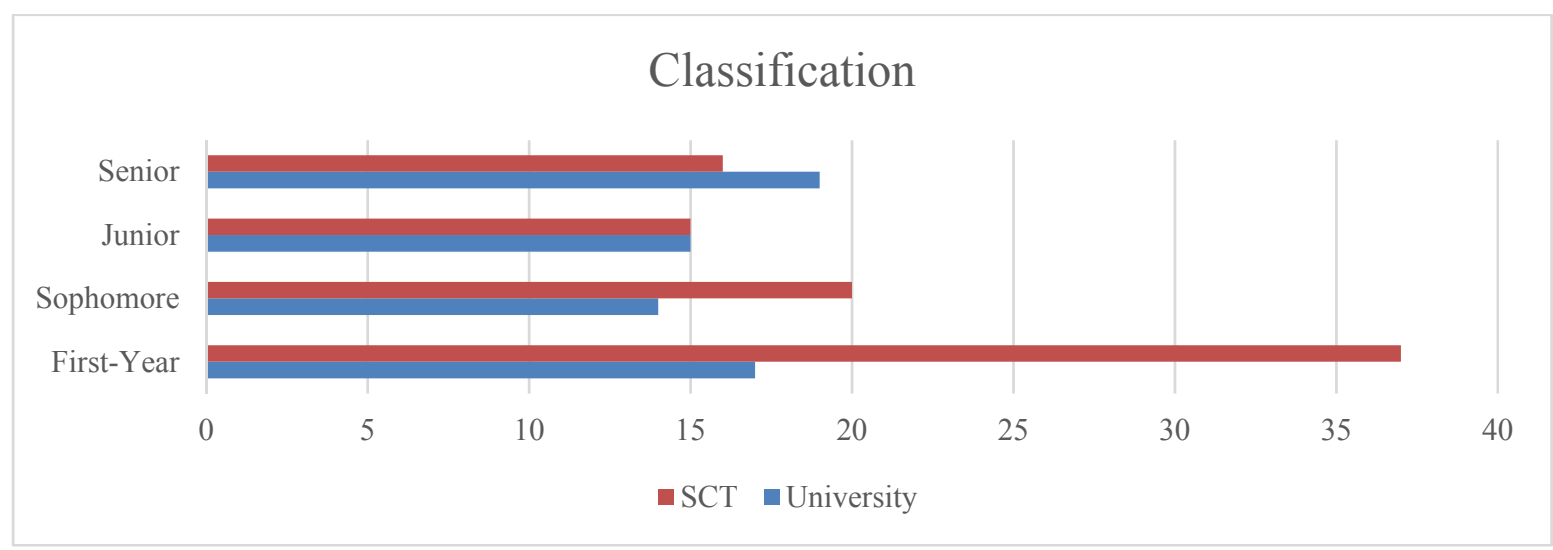

Figure 11. Classification

Interestingly, there was no significant difference in the roles of the incident between firstyear students referred and overall referrals. Specifically, $82 \%$ of referrals were made for students of concern both in the overall referrals to the SCT and for first-year students. 
Furthermore, the referrals for students accused of violating the Code of Student Conduct was also the same for first-year students and the overall referrals (10\%). On the other hand, first-year students were more frequently referred to the SCT for every referral type than any other classification, except for consultation. The referrals for consultation for first-year students was one fewer than seniors during the reporting period. The most frequently referred types for first-year students were medical, self-injurious behavior, and general care. First-year complainants consisted of $7 \%$ of referrals while $6 \%$ of the overall referrals were for complainants; however, first-year is the only classification with no student death referrals.

In 1970, the University of South Carolina sought to bond first-year students and create a new way of learning. Originally designed in response to riots on campus, the president of the university created a course that revolutionized the way institutions address first-year student learning and development (Watts, 1999). Given that the original design for these programs emerged from a need to create support for students during difficult times and the findings of this research about first-year students, it may be advantageous to examine how these programs can work together. Orientation programs across the nation were designed from the basis of this project and operate with the mission to "assist new students with the transition" to college (University of Louisville, n.d.). A future collaborative effort between the National Behavioral Intervention Team Association (NaBITA) and the National Resource Center for First Year Experience and Students in Transition could create a process for the evaluation of current programs and effectiveness in creating resiliency for students transitioning to college. These findings suggest that all first-year students need support to assess whether these programs 
designed to assist students transitioning to college can be used to decrease the need for referrals to the SCT. For example, targeted programming for first-year students may promote stress management, resiliency, and substance abuse awareness and lead to fewer referrals. Introduction to these topics provide expectations of the university community and resources needed to be successful if faced with difficulty. If students enter the college environment aware of resources to be successful or ways to request assistance, it could lead to academic advancement and fewer referrals.

\section{Nature of referrals}

For students referred to the SCT, an incident occurred that disrupted the student's college experience. These referrals varied in intensity, occurred both on and off campus, and consisted of all measured referral types. According to Zdziarski (2007), crisis management is the response to an event that disrupts or has the potential of disrupting the normal educational process. The SCT is designed to provide crisis management resources. These referrals often originate from the first point of contact regarding the incident such as a student's parent, faculty member, friend, or police. Referral sources to the SCT were similar to previous literature $(\mathrm{Cao}, 2011)$ that indicated academics, police, and other students, family and/or friends referred students most frequently to the team at the University of Iowa. At the University of Louisville, the SCT received the highest number of referrals from the police (46\%), other students and/or parents (26\%), and academic departments (16\%).

Police are responsible for responding to complaints and concerns of each referral type in order to promote safety to the university community. One way the police perform this function within the team is through threat assessment, a systematic review of 
information available to determine likelihood of violence against self or another person (Borum, et al. 1999). A high number of SCT referrals were also connected to law violations and the need for emergency response such as medical referrals (24\%), selfinjurious behavior (15\%), sexual misconduct (8.1\%), substance abuse (7.2\%), threats of harm to others $(4.5 \%)$ and additional mental health concerns (4\%).

In comparison, the University of Iowa's Threat Assessment Team discussed 171 students referred for threat of harm to others and self-injurious behavior (Cao, 2011). Of those referrals, $20 \%$ were also related to alcohol, $57 \%$ involved a history of mental health concerns, $14 \%$ of students were criminally charged, and $3.5 \%$ involved a weapon.

Considering these findings and findings about referrals to the SCT heavily involve police and threat assessment at some level, teams may benefit from an objective assessment tool to evaluate risk and intentional engagement of police.

Risk assessment. A resource to consider is the NaBITA Threat Assessment Tool (Sokolow et al., 2014) which measures behavior at three levels (generalized risk, harm to self, and harm to others). The harm to self scale categorizes behavior in a progressive continuum of "Distress" to "Disturbance" to "Dysregulation/Decompensation" and may be beneficial in the risk ranking of self-injurious behavior by the SCT. Additionally, the instrument presents a nine stage rubric that shows progression toward violent action for threats of harm to others. In this rubric of hostility and violence, the levels begin at the lowest with a "Hardening" view and progresses into "Debate and Contentious Arguments", then "Actions Not Words", to "Images and Coalitions", then "Loss of Face", and "Strategies of Threat", to "Limited Destructive Blows", then "Fragmentation of the Enemy", and lastly "Plunging Together into the Abyss". The last assessment in the 
instrument ties each of these rubrics together to formulate an overall risk assessment as mild, moderate, elevated, severe, or extreme. This overall risk assessment is assigned to intervention tools that address the level of risk based on its classification. Using a tool such as this to provide objective risk assessments may be beneficial to the team to ensure the same level of care and appropriate resources for every student. Additionally, it may be necessary to show that all students receive the same type of assessment when referred as well as any assigned risk level in times of litigation.

Police involvement. Given police involvement in $46 \%$ of referrals to the SCT, it may be useful to review referral protocol and criteria with university and local police prior to the beginning of the fall semester. Referrals to SCT involved both on campus (66\%) and off campus (30\%) incidents; therefore, it is possible that off campus students may not receive the same level of care as students who had direct interaction with university police. A potential reason that the highest percentage of referrals came from incidents that occurred on campus is because there are many more university members present to report an incident on campus than there are off-campus. Additionally, first-year students represent the highest classification of students in the residence halls which may also be a reason for the high number of referrals for first-year students. Even though more students live off-campus than on-campus, the jurisdiction of university police does not extend to all neighborhoods. Additionally, federal law requires university employees to report crimes (U.S. Department of Education, 2016).

A meeting with local law enforcement that communicates the vision and expectations of the SCT may build a culture of reporting off campus incidents. Additionally, a written protocol for referrals by external sources and memo of 
understanding with local police may provide a foundation for the process of referring off campus incidents to the SCT. To consistently provide students care during critical incidents, the SCT must receive a referral in some way. A culture of reporting off campus incidents would allow the SCT to assist students early after the incident occurred which could also assist those students academically and beyond.

Timing of referrals. Another element of the referrals is what week of the semester the referral is first discussed by the team. To provide teams with information about when referrals tend to increase, the current research measured the first week a student is discussed by the SCT. Findings suggested the highest number of referrals were weeks $5,7,9$, and 11 and as many as $10 \%$ of referrals occurred when classes are not in session. This information shows that the referrals increase from the beginning of each semester, maintain a high number of referrals for new incidents during the middle of the semester, and decrease again toward the end of the semester even though they continue to occur after final exams. The timing of these referrals are consistent with Drysdale et al.'s (2010) research findings suggesting violent incidents occur throughout the calendar year yet increase during April and October. Similarly, week 7, which is associated with the highest number of new referrals, occurred during October of the fall semesters. Furthermore, the week associated with the highest number of overall discussions occurred during April of the spring semesters.

The SCT may use these findings to increase support during weeks of high referrals. On-call responders may need to be increased during high referral weeks to decrease the potential number of late night responses per person. This increase in staff could assist in combating responder fatigue and provide additional assistance to students 
in crisis. To assist after hour referrals, it may also be necessary to facilitate ways that allow responders access to office resources from afar (e.g., remote desktop access). Similarly, it may be necessary to develop a $24 / 7$ on-call counseling rotation for times of increased referrals for self-injurious behavior. A way to engage the SCT differently may be to create open office hours for consultation with SCT members. Office hours would allow referral sources the opportunity for dialogue about concerning behaviors with members of the SCT to determine whether a referral is necessary and to provide an initial assessment for risk. Office hours also provide an opportunity to build rapport with the university community, increasing the trust and reputation of the SCT. Furthermore, the team could use this knowledge to allow more time for student discussions during weeks of high referrals.

Care and intensity. The second largest type of referral to the SCT was for general care (18\%). This care consisted of homelessness resources, absence notifications, course withdrawal assistance, hospital visits, mandated assessment, and/or parental notification. Any time a student was referred to the SCT, they were offered these basic resources, if applicable. The general care category is considered a baseline referral for low level, non-specific to another category, cases. For example, the SCT provided consultations (5\%) with those who contacted members of the team to discuss whether or not a concern should be referred. If no other action was taken beyond a consultation with the referral source or the referral was otherwise low intensity, the student was discussed once by the SCT (42\%). Other referrals were discussed by the team twice $(30 \%)$ or three or more times (28\%) categorizing them as increasing in intensity as the discussion number increased. Referrals discussed three or more times consisted of self-injurious 
behavior and threats of harm to others. Because the SCT meets bi-weekly and referrals are discussed three or more times, it is not uncommon for a referral to be discussed during nearly half the semester.

It may be beneficial to assess the SCT referral discussions in future research. This assessment may address the need to identify criteria for what referrals are discussed by the SCT. A rubric could determine whether the SCT should discuss a referral and if determined not necessary could decrease the number of referrals discussed per meeting. This analysis could also decrease length of discussion. The SCT may determine low intensity discussions may only be necessary to check names of students referred. Another option may be to categorize all discussions by type of referral to encourage the same type of discussion and action plan for each referral. For example, referrals requiring low intensity discussions may be discussed by type of referral (e.g., consultations). This approach allows SCT members to discuss particular students named within each category, if necessary, but does not require individual discussions per student. Organizing a discussion agenda by referral type provides the SCT context from one referral to another in the form of action plans and resources. Additionally, because many referrals are discussed during multiple meetings, it is helpful to maintain ongoing case discussion notes. The University of Louisville's SCT discussion notes provide historical documentation of action taken by the SCT and incident summaries to remind SCT members of previous discussions from meeting to meeting. Discussion notes should be stored in a secure database system that allows access from off campus in the case that the notes are needed to address an incident from afar. 
The following section discusses the predictability of earning attempted credits for those referred to the SCT and provides recommendations. Specifically, first-year students are referred to the SCT more frequently than other students and the following section discusses the impact on academic advancement. Recommendations are made to increase first-year resiliency through peer support and mental health support.

\section{Attempted and earned credit hours}

Earning attempted credit hours for the semester in which the student was referred to the SCT was negatively associated with 3 or more discussions, during week 7 , regarding self-injurious behavior among freshmen and non-undergraduate students enrolled in the School of Social Work referred by academics or other.

Peer support. As previously mentioned, all academic departments need resources for students in crisis. The School of Social Work and the School of Interdisciplinary and Graduate Studies may wish to explore ways to encourage academic advancement as referrals are a significant negative predictor on earning credit hours. The 2020 Strategic Plan for the School of Social Work discusses the goal to maintain students from one year to the next (University of Louisville, 2016). According to Skyfactor (2015), highly academic resilient first year students were more likely to report feeling connected to their peers. If the school is considering ways to retain students from one year to the next, it could be beneficial to consider these findings. A recommendation is to provide opportunities for students to support each other in the program. Providing peer support may create a sense of belonging and bond between the majors that encourages study groups and moral support during difficult times. 
Mental health support. Findings indicate students who exhibit forms of selfinjurious ideation, gestures, and attempts are significantly less likely to earn attempted credit hours than others. It is not surprising that students who find it difficult to function due to feelings of hopelessness are not able to perform as well academically as those not experiencing this depression. If SCT members are able to identify self-injurious behavior before the intensity increases and provide appropriate resources, it may be possible to increase the potential for earning attempted credit hours. An instrument assessing progressive mental health risks could encourage early behavior intervention which could lead to academic advancement. As Pavela and Joffe (2007) stated, early intervention with troubled students is a role of the SCT.

First-year resiliency. First-year students are the most frequently referred to the SCT and those referrals negatively predict the earning of attempted credit hours for the referral semester. Even though special attention is given to first-year students through orientation programs upon arrival, first-year students need additional support. Considering the findings and recommendations for peer support, mental health assessment, risk assessment, and SCT function, it appears that all themes surround the need for first-year student resiliency.

Students possessing a first-year classification have the fewest number of credit hours than any other classification. These students have established fewer coping mechanisms than students who have been in college longer and need assistance to gain them. Students create ways to achieve expectations and students who do not have the means for achieving goals may rebel. For example, concerning behaviors (e.g., suicidal ideation) could be a response to the institution's expectations and the perception that the 
expectations cannot be met. Given that first-year students are not only the most likely to be referred to the team but also significantly less likely to earn attempted credit hours if referred, it provides further rationale to explore different avenues for assisting first-year students in their transition to the university environment. In a study examining methods for student success among first-year students in their transition to college (Rahat \& Ilhan, 2016), researchers found that resiliency characteristics were more likely to predict adjustment to college than other strategies such as social support, relational selfconstrual, and coping styles. Given findings from previous research, these conclusions, and that over $70 \%$ of first-year students live on campus, the SCT may be interested in collaborating with the Office of First Year Initiatives and the Office of Housing \& Residence Life to provide a program designed for incoming first-year students that promotes the development of resiliency characteristics.

\section{Recommendations for practice}

It is important to consider the implications of these findings on institutions of higher education, the campus community, and teams responding to these referrals. Now that patterns have been identified within the referrals to the SCT, the university has an opportunity to provide targeted programs to students/faculty/staff regarding ways to identify, report, and potentially mitigate concerning behavior. The following section of this chapter presents recommendations for practice.

Training and preparation. The following portion of this chapter provides recommendations for training and incident preparation. The findings of the current research provide the SCT the ability to anticipate referrals and how the referral may impact academic advancement. Members of the university community and beyond can 
benefit from training related to identification of concerning behavior and how to support students involved in critical incidents.

Considering the types of behavior reported, training and preparation materials should be available reporting responsibilities and options. It may be beneficial to create a calendar of trainings to ensure they are presented regularly and to inform the community about when they can expect to be trained. Because the findings suggest the largest referral type was medical, it may be useful to provide training for academic departments on ways they can support students who are hospitalized. Training for self-injurious behavior identification and reporting is also needed for students living in the residence halls, as these students often interact in close quarters. Given the findings that students referred by other students and/or family are less likely to earn attempted credit hours, training for all students and families about early intervention may also be beneficial. Additionally, suicide prevention training, bystander intervention training, sexual misconduct reporting responsibilities, and conflict resolution skills are valuable trainings for all students as well as para/professionals serving in a crisis response capacity.

Students may benefit from passive programming such as email tips about stress and time management during high stress academic times (e.g., mid-terms and/or final exams). It may also be beneficial to provide policy awareness programming to decrease referrals for substance abuse. On the other hand, because substance abuse is discussed by the SCT, it may also be necessary to promote the Good Samaritan Consideration (University of Louisville, 2017). This provision encourages students to report health and safety concerns without reluctance due to concern that students would be in violation of the Code of Student Conduct. 
A communication plan for referral sources may also be beneficial to standardize strategies and maintain positive reputations for responding to critical incidents. While referrals differ in intensity, the communication lines during all referrals are extremely important. As Coombs (2007) indicated, the steps for maintaining a credible reputation are 1) taking responsibility for the crisis, 2) history of crises and 3) reputation as a result of previous crises. It is important to consider how referral sources perceive the management of the referral to promote the team's reputation (Murphy, 1996). To create an effective communication plan, it may be advantageous to ask referral sources about their perceived experience in referring to the SCT. It is also important to be transparent with referral sources about the level of follow-up they will receive after the referral. This dialogue about communication expectations and plans will provide referral sources with an understanding of the process which may also promote a positive reputation.

Mitigation. Using the findings and recommendations, it may be possible to decrease referrals and critical incidents. These strategies may also encourage academic advancement through collaboration with Academic Affairs and the SCT. The following section describes recommendations for research and practice designed to mitigate risk.

Themes presented about weeks of the semester with high referrals may call for the need to assess if academic stress is particularly high during corresponding weeks. The SCT has an opportunity to partner with Academic Affairs to survey syllabi due dates to determine what weeks of the semester are most associated with exams and assignments. If academic strain could be decreased through the use of alternative exam/assignment schedules, critical incidents may also decrease. A slight alteration of due dates among an 
academic department may significantly decrease referrals and increase academic advancement.

Mitigation also comes in the forms of student discipline as members of the SCT serve in the role of conduct officers who are responsible for separating students who are threats to the health and/or safety of the campus community. Sometimes, this mitigation has a negative association with earning attempted credit hours because the student may no longer have the opportunity to do so (e.g., suspension or expulsion). In situations like these, the university must make a decision about whether it is more important for a referred student to earn attempted credit hours or to protect the university community through a separation. Deferred suspensions could be a used to allow the student to earn their attempted credit hours after a decision has been made to separate the student for conduct reasons. If the student was able to complete coursework from afar, it would allow the institution to achieve the goals for academic advancement and community safety.

The following section of this chapter focuses on recommendations for future research about team function and referrals. The coding structure of this dissertation provides framework for future research about demographic information of referrals.

\section{Recommendations for future research}

Because the body of research about teams is still growing, the methodology and findings of the current research provides a framework for team data collection and analysis. The current research variables should be replicated in future research to allow for comparison across institutions of higher education. Additional recommendations for future research include team structure and impact on team function. Also, future research 
regarding the impact of SCT action on academic persistence to graduation will provide longitudinal data to these findings. The following section of this chapter discusses recommendations for future research on team structure and function, referrals, and impact of the services provided by the team.

Team structure and function. Team structure and function are additional recommendations for future research. Because members of the SCT and many other teams were selected based on role at the institution (Dunkle, et al., 2008), future research may focus on the impact of those roles on the overall function of the team. This assessment may provide insight on functions that need additional development and validate those that produce positive results on academic advancement. Functions such as referrals for general care may also be examined as predictors for academic advancement in future research. The next section of this chapter expands on this section about research on teams to the nature of the referrals made to the team.

Nature of referrals. The following research recommendations were drawn from questions outside the scope of this dissertation. These recommendations are designed to expand the findings of the current research about the nature of referrals to teams. Demographic considerations may be to create a profile of employees referred to teams, if applicable, compare profiles between the roles in the incident. A new variable to consider as a predictor of academic advancement is student engagement (e.g., athletics, employment, and/or student organizations). Additionally, the use of National Survey of Student Engagement (NSSE) data, 
which includes engagement data about first-year students and senior students could also be used to compare levels of engagement before and after a referral.

Additionally, the expansion of categories for referral types will also allow for a more complete description of the referral types and examination of these variables as predictors for academic advancement. Specifically, recategorize the following types from "medical" to "EMS transport" and "long term stays"; "harm to others" to "threats" and "physical harm"; and include "robbery" as a new referral type. It may provide additional insight into the academically straining times to compare high referral weeks with institutions on alternative academic schedules (e.g., quarters, semesters, summer sessions, and j-terms). Lastly, a comparison of referral type data across institutions of higher education (e.g., military, HBCU, women's, private, Ivy league, nontraditional grading processes) would provide additional themes about the nature of referrals to teams.

\section{Conclusion}

The expectations of a university community to provide safety, security, and student well-being have encouraged universities to create teams to assess and respond to concerning behavior. The purpose of the current research was to describe the demographic profile of students referred to the SCT, the nature of the referrals to the SCT, and whether those variables predict if a student referred earns attempted credit hours for the semester they were referred. In the first chapter, the statement of the problem described the need to understand the work of teams on college campuses in 
order to add to the growing knowledge base about a growing field. Three research questions were presented to describe the demographic profile, nature of referrals, and prediction of earned credit hours.

Chapter two introduced the conceptual framework as well as previous literature about critical incidents and teams. Astin's (1991) Input-Environment-Output (I-E-O) model for assessment as the foundational concept was used to organize the current research. It contextualized the variables of demographic as input, nature of referrals as environment, and earning attempted credit hours as output. Merton's Strain theory (1938) provided context for the current research by explaining why some students behave in ways that are incongruent with the university's expectations. Threat assessment frameworks were also described to illustrate ways to respond to these concerning behaviors. The literature review presented previous research about critical incidents, requirements for team creation, and the work of teams on college campuses.

Chapter three described the methodological approach of the current research, including the research design and population, variables, setting, and procedure. Additionally, each research question was presented along with an explanation of corresponding analyses. Lastly, potential threats for internal and external validity were described.

In chapter four, results from the statistical tests were organized by research question and presented. These results showed that the demographic profile for those referred to the SCT was not significantly different than the demographic profile of the overall student population. The nature of the referrals consisted of primarily medical concerns (24\%) and general care (18\%). Referrals were 11\% multiple concerns, $8 \%$ 
sexual misconduct, $7 \%$ substance abuse, $5 \%$ harm to others, $4 \%$ mental health, and $4 \%$ were referred for student conduct reasons. These referrals were discussed once (42\%), twice (30\%), and three or more times (28\%). Incidents discussed occurred on campus (66\%), off campus (30\%), and in unknown locations (4\%) and most discussions occurred during weeks 7 (13 referrals), week 9 (12 referrals), and weeks 1, 5, 8, and 12 all averaged 11 referrals. Referrals primarily came from the University of Louisville Police Department (46\%) and other sources (26\%) while the remaining referrals were from the Office of Housing \& Residence Life (8\%), 2\% from multiple sources, $1 \%$ from conduct and $1 \%$ from the PEACC program. Additionally, results showed that first-year students were most commonly referred to the SCT and the classification is negatively associated with earning attempted credit hours. Other negatively associated variable categories were 3 or more discussions, week 7 , self-injurious behavior, and referrals by academics.

This chapter discussed notable findings and offered recommendations for collaboration, practice, and research. Overall, this research was designed to describe the work of the SCT and attempt to predict academic advancement. Using Astin's I-E-O Model of Assessment as a foundation, the demographic profile of the referrals represented the Input variable, the nature of referrals represented the Environment variable, and academic advancement represented the predicted Output. The SCT may use the findings presented to address additional research questions, create training opportunities, and potentially mitigate risk. Other teams may also use the research design, findings to compare caseloads, and recommendations for practice and research to continue building knowledge on this topic. It may also be possible to create protocols that address academic advancement in the future. If done well, the university is able to 
achieve multiple goals simultaneously through academic achievement and the promotion of a safe environment. 


\section{REFERENCES}

American College Health Association. (2009). National College Health Assessment (ACHA-NCHA), spring 2008 reference group report (abridged). Journal of American College Health, 54, 201-211.

Americans with Disabilities Act of 1990, Pub. L. No. 101-336, § 35.139, 2000.

Arehart-Triechel, J. (2002). Mental illness on the rise on college campuses. Psychiatric News, 37(6), 6-38.

Astin, A. W. (1984). Student involvement: A developmental theory for higher education. Journal of College Student Personnel, 25(4), 297-308.

Astin, A. W. (1991). Assessment for excellence: The philosophy and practice of assessment and evaluation in higher education. New York, NY: ACE \& Macmillan Publishing Co.

Atkinson, J. M. (1969). Suicide and the student. University Quarterly, 23, 213-224.

Benton, S. A., Robertson, J. M., Tseng, W. C., Newton, F. B., \& Benton, S. L. (2003). Changes in counseling center client problems across 13 years. Professional Psychology: Research and Practice, 34(1), 66-72.

Berzon, A., \& Eaton, L. (2011). Colleges re-examine safety after rampage. Wall Street Journal. Retrieved from http://online.wsj.com

Borum, R. F. (1999). Threat assessment: Defining an approach for evaluating risk of targeted violence. Behavioral Sciences and the Law, 17, 323-337. 
Borum, R., Fein, R., Vossekuil, B., Berglund, J. (1999). Threat assessment: Defining an approach for evaluating risk of targeted violence. Behavioral Sciences and the Law, (17), 323-337.

Bowden, R. (2007). Evolution of responsibility: From "in loco parentis" to "ad meliora vertamur". Education, 127(4), 480-489.

Braaten, L. J., \& Darling, C. D. (1962). Suicidal tendencies among college students. Psychiatric Quarterly, 36, 665-692.

Brent, D. A. (2002, June). Some strategies to prevent youth suicide. Paper presented at the Adolescent Risk Conference, Annenberg Public Policy Center, University of Pennsylvania, Philadelphia.

Briere, J., \& Gil, E. (1998). Self-mutilation in clinical and general population samples: Prevalence, correlates, and functions. American Journal of Orthopsychiatry, 68, 609-620.

Bruyn, H. B., \& Seiden, R. H. (1965). Student suicide: Fact or fancy. Journal of the American College Health Association, 14, 69-77.

Carpenter, R. G. (1959). Statistical analysis of suicide and other mortality rates of students. Journal of Preventive and Social Medicine, 13, 163-174.

Cao, Y. (2011). An epidemiological analysis of a university threat assessment team caseload (master's thesis). Retrieved from http://ir.uiowa.edu/etd/1206.

Center for the Study of Collegiate Mental Health (2009). Pilot study, executive summary. Retrieved March 1, 2015, from http://www.sa.psu.edu/caps/research_center.shtml.

Collins, R. L., Parks, G. A., \& Marlatt, G. A. (1985). Social determinants of alcohol consumption: The effects of social interaction and model status on the self- 
administration of alcohol. Journal of Consulting and Clinical Psychology, 53, 189-200.

Coombs, W. T. (2007). Protecting organization reputations during a crisis: The development and application of situational crisis communication theory. Corporate Reputation Review, 10(3), 163-176.

Cornell, D. (2008). No title. NASPA Leadership Exchange.

Cornell, D. (2010). Threat assessment in college settings. Change, 1, 8-15.

Correia, C. J., Murphy, J. G., Irons, J. G., \& Vasi, A. E. (2010). The behavioral economics of substance use: Research on the relationship between substance use and alternative reiforces. Journal of Behavioral Health and Medicine, 1, 216-237.

Creswell, J. W. (1998). Qualitative inquiry and research design: Choosing among five traditions. Thousand Oaks, CA: Sage.

Delworth, U. (1989). Dealing with the behavioral and psychological problems of students. San Francisco, CA: Jossey-Bass.

Dixon vs. Alabama State Board of Education. (1961).

Drysdale, D. A., Modzeleski, W., \& Simons, A. B. (2010). Campus attacks: Targeted violence affecting universities. Washington, D.C.: U.S. Secret Service, U.S. Department of Homeland Security, Office of Safe and Drug-Free Schools, U.S. Department of Justice.

Dunkle, J. H., Silverstein, Z. B., \& Warner, S. L. (2008). Managing violent and other troubling students: The role of threat assessment teams on campus. Journal of College and University Law, 34, 585-636. 
Fauman, B. J., \& Hopkinson, M. J. (2010) Special population. In J. Kay \& V. Schwartz (Eds.) Mental health care in the college community (pp. 247-263). Hoboken, NJ: Wiley-Blackwell.

Finding hope and help college initiative: A college mental health planning and resource guide. (2002). Alexandria, VA: National Mental Health Association. Retrieved from http://www.nmha.org/camh/college

Fischer, K., \& Wilson, R. (2007). Virginia Tech was slow to respond to gunman, panel finds. Chronicle of Higher Education, 54(2), 3.

Flannery, D. J., \& Quinn-Leering, K. (2000). Violence on college campuses: Understanding its impact on student well-being. Community College Journal of Research and Practice, 24, 839-855.

Fox, J. A., \& Savage, J. (2009). Mass murder goes to college: An examination of changes on college campuses following Virginia Tech. American Behavioral Scientist, $52(10), 1465-1485$.

Gallagher, R. P. (2005). National Survey of Counseling Center Directors. Alexandria, VA: International Association of Counseling Services.

Gover, A. R., Kaukin, C., \& Fox, K. A. (2008). The relationship between violence in the family of origin and dating violence among college students. Journal of Interpersonal Violence, 23, 667-1693.

Gratz, K. L. (2001). Measurement of deliberate self-injurious behavior: Preliminary data on the deliberate self-injurious behavior inventory. Journal of Psychopathology and Behavioral Assessment, 23, 253-263. 
Gray, R. H. (2008). Virginia Tech one year later: How campuses have responded. Campus Safety, 16(2), 18-28.

Gross, K. (1990). After their daughter is murdered at college, her grieving parents mount a crusade for campus safety. People, 33(7), 113.

Haas, A. P., Hendin, H. \& Mann, J. J. (2003). Suicide in college students. American Behavioral Scientist, 46, 1224-1240.

Harris, E. C., \& Barraclough, B. (1997). Suicide as an outcome for mental disorders: A metanalysis. Journal of Psychiatry, 170, 205-228.

Harvard Public Health Review. (2006). Death by violent means: Who's at risk? Retrieved from http://diseaseriskindex.harvard.edu/review/rvw_spring06/txt_spring06_violence.h $\mathrm{tml}$

Higher Education Mental Health Alliance. (2012). Balancing safety and support on campus: A guide for campus teams. New York, NY: The Jed Foundation.

Jeanne Clery Disclosure of Campus Security Policy and Campus Crime Statistics Act. 20 U.S.C. $\S 1092(f)(2000)$.

Kang, H. (2013). The prevention and handling of the missing data. Korean Journal of Anesthesiology, 64(5), 402-406.

Kentucky Revised Statute $§ 9485-9489 ; 993$. (2000).

Kerr, P. L., Muehlenkamp, J. J., \& Turner, J. M. (2010). Nonsuicidal self injury: A review of current research for family medicine and primary care physicians. Journal of the American Board of Family Medicine, 23(2), 240-259. 
Kessler R. C., Berglund, P., Borges, G., Nock, M., \& Wang, P. S. (2005). Trends in suicide ideation, plans, gestures, and attempts in the United States, 1990-1992 to 2001-2003. Journal of American Medical Association, 293, 2487-2495.

Kessler, R. C., Berglund, P., Demler, O., Jin, R., Merikangas, K. R., \& Walters, E. E. (2005). Lifetime prevalence and age-of-onset distributions of DSM-IV disorders in the national comorbidity survey replication. Archives of General Psychiatry, 62(6), 593-602.

Kitzrow, M. (2003). The mental health needs of today's college students: Challenges and recommendations. NASPA Journal, 41(1), 165-179.

Klonsky, E. D., Oltmanns, T. F., \& Turkheimer, E. (2003). Deliberate self-injurious behavior in a nonclinical population: Prevalence and psychological correlates. The American Journal of Psychiatry, 160, 1501-1508.

Knowles, C., \& Dungy, G. (2010). The emotional health and violence connection: Prevention, intervention, and resiliency. In B. O. Hemphills, Enough is enough: A student affairs perspective on preparedness and response to a campus shooting. Sterling, VA: Stylus.

LaBlanc, B. H. (2010). Managing the whirlwind: Planning for and responding to a campus in crisis. In B. O. Hemphill, Enough is enough: A student affairs perspective on preparedness and response to a campus shooting (pp. 53-82). Sterling, VA: Stylus.

Lake, P. \& Tribbensee, N. (2002). The emerging crisis of college student suicide: Law and policy responses to serious forms of self-inflicted injury. Stetson Law Review, $32,125-157$. 
Mardis, J. M., Sullivan, D. J., Gamm, C. (2013). Behavioral-intervention and threatassessment teams in higher education: Results of an exploratory study. Journal of the Association of Student Conduct Administrators, 5, 1-30.

Mason, B., \& Smithey, M. (2012) The effects of academic and interpersonal stress on dating violence among college students: A test of classical strain theory. Journal of Interpersonal Violence, 27(5), 974-986.

Meloy, J. R. (2012). The role of warning behiaviors in threat assessment: An exploration and suggested typology. Behavioral Sciences and the Law, 30, 256-279.

Meloy, J. R., Hoffman, J., Guldimann, A., James, D. (2011). The role of warning behaviors in threat assessment: An exploration and suggested typology. Behavioral Sciences and the Law, 30, 256-279.

Merton, R. K. (1938). Social structure and anomie. American Sociological Review, 3(5), $672-682$.

Mintzberg, H. (1979). The five basic parts of the organization. In H. Mintzberg, Classics of organization theory (pp. 219-230). Belmont, CA: Thomson Wadsworth.

Moreno, C., Laje, G., Blanco, C., Jiang, H., Schmidt, A. B., Olfson, M. (2007). National trends in the outpatient diagnosis and treatment of bipolar disorder in youth. Archives of General Psychiatry, 64, 1032-1039.

Murphy, P. (1996). Chaos theory as a model for managing issues and crises. Public Relations, 22(2), 95-113.

National Center on Addiction and Substance Abuse. (2007). Wasting the best and the brightest: Substance abuse at America's colleges and universities: United States. 
Retrieved from

http://www.casacolumbia.org/ProductSearch.aspx?CATID=121920079233524.

National Center for Health Statistics. (1999). Death rates for 358 selected causes, by 5 year age groups, race, and sex: United States. Retrieved from http://www.cdc.gov/nchs/data.

National Survey of Student Engagement. (2017). Lessons from the field-Volume 4: Digging deeper to focus and extend data use. Bloomington, IN: Center for Postsecondary Research, Indiana University School of Education.

Nock, M.K., \& Kessler, R.C. (2006). Prevalence of and risk factors for suicide attempts versus suicide gestures: Analysis of the National Comorbidity Survey. Journal of Abnormal Psychology, 116, 616-623.

Parnell, R. W. (1951). Mortality and prolonged illness among Oxford undergraduates. Lancet, 1, 731-733.

Pavela, G., \&. Joffe, P. (2007, October 9). Responding to troubled and at-risk students. NASPA Webinar.

Pavela, G. (2008). Colleges won't help students by fearing them. Chronicle of Higher Education, 54(25), A37.

Penven, J. C. (2012). Threat assessment teams: A model for coordinating the institutional response and reducing legal liability when college students threaten suicide. Journal of Student Affairs Research and Practice, 49, 299-314.

Pfeffer, J. (1981). Understanding the role of power in decision making. In Classics of organizational theory (pp. 289-303). Belmont, CA: Thomson Wadsworth. 
Pollard, J. W., Nolan, J. J., \& Deisinger, E. D. (2010). The practice of campus-based threat assessment: An overview. Journal of College Student Psychotherapy, 26(4), 263-276.

Rahat. E., \& Ilhan, T. (2016). Coping styles, social support, relational self-construal, and resilience in predicting students' adjustment to university life. Educational Sciences: Theory and Practice, 16(1), 187-208.

Randazzo, M., \&. Plummer, E. (2009). Implementing behavioral threat assessment on campus: A Virginia Tech demonstration project. Blacksburg, VA: Virginia Polytechnic Institute and State University.

Redden, E. (2008, April 7). Predicting and preventing campus violence. Retrieved from www.InsideHigherEd.com

Rook, A. (1959). Student suicides. British Medical Journal, 1, 599-603.

Roudsari, B. S., Leahy, M. M., \& Walters, S. T. (2009). Correlates of dating violence among male and female heavy-drinking college students. Journal of Interpersonal Violence, 24, 1892-1905.

Royse, D. D. (2010). Program evaluation: An introduction (5th ed.). Belmont, CA: Wadsworth Cengage Learning.

Serras, A., Saules, K. K., Cranfield, J.A., \& Eisenberg, D. (2010). Self-injury, substance abuse, and associated risk factors in a multi-campus probability sample of college students. Psychology of Addictive Behaviors, 24(1), 119-128.

Shaffer, D., \& Craft, L. (1999). Methods of adolescent suicide prevention. Journal of Clinical Psychology, 60, 70-74. 
Shafritz, J. M. (2005). Classics of organization theory. Belmont, CA: Thomas Wadsworth.

Shaikh, B. T., \& Deschamps, J. P. (2006). Life in a university residence: Issues, concerns, and responses. Education for health, 19(1), 43-51.

Skyfactor (2015). What is the relationship between resiliency and a first-year student's academic experience? Mapworks. Retreived from http://skyfactor.com/wpcontent/uploads/2015/05/What-is-the-relationship-between-resiliency-and-afirstyear-students-academic-experience.pdf.

Sokolow, B. A., Lewis, W S., Schuster, S. K., Swinton, D. C., \& Van Brunt, B. J. (2014). Threat assessment in the campus setting. The NaBITA Whitepaper. Retrieved from NCHERM: https://www.ncherm.org/resources/publications/\#WhitePapers

Sokolow, B. A. (n.d.). The NCHERM 2009 whitepaper: 2nd generation behavioral intervention best practices. Retrieved from NCHERM: www.nabita.org/docs/2009NCHERMwhitepaper.pdf

Sokolow, B. A., Lewis, W. S., Schuster, S. K., \& Swinton, D. (2014). The book on BIT. Malvern, PA: National Behavioral Intervention Team Association (NaBITA).

Spicer, R. S., \& Miller, T. R. (2000). Suicide acts in 8 states: incidence and case fatality rates by demographics and method. American Journal of Public Health, 90, $1885-1891$.

Substance Abuse and Mental Health Services Administration (2000). Results from the 2000 national survey on drug use and health: Summary of national findings. Rockville, MD: Substance Abuse and Mental Health Services Administration. 
Substance Abuse and Mental Health Services Administration (2002). Results from the 2000 national survey on drug use and health: Summary of national findings. Rockville, MD: Substance Abuse and Mental Health Services Administration. Substance Abuse and Mental Health Services Administration (2006). Results from the 2000 national survey on drug use and health: Summary of national findings. Rockville, MD: Substance Abuse and Mental Health Services Administration. Substance Abuse and Mental Health Services Administration (2008). Results from the 2000 national survey on drug use and health: Summary of national findings. Rockville, MD: Substance Abuse and Mental Health Services Administration. Suicide Prevention Resource Center. (2014). Suicide among college and university students in the United States. Waltham, MA: Education Development Center, Inc.

Temby, W. D. (1961). Suicide. In G. B. Blaine Jr. \& C. C. McArthur (Eds.), Emotional problems of the student. London: Butterworth.

Ten most violent acts committed on a college campus. (n.d.). In Collegestats.org. Retrieved from: http://collegestats.org/2012/09/the-10-most-violent-actscommitted-on-a-college-campus/

The Family Educational Rights and Privacy Act, 93-380 (Pub. L. 1974).

Tierney, W. G. (1988). Organizational culture in higher education: Defining the essentials. Journal of Higher Education, 59, 2-21.

U. S. Department of Education. (2007). Balancing student privacy and school safety: A guide to the family educational rights and privacy act for colleges and universities. Washington, DC. 
University of Louisville. (2017). First year initiatives. Retreived from http://louisville.edu/firstyear/about-1

University of Louisville. (2016). Kent school of social work 2020 strategic plan.

Retrieved from http://louisville.edu/kent/about/outcomes-assessment-datastrategic-plan-scorecard-diversity-plan-1

University of Louisville. (2017). PEACC: Prevention, education, advocacy, on campus and in the community. Retreived from http://louisville.edu/peacc

University of Louisville. (2008). Student care team. Retrieved from http://louisville.edu/dos/facultystaff/student-care-team

University of Louisville. (2012). Common data set 2011-2012. Retrieved March 1, 2015 from http://louisville.edu/oapa/institutional-research-and-planning/folder.201508-13.2184249854/facts-and-figures-about-uofl-1/cds

University of Louisville. (2016). Just the facts. Retrieved June 23, 2017 from http://louisville.edu/oapa/institutional-research-and-planning/quick-facts/just-thefacts-publication-1

University of Louisville. (2015). Just the facts. Retrieved June 23, 2017 from http://louisville.edu/oapa/institutional-research-and-planning/quick-facts/just-thefacts-publication-1

University of Louisville. (2014). Just the facts. Retrieved March 1, 2015 from https://louisville.edu/oapa/institutional-research-and-planning/folder.2015-0813.2184249854/facts-and-figures-about-uofl-1/just-thefacts/JusttheFacts2014finalWEB.pdf 
University of Louisville. (2013). Just the facts. Retrieved June 23, 2017 from http://louisville.edu/oapa/institutional-research-and-planning/quick-facts/just-thefacts-publication-1

University of Louisville. (2012). Just the facts. Retrieved June 23, 2017 from http://louisville.edu/oapa/institutional-research-and-planning/quick-facts/just-thefacts-publication-1

University of Louisville. (2011). Just the facts. Retrieved June 23, 2017 from http://louisville.edu/oapa/institutional-research-and-planning/quick-facts/just-thefacts-publication-1

University of Louisville. (2016). Student sexual misconduct policy. Retrieved from http://louisville.edu/dos/students/studentpoliciesandprocedures/student-sexualmisconduct-policy

University of Louisville Police Department. (n.d.) University of Louisville Policy on Disclosure of Campus Security and Crime Statistics. Retrieved from http://louisville.edu/police/clery-crime-reports/university-of-louisville-policy-ondisclosure-of-campus-security-and-crime-statistics

University of Louisville. (n.d.) About College of Arts \& Sciences. Retrieved on June 25, 2017 from http://louisville.edu/artsandsciences/about

U.S. Department of Education, Office for Civil Rights. (April 4, 2011). "Dear colleague" letter guidance, supplementing the OCR's revised sexual harassment guidance (2001). Retrieved from: https://www2.ed.gov/about/offices/list/ocr/letters/colleague-201104.pdf 
U.S. Department of Education, Office of Postsecondary Education. (2016). The handbook for campus safety and security reporting: 2016 edition. Retrieved from https://www2.ed.gov/admins/lead/safety/handbook.pdf

Van Brunt, B., Sokolow, B., Lewis, W., \& Schuster, S. (2014). NaBITA Team Survey. Retrieved from www.nabita.org

Voelker, R. (2003). Mounting student depression taxing campus mental health services. Journal of the American Medical Association, 289, 2055-2056.

Virginia Tech Review Panel., \& Virginia Tech Review Panel. (2007). Mass shootings at Virginia Tech, April 16, 2007: Report of the Virginia Tech Review Panel presented to Timothy M. Kaine, Governor, Commonwealth of Virginia. Richmond, VA: Virginia Tech Review Panel.

Vogt, W. P. (2005). Dictionary of statistics \& methodology: A nontechnical guide for the social sciences $\left(3^{\text {rd }}\right.$ ed.). Thousand Oaks, CA: Sage Publications, Inc.

Vossekuil, B. F. (2002). The final report and findings of the safe school initiative: Implications for the prevention of school attacks in the United States. U. S. Department of Education, Office of Elementary, and Secondary Education, Safe and Drug-Free Schools Program, U. S. Secret Service, National Threat Assessment Center. Washington, DC.

Wallace v. Broyles, 961 S.W.2d 712 (Ark. 1998).

Watts, E. (1999). The freshmen year experience, 1960-1990: An experiment in humanistic higher education (Doctoral dissertation). Retrieved from http://www.sc.edu/fye/resources/fyr/pdf/FYEHistory_ElsieFroment.pdf 
Webb, N. B. (1986). Before and after suicide: A preventative outreach program for colleges. Suicide and Life-Threatening Behavior, 16(4), 469-480.

Weinsenback, K. E. (2011). A model for assessment and mitigation of threats on the college campus. Journal of Educational Administration, 49(1), 76-94.

Weisenback, K. E. (2011). A model for assessment and mitigation of threats on the college campus. Journal of Educational Administration, 49(1), 76-94.

White v. University of Wyoming, 954 P.2d 983 (Wyo. 1998).

Whitlock, J., Eckenrode, J., \& Silverman, D. (2006). Self-injurious behavior in a college population. Pediatrics, 117, 1939-1948.

Whitman, N. A., Spendlove, D. C., \& Clark, C. H. (1986). Increasing students' learning: A faculty guide to reducing stress among students. ASHE-ERIC Higher Education Report No.4. George Washington University.

Wolfe, D. A., Scott, K., Reitzel-Jaffe, D., Wekerle, C., Grasley, C., \& Straatman, A. L. (2001). Development and validation of the conflict in adolescent dating relationships inventory. Psychological Assessment, 13(2), 277-293.

Youth Risk Behavior Surveillance: National College Health Risk Behavior Survey United States, 1995. (1997, November 14). Morbidity \& Mortality Weekly Report, CDC Surveillance Summaries, 46, 1-56.

Zdziarski, E. L., Dunkel, N. W., Rollo, M. (2007). Campus crisis management: A comprehensive guide to planning, prevention, response, and recovery. San Francisco, CA: Jossey-Bass. 
Appendix A

Code of Student Conduct Charges

- Physical Harm. Intentionally or recklessly causing physical harm to another person.

- Weapons. Unauthorized use, possession, or storage of any weapon, ammunition, or realistic replica of a weapon on University premises or at a University-sponsored activity unless an exemption is allowed in accordance with the University's weapons policy. The term "weapon" means any object or substance designed to inflict a wound, cause injury or incapacitate including, but not limited to, any weapon from which a shot readily capable of producing death or serious injury may be discharged; any knife other than an ordinary pocket knife; sharp tools such as axes; billy or nightstick; blackjack or slapjack; nunchaku karate stick; shuriken or death star; and artificial knuckles made from metal, plastic or similar hard material. (http://louisville.edu/police/deadly-weapons-policy)

- False Report. Intentionally initiating or causing any false report, warning, or threat of fire, explosion, or other emergency.

- Fire Safety. Intentionally or recklessly misusing or damaging fire or other safety equipment, causing a fire which damages University or personal property or causes injury, or failure to evacuate a University-controlled building during a fire alarm.

- Theft. Theft or misuse of property or of services on University premises, at University-sponsored activities, or from University organization(s) or group(s), or knowing possession of stolen property or use of stolen services on University premises, at University-sponsored activities, or from University organization(s) or group(s).

- Destruction of Property. Intentionally or recklessly destroying or damaging property or the property of others.

- Destructive Devices. Unauthorized use, possession, or storage of fireworks; destructive device; incendiary, dangerous, or noxious devices or materials; or chemicals that could pose a health risk, either by themselves or in conjunction with other chemicals.

- Threatening. Threatening or endangering the health, well-being, property, or safety of any person(s).

- Sexually Abusive Contact. Engaging in sexual intercourse, anal intercourse, or oral intercourse, touching of the genitals, breasts, buttocks, or inner thighs, sodomy or any other physical conduct or touching of a sexual nature without consent and/or by force.

- Sexual Harassment. Engaging in unwelcome sexual advances, requests for sexual favors, or other verbal or physical conduct of a sexual nature. Conduct constitutes sexual harassment when:

o submission to such conduct is made either explicitly or implicitly a term or condition of an individual's employment, or participation in a universitysponsored education program or activity;

o submission to or rejection of such conduct by an individual is used as the basis for employment or academic decisions affecting such an individual;

o such conduct creates a hostile environment if the harassment is so severe, pervasive, and objectively offensive so as to deny or limit a person's ability to 
participate in or benefit from the University's programs, services, opportunities, or activities; or

o such conduct has the purpose or effect of unreasonably interfering with an individual's employment or academic performance.

- Hazing. Engagement, encouragement, or facilitation, by any organization or by any individual on behalf of an organization or group (recognized or not recognized by the university), or visitor within the University of Louisville community in any action or situation which recklessly or intentionally endangers mental or physical health; creates an atmosphere of servitude; involves dangerous, demeaning, or ridiculing activities; involves the forced consumption of liquor or drugs; for the purpose of initiation, admission into, affiliation with, or as a condition of continued membership in, a group or organization. It is also a violation to allow yourself to be hazed. The express or implied consent of the individual will not be a defense. Apathy or acquiescence in the presence of hazing is not a neutral act; it is a violation of the Code.

- Misuse of Technology. Intentional or reckless interference with or disruption of University technology services or resources [e.g., computer disk storage, data, software, voice communications (local or long distance,) network], unauthorized use, misuse, abuse, alteration, disclosure or destruction of University technology services or resources, improper access to University technology services/resources, or violation of intellectual property (e.g., copyright) rights or restrictions of others.

- False Complaint. Intentionally filing a false complaint under the Code.

- Demonstration. Participating in, leading, or inciting a demonstration, riot, or activity that disrupts the normal operations of the University and/or infringes on the rights of other members of the University community.

- Voyeurism. Transmitting, recording or photographing the image or voice of another person without his/her knowledge or consent while in an environment that is considered private or where there is an expectation of privacy, such as a residence or bathroom.

- Deliberate Incapacitation. Deliberate constraint or incapacitation of another, without that person's knowledge or consent, or without reasonable explanation.

- Failure to Report. Failing to report immediately any serious health or safety risk to the police, the Dean of Students Office or other appropriate University personnel.

- Stalking. Intentionally or recklessly directing behavior at a specific person(s) involving repeated (two or more occasions) of visual or physical proximity, nonconsensual communication, expressed or implied threats of death or bodily harm, or a combination thereof, causing a reasonable person fear. Stalking behaviors may include persistent patterns of leaving or sending the person(s) unwanted items or gifts ranging from seemingly romantic to bizarre, following the person(s), lying in wait for the person(s), or harassing the person(s) via the internet or other forms of online and computer communications (i.e., Cyberstalking).

- Driving Under the Influence. Driving under the influence of alcohol or other controlled substance(s).

- Harassment. Engaging in conduct that is so severe, pervasive, and objectively offensive, and that so undermines and detracts from the person(s) educational 
experience or work environment, that the person(s) are effectively denied equal access to an institution's resources and opportunities.

- Dating Violence. Intentionally, knowingly, or recklessly causing physical or sexual abuse to a person who is or has been in a social relationship, romantic or intimate nature with the accused. Whether or not a dating relationship exists is determined based on the length of the relationship, the type of relationship, and the frequency of interaction between the persons involved in the relationship.

- Domestic Violence. Intentionally, knowingly, or recklessly causing physical or sexual abuse to a current or former spouse, to a person whom shares a child in common with the accused, or to a person who is cohabitating with or has cohabited with the accused as a spouse or intimate partner.

- Retaliation. Action taken by an accused individual or an action taken by a third party against any person because that person has reported a violation of the University's sexual misconduct policies or because that person has filed a complaint, served as a witness, assisted, or participated in an investigation or proceeding. This includes action taken against a bystander who intervened to stop or attempt to stop discrimination, harassment, or sexual misconduct. Retaliation includes intimidating, threatening, or coercing an individual because of the individual's complaint or participation.

- Sexual Exploitation. Taking of non-consensual or abusive sexual advantage of another by a person(s), or the inducement of another person to do the same; or for one's own advantage or benefit; or to benefit or advantage anyone other than the one being exploited. 


\section{CURRICULUM VITA}

Laura Elizabeth Ulmer

1714 Hancock Ave

Norfolk, Virginia 23509

ulmer.laura@gmail.com

740.525 .2443

Education

B.A., Psychology, Mount Union College

Office of Student Conduct \& Academic Integrity

Old Dominion University 11ulmer@odu.edu

757.683 .3431

M.Ed., College Student Personnel, Ohio University

2001-2005

Ph.D., Counseling \& Personnel Services, University of Louisville

2005-2007

2011-2017

Awards

University of Louisville Office of Intramural \& Recreation Sports Solid Performance Staff Award

2015

University of Louisville Student Affairs

Outstanding New Professional Award

2012

North Carolina College Personnel Association

Outstanding New Professional Award

2009

Wingate University Student Government Association

Staff Award

2008

\section{Publications}

Foran, W., Severy, M., Campbell, E., Ulmer, L. (2007). Purposeful professional mentorship. Essentials.

Professional Associations

National Behavioral Intervention Team Association (NaBITA)

Advisory Board Member

2013 - Present

Present

Journal for Behavioral Intervention Team (JBIT) Editorial Board Present

Association for Student Conduct Administrators (ASCA)

2010 - Present

Community of Practice: Threat Assessment \& Behavioral Intervention

Chair

$2014-2015$

Assistant Chair

$2013-2014$

Gehring Host Committee

Co-Chair

$2013-2014$

Communications Chair

2012

Member \& Training Track Participant

2011

Association for College Student Personnel (ACPA)

$2004-2015$

Member-at-Large for Entry Level Professionals

$2008-2011$

College Personnel Association of Kentucky

$2010-2015$

Careers in Student Affairs Conference Keynote Speaker

2010 
Presentations

A Window Into BIT: Closing Panel. (2017). National Behavioral Intervention Team Association Annual Conference.

TIX and BIT: Offering Support Services for the Accused. (2017). National Behavioral Intervention Team Association Annual Conference.

A Care Team's Five Year Case Summary and Implications for Our Work. (2017). National Behavioral Intervention Team Association Annual Conference.

iMatter! Toolkit: Resources for Teams to Combat Burnout \& Compassion Fatigue. (2016). National Behavioral Intervention Team Association Annual Conference.

Department Trains Leaving the BIT Station: Coordination of the Student Care Journey. (2016). Association for Student Conduct Administrators Annual Conference.

We Care About You. (2015). National Behavioral Intervention Team Association Annual Conference.

BIT, CERT, and TAT: What Do These Teams Mean to Your Campus? (2014). Association of Student Conduct Administrators Annual Conference.

Conduct in the Online Environment. (2014). Paperclip Communications. (Webinar).

Using Metaphors to Drive Student Learning. (2011). American College Personnel Association Annual Convention.

Transitioning into New Roles: Supervising, Advising, Mentoring, \& Leading. (2010). American College Personnel Association Annual Convention.

Purposeful Professional Mentoring. (2009). American College Personnel Association Annual Convention.

Developing Metaphors to Drive Student Learning. (2008). North Carolina College Personnel Association Conference.

Purposeful Professional Mentoring. (2008). North Carolina College Personnel Association Annual Conference.

Be Excited, Be Existing, Be Exhausted. (2006). Midwest Meeting of Graduate Students in Student Personnel (MMOGSISP). 